\title{
DETERMINING THE EFFECT OF EXTERNAL SHADING STRATEGIES ON ENERGY AND DAYLIGHT OF FULLY GLAZED OFFICE BUILDINGS IN TORONTO
}

\author{
By \\ Maryam Sadat Morakabian \\ Bachelor of Architectural Engineering \\ Ajman University of Science \& Technology, U.A.E., 2011 \\ A Major Research Project \\ Presented to Ryerson University \\ in partial fulfillment of the \\ requirements for the degree of \\ Master of Building Science \\ in the Program of \\ Building Science
}

Toronto, Ontario, Canada, 2015

@Maryam Morakabian 2015 


\section{Author's declaration}

I hereby declare that I am the sole author of this MRP. This is a true copy of the MRP, including any required final revisions.

I authorize Ryerson University to lend this thesis to other institutions or individuals for the purpose of scholarly research.

I further authorize Ryerson University to reproduce this thesis by photocopying or by other means, in total or in part, at the request of other institutions or individuals for the purpose of scholarly research.

I understand that my MRP may be made electronically available to the public. 
Determining the Effect of External Shading Strategies on Energy and Daylight of Fully Glazed office Buildings in Toronto

Master of Building Science, 2015

Maryam Sadat Morakabian

Graduate Program in Building science

Ryerson University

\begin{abstract}
With regard to overheating and heat lost potential, transparent parts of the building envelope have a significant impact on building energy consumption. The project investigates the impact of fully glazed façades on energy intensity and daylight quality of office buildings in Toronto. Also it explores the potential of various external shading strategies in minimizing energy consumption and enhancing daylight quality. Different types of external shadings including overhangs, vertical fins and diagrid screen were investigated in terms of heating, cooling and lighting energy use and daylight performance.

The diagrid screen, in comparison to conventional shading strategies, demonstrates significantly better impact on cooling load reduction and improving daylight quality in interior spaces. This study helped to evaluate the strengths and weaknesses of each shading system and provides guidelines for architects in the process of designing façades of glazed office buildings to widen the options for aesthetically pleasing, high performance façades.
\end{abstract}




\section{Acknowledgements}

I would like to express my gratitude to all the people that help me in successful completion of my MRP. I would like to thank my supervisor, Dr. Mark Gorgolewski for his continued support and guidance and his constructive comments throughout the progress of the project. Also I would like to acknowledge Dr. Umberto Berardi for his valuable suggestions as a second reader.

I wish to express my sincere thanks to all faculty of Building Science at Ryerson University and my instructors Dr. Miljana Horvart, Dr. Mark Gorgolewski, Dr. Zaiyi Liao, Dr. Umberto Berardi, Prof. Vera Straka and Prof. Hitesh Doshi for their valuable lessons and guidance to the successful completion of the program.

Finally I am grateful to my parents and my husband Siavash, who supported me and encouraged me throughout the course of this study. 
Table of Contents

Author's Declaration

Abstract.

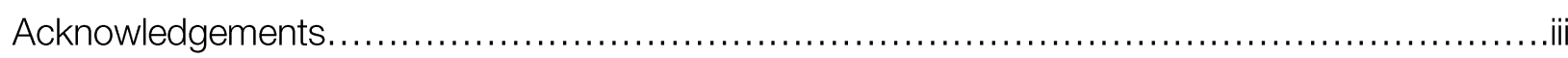

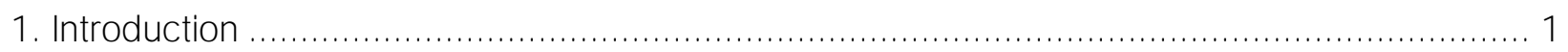

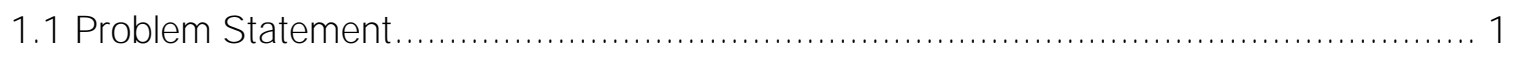

1.2 Objective and Research Questions ............................................................... 3

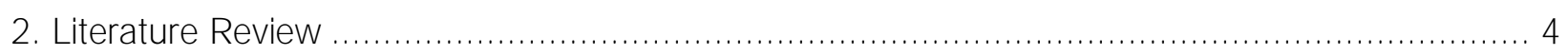

2.1. Impact of Glazed Building Envelop on Energy Demand ........................................ 4

2.2 Impact of Glazed Façade on Daylight and View ..................................................... 6

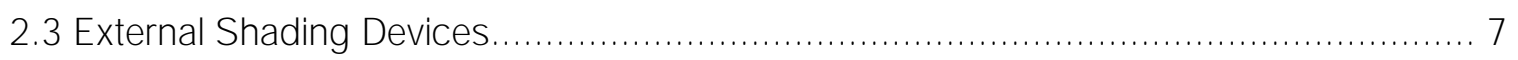

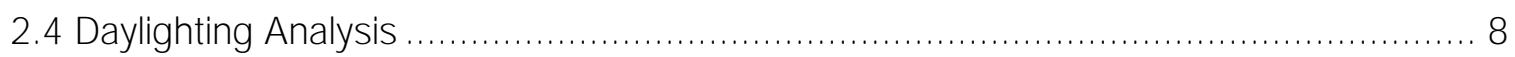

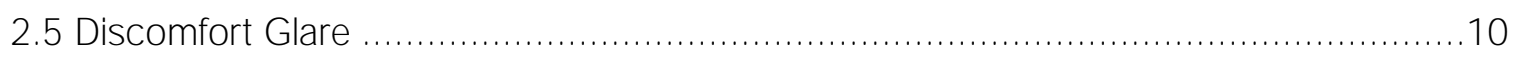

2.6 Geometric or Ornamental Shading Screen .......................................................10

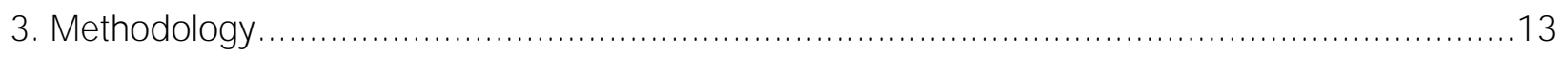

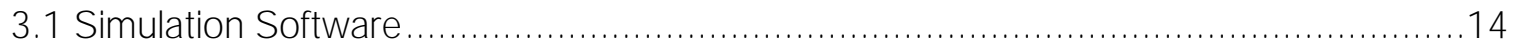

3.1.1 Energy Simulation Software ...........................................................14

3.1.2 Lighting Simulation Software and Metrics............................................15

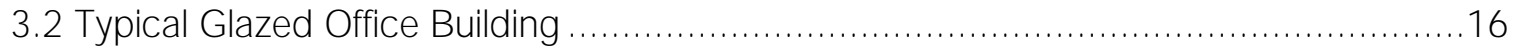

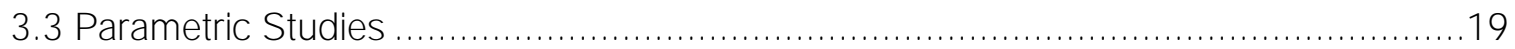

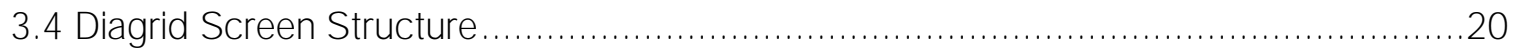

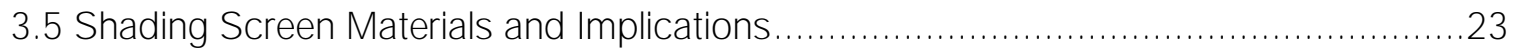

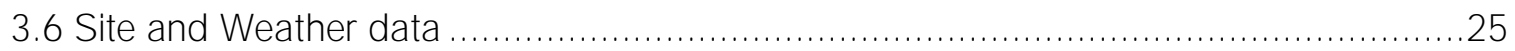

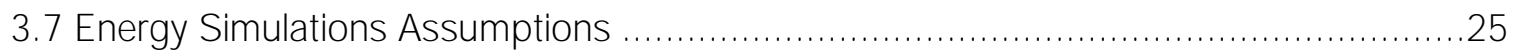

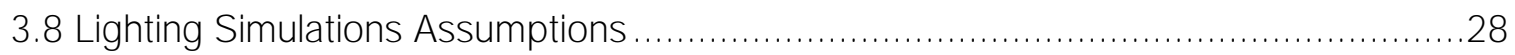

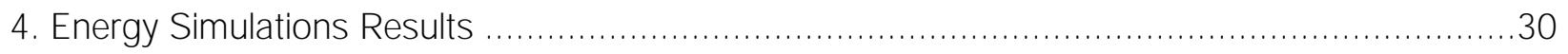

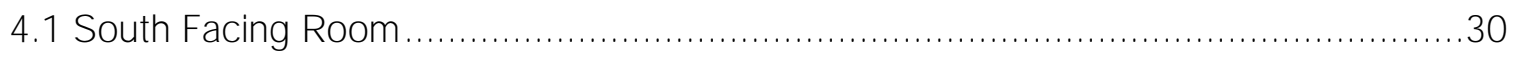

4.2 Discussion on Individual Energy Factors - South Room ........................................33

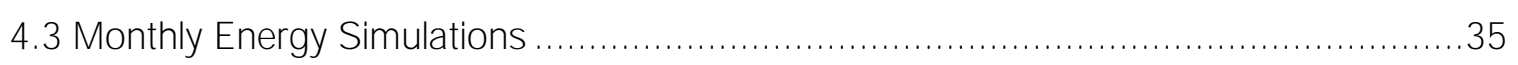

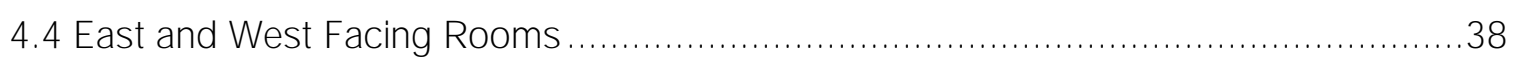

4.5 Discussion on Individual Energy Factors - East/West Room .................................39

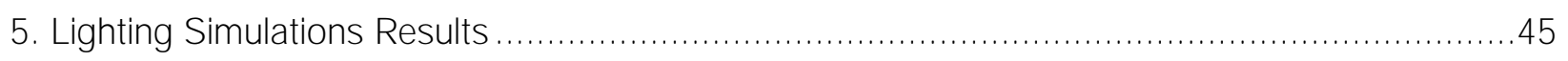

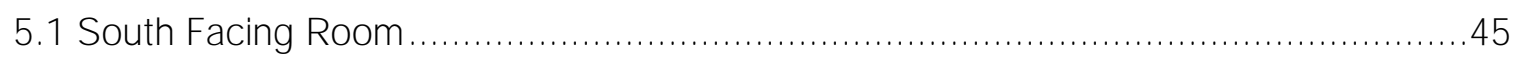

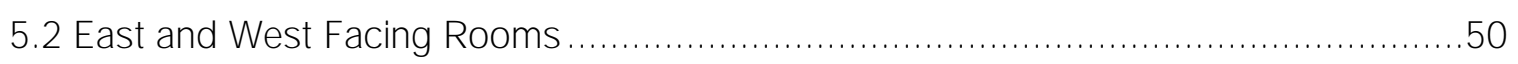




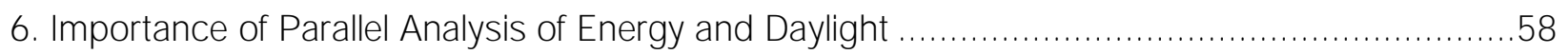

7. Diagrid Screen Design Modification on South Façade ...................................................60

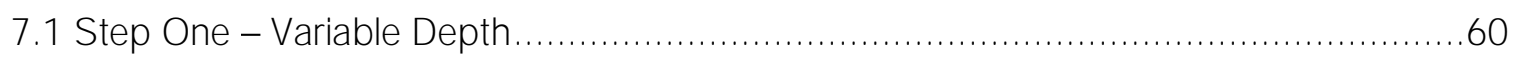

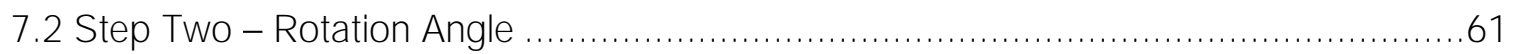

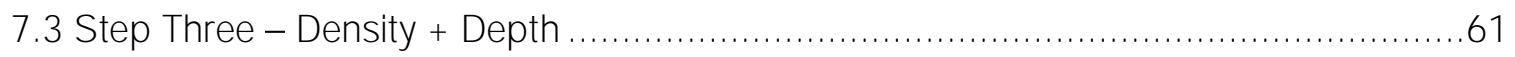

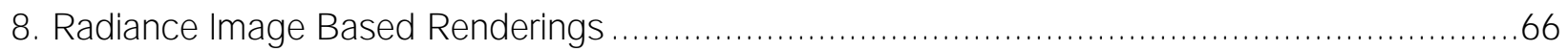

9. Conclusion and Recommendations for Future Work .................................................... 72

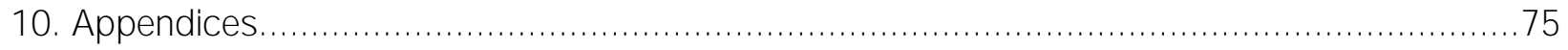

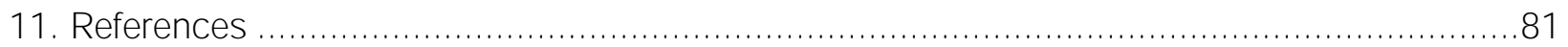

\section{List of Tables}

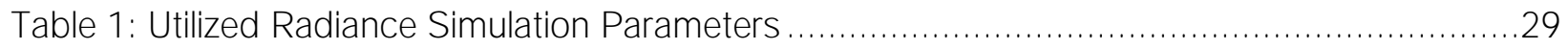

Table 2: Energy Use of South Facing Room with Various Shading Strategies............................32

Table 3: Energy Use of East Facing Room with Various Shading Strategies ..............................43

Table 4: Energy Use of West Facing Room with Various Shading Strategies ..............................44

Table 5: Percentage of Occupied Hour with Daylight Metrics of DA, UDI and DAmax - South Room

Table 6: Percentage of Occupied Hour with Daylight Metrics of DA, UDI and DAmax - East Room

Table 7: Percentage of Occupied Hour with Daylight Metrics of DA, UDI and DAmax - West Room

Table 8: Energy Pattern of the South Room throughout the Process of Diagrid Screen Modification 


\section{List of Figures}

Figure 1: Characteristics of the facade module used in the study by Verso et al. (2014) .............. 5 Figure 2: Shades over $59 \%$ of Window Area of New York Buildings, US Green Building Council (2014)

Figure 3: Modern Applications of Mashrabiya Shading Screen, Right: Masdar City, Abu Dhabi -

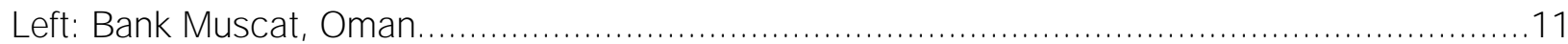

Figure 4: Methodological Framework ............................................................... 14

Figure 5: Bay Adelaide Center - West Tower - Typical Floor Plan .......................................17

Figure 6: LEED Credit Achieve by the Project in Energy Section ........................................ 17

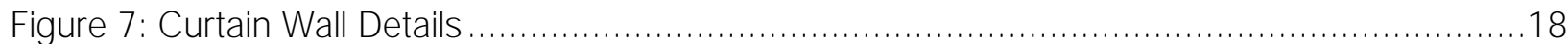

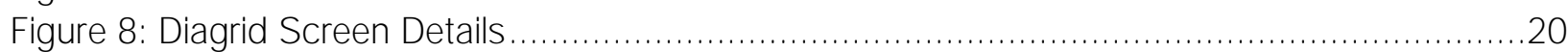

Figure 9: Parametric Study Framework ................................................................. 21

Figure 10: Example of Buildings with Diagrid Façade - From Top Right: Varyap Merıdıan H

Block,MTF Office building Project, Istanbul, Turkey - Atlas Building, Wageningen, Netherlands-

Haus Dado Office Building, Dubendor, Germany - Mikrocop Data Storage Office Building ,

Ljubljana, Slovenia - Urban Planning Museum by Henn Architekten, Nantong, China ..................22

Figure 11: Diagrid Screen Connections, Dado Houese, Germany .......................................24

Figure 12: Selected Rooms for Energy and Daylighting Simulations .................................26

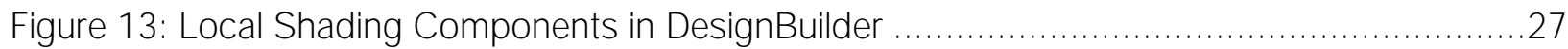

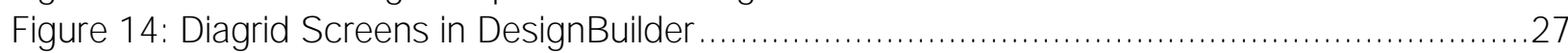

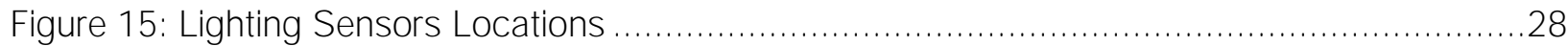

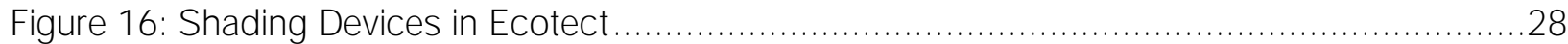

Figure 17: Energy Use Pattern of South Facing Room with Various Shading Strategies................30

Figure 18: Space Heating of South Facing Room with Various Shading Strategies......................33

Figure 19: Space Cooling of South Facing Room with Various Shading Strategies .....................34

Figure 20: Artificial Annual Lighting Energy Use of South Facing Room with Various Shading

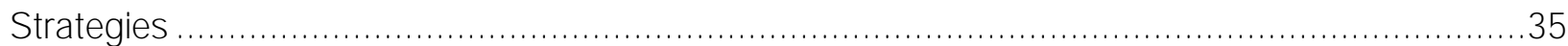

Figure 21: Monthly Space Heating Energy Use Comparison between No shade, Overhang and

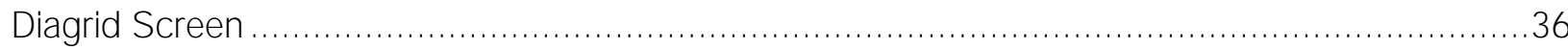

Figure 22: Monthly Space Cooling Energy Use Comparison between No shade, Overhang and

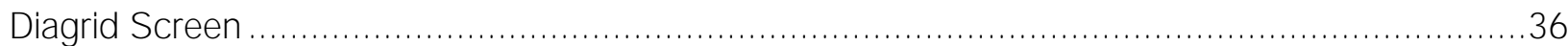

Figure 23: Monthly Lighting Energy Use Comparison between No shade, Overhang and Diagrid

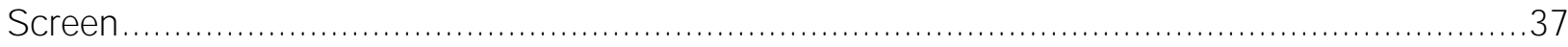

Figure 24: Energy Use Pattern of East Facing Room with Various Shading Strategies .................38

Figure 25: Energy Use Pattern of West Facing Room with Various Shading Strategies ................38

Figure 26: Space Heating of East Facing Room with Various Shading Strategies .......................40

Figure 27: Space Heating of West Facing Room with Various Shading Strategies ......................40

Figure 28: Space Cooling of East Facing Room with Various Shading Strategies ........................41

Figure 29: Space Cooling of West Facing Room with Various Shading Strategies .......................41

Figure 30: Lighting Energy Use Intensity of East Facing Room with Various Shading Strategies....42

Figure 31: Lighting Energy Use of West Facing Room with Various Shading Strategies ...............42

Figure 32: Daylight Autonomy (DA) in South Room ..................................................... 45

Figure 33: Useful Daylight Index in South Room ......................................................... 46

Figure 34: DAmax in South Room ................................................................. 47

Figure 35: Demonstration of DA, UDI and DAmax in South Room - Sensor 1 .......................47 
Figure 36: Demonstration of DA, UDI and DAmax in South Room - Sensor 2 ..........................48

Figure 37: Demonstration of DA, UDI and DAmax in South Room - Sensor 3 ........................48

Figure 38: Daylight Autonomy (DA) in East Room ........................................................ 50

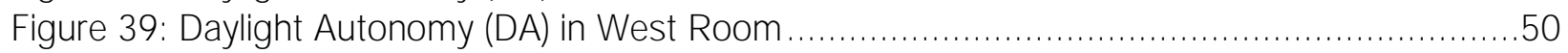

Figure 40: Useful Daylight Index in East room with Various Shading Strategies ...........................51

Figure 41: Useful Daylight Index in West room with Various Shading Strategies .........................51

Figure 42: DAmax in East room with Various Shading Strategies .........................................52

Figure 43: DAmax in West room with Various Shading Strategies ......................................52

Figure 44: Comparison of DAmax in the East and West Facing rooms with No Shade .................53

Figure 45: Demonstration of DA, UDI and DAmax in East Room - Sensor 1 ...........................54

Figure 46: Demonstration of DA, UDI and DAmax in East Room - Sensor 2 ...........................54

Figure 47: Demonstration of DA, UDI and DAmax in East Room - Sensor 3 ...........................54

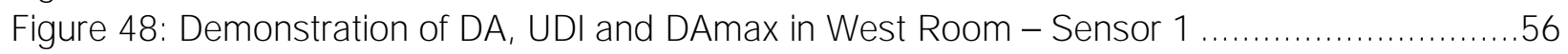

Figure 49: Demonstration of DA, UDI and DAmax in West Room - Sensor 2 ...........................56

Figure 50: Demonstration of DA, UDI and DAmax in West Room - Sensor 3 ..........................56

Figure 51: Benefits of Diagrid Screen in Redirecting Light into the Space..............................61

Figure 52: Comparison of Energy Use Pattern of Modified Shading Screen with Various Shading

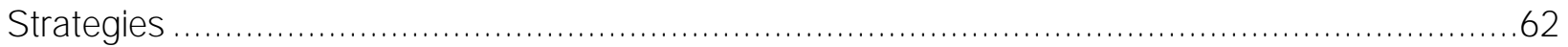

Figure 53: Design Process steps of Diagrid Screen ...................................................... 63

Figure 54: Rotation Angle of Diagrid Screen Based on Solar Incidents ................................63

Figure 55: Comparison of DA in the Room with Modified Screen .......................................64

Figure 56: Comparison of UDI in the Room with Modified Screen .......................................64

Figure 57: Comparison of DAmax in the Room with Modified Screen ....................................65

Figure 58: Radiance Renderings of South Room with Various Shading Strategies - May 21 - 3 pm

Figure 59: Illuminance Level of the South Room with No Shade \& Modified Diagrid Screen in False Color - May 21 - 3 pm.....

Figure 60: Radiance Renderings of South Room with Various Shading Strategies - March 21 - 3

pm

Figure 61: Illuminance Level of the South Room with No Shade \& Modified Diagrid Screen in False Color - March 21 - 3 pm . 68 Figure 62: Radiance Renderings of South Room with Various Shading Strategies - J uly 21 - 3 pm

Figure 63: Illuminance Level of the South Room with No Shade \& Modified Diagrid Screen in False Color - J uly 21 - 3 pm.

Figure 64: Radiance Renderings of South Room with Various Shading strategies - August 21 - 3

pm

Figure 65: Illuminance Level of the South Room with No Shade \& Modified Diagrid Screen in False Color - August 21 - 3 pm

Figure 66: Radiance Renderings of South Room with Various Shading strategies - Dec21 - 3pm71 Figure 67: Illuminance Level of the South Room with No Shade \& Modified Diagrid Screen in False Color - Dec $21-3 p m$. 


\section{Introduction}

\subsection{Problem Statement}

In non- residential buildings, comfort, energy demand and lighting are significantly influenced by the façade. High performance buildings usually do not have highly glazed facades as windows are the least insulating and highest air leakage component of the building envelope. Although window provides many benefits that enhance building performance and occupant comfort through passive heating, daylight and views, in many newly constructed buildings, most of these benefits are overshadowed by excessive window area and lack of solar protection. Window assemblies often cause problems such as increased heating load due to daily heat loss and increased cooling loads due to overheating (Tong LEE, Black \& Lomanowski, 2010). Nowadays, the number of commercial buildings covered with floor to ceiling curtain walls are increasing and to make up for the energy lost through the envelope, superior mechanical systems are often installed in building. One of the main reason is that floor to ceiling windows have more impact on rent than any other building feature (Urban Green Council, 2014). Energy performance optimization is a crucial factor in office buildings. Energy consumption in the commercial and institutional building sector accounts for almost $13.8 \%$ of secondary energy use in Canada and almost $8.9 \%$ of the country's greenhouse gas (GHG) emissions (National Resources Canada, 2008).

In Toronto around $27 \%$ of $\mathrm{CO}_{2}$ gas emissions generated by commercial buildings which $19 \%$ of it causes by heating and cooling energy uses. Energy usage of office buildings from 1990 to 2007 have been increased by $14 \%$ (Greater Toronto CivicAction Alliance, 2010), and envelope parameters such as window to wall ratio, window thermal performance and opaque wall thermal performance are some of the important factors effecting this energy consumption (CMHC, 2014).

So envelope design should support the energy concept of the building and avoid overheating during the warm seasons and reduce heating loads during the cold seasons. Furthermore, functions of the façade design should also include daylighting, glare control, natural ventilation and maintaining privacy.

Daylighting is one of the important envelope dominated attributes which has a direct impact on occupant comfort and well-being. Fully glazed façades allow a lot of natural light to penetrate into the space which might be an effective strategy to reduce electrical lighting intensity, but it can also causes glare and visual discomfort. Several active and passive shading strategies like overhangs, fins, light shelves, internal blinds and shading screens can be used to control direct sunlight. 
According to the international definition of climate zone, Toronto is situated at zone 6 (ASHRAE, 2007), which is identified as cold humid with heating degree days between 4000 and 5000 . In Toronto, buildings require energy not only for heating, but also for a significant amount of cooling, over a 4-5 months period (Ross, 2009). Solar protection strategies can be an effective tools in highly glazed buildings, to control direct solar radiation and glare, and also significant reduction of cooling load.

The function of external shading devices is to shade direct sun but not obstruct daylight access. North facing windows receive predominantly diffuse solar radiation and indirect daylight, and therefore do not need overhang (LANL, 2002). South facing windows will benefit from horizontal shading devices (such as: awings, overhangs, and recessed windows). Vertical fins on east and west windows can be effective at reducing direct solar radiation and glare. In case of Toronto climate, exterior sun control is recommended for south, east, and west façades (ASHRAE, 2004). Following these guidelines, in order to develop baselines for the design of diagrid screen in this project, horizontal overhangs with various depths are considered to shade the south façade and vertical fins are considered for east and west orienting windows.

This research is a study of impacts of glazed façade on energy demand and daylight quality in office spaces with various orientations, and the process of designing a diagrid external shading screen to enhance heating, cooling and lighting energy demands and occupant thermal and visual comforts. The study offers some insight on the impacts of various external shading solutions on different orienting rooms around the perimeter of glazed office buildings in Toronto, to realize how they affect energy intensity and daylight quality in spaces. The goal is to look at more advance shading solutions and to develop a shading screen solution with improved functional, ecological and aesthetic properties to be applied in future developments and other regions with similar climatic conditions. 


\subsection{Objective and Research Questions}

Integration of conventional shading devices such as overhangs and vertical fins with newly developed complex building forms and high rise skyscrapers is often difficult and challenging. Also relying on internal blinds to control solar gain and glare is not optimized since building occupants do not interact with internal shading devices effectively and once shading is lowered it will often stay in that position for a long time. Moreover once sunlight is transmitted through the glass most of its energy will be trapped in the building. Ornamental or geometric building skins or external shading screens have the potential to be considered as an option to be integrated with the glazed façade of commercial buildings to improve their aesthetic, comfort and energy performance.

The research aims to answer following questions:

- What are the effects of highly glazed facades on energy performance of spaces around the perimeter of office buildings in Toronto?

- How highly glazed facades impact daylight quality of spaces around the perimeter of office buildings in Toronto?

- What are the potential energy and daylight comfort benefits and disadvantages of alternative shading systems for a typical highly glazed office buildings in Toronto?

- What are the key parameters affecting the energy and daylighting performance of external shading screen systems? 


\section{Literature Review}

\subsection{Impact of Glazed Building Envelop on Energy Demand}

Over the last decade, attention towards the global energy performance of buildings, which results from heating, cooling, lighting and hot water energy consumptions, has increased significantly and these energy demand contributions play a crucial role in pursuing the goal of Zero or Near Zero Energy buildings. Moreover, new technologies have made it possible to enhance the performance of building facades and increase the use of advanced transparent components Verso, Serra, Giovannini \& lennarella, 2014). However low-energy and passive buildings in northern climates typically are not designed with highly glazed facades as windows are traditionally the least insulating and highest-air leakage component of the building envelope. ASHRAE (2004) recommends that 20\% - 40\% Window to Wall Ratio (WWR) is suitable for Toronto climate (climate zone 6).

Based on US Urban Green Council (2014), aside from building structure, envelope is the longest lasting building component and it has significant impact on construction, operation and maintenance cost and energy use of building. For instance the average curtain wall can last for longer than 50 years. So as other parts of the building such as HVAC system get updated overtime, the envelope will stay the same and will be responsible for a greater share of energy consumption.

Also transparent parts of the envelop have very little ability to control heat flow and solar radiation and even very good commercial clear glazing still allows about one-third of the sun's heat to enter (Straube, 2008). The load on building services is highly linked to envelope efficiency, the better the envelope perform the less energy is needed for heating and cooling. Consequently, window assemblies are often considered a liability causing problems such as increased heating loads due to daily net-heat loss, glare, and increased cooling loads due to overheating. Most buildings with high window-wall ratios (WWR) are considered to be energy inefficient (Tong LEE et al., 2010).

Pope (2008) evaluated the effect of window to wall ratio (from 40\% to 95\%) on a MNECB'97 (Model National Energy Code for Buildings) for small office archetype. He observed that higher energy performance benefits can be achieved through lower window to wall ratio along with high performance glazing. For instance, windows with triple pane, $U$ value (thermal transmittance) of 0.94 and SC (shading coefficient) of 0.31 found to reduce energy consumption by $16 \%$ with $40 \%$ WWR and with the same specification, if WWR increases to $55 \%$, still performance benefit is achievable, with a $10 \%$ reduction from $M N E C B$. 
Recently the research activity has been carried out in the Department of Energy at the Politecnico di Torino by Verso et al. (2014), focusing on assessing the role played by the transparent components on the overall energy performance of an office room. The study was based on existing office building with different façade configurations. Three part of the façade were analyzed to cover a wide range of glazing and opaque materials that would be able to control thermal losses, solar gains and daylight admitted to the spaces, adapting high performance conventional components. Figure 1 shows various façade configurations studied in this research. The results show that from lighting viewpoint, the best cases are those with highest transparency of the façade and higher visible transmittances which allow a greater amount of daylight to enter the room. Instead from the heating and cooling viewpoint, the cases with opaque strips in the façade are the best performing, as they reduce thermal losses in winter and solar gains in summer. So the study shows that in terms of energy performance, most valuable configurations requires a trade-off between lighting and heating/cooling energy performance. At the end of the parametric study, the best performing configuration for north-south cellular office resulted to be a fully glazed façade, with a selective glazing (VT of $59 \%$ and SHGC of $37 \%$ and U-Value of $1 \mathrm{~W} / \mathrm{m} 2 \mathrm{~K}$ ). Daylight glare possibility and visual discomfort causing by glare, was not taken into consideration in this research.

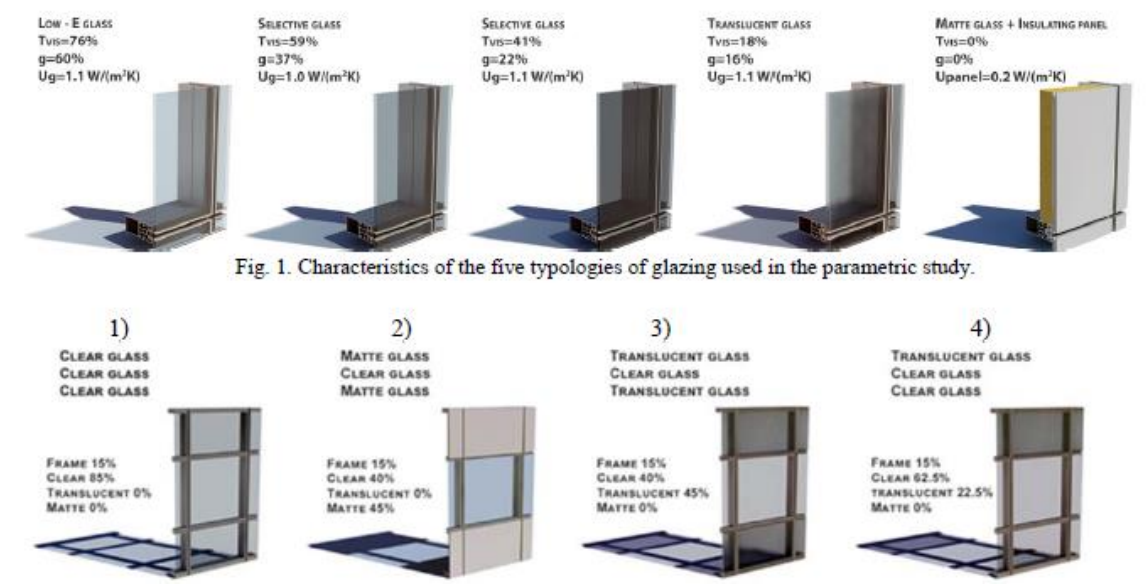

Figure 1: Characteristics of the facade module used in the study by Verso et al. (2014)

Gratia and De Herde (2003) have assessed the impacts of building geometry, orientation and window to wall ratio on energy performance of office building in Belgium. The study revealed that large glazing areas with sun control facing south are preferable compared to north oriented glazing without solar protection. This result is also confirmed by Verso et al. (2014) who showed that global energy consumption is higher for east-west facing rooms than north-south facing rooms. 


\subsection{Impact of Glazed Façade on Daylight and View}

View and connection to outside are other reasons behind designing glazed façades. But views are not all that come with floor to ceiling glasses. It may lead to loss of privacy, glare, increased noise and excessive heat in summer or freezing walls in winter. Also views from all-glass buildings cost tenants a premium in energy bills and even the monthly rent.

The U.S. Green Building Council (2014), in New York, undertook a study of fully glazed residential and commercial buildings. The aim of research was to investigate the behavior of tenants living in fully glazed buildings in New York. The study revealed that blinds or shades covered about 59 percent of the window areas all the time, without significant difference based on the orientation a window faced (north, south, east, or west), or between commercial or residential buildings. So based on this study, glare may not be the only reason blinds are widely use and privacy or the inconvenience of raising them once they are lowered are some other reasons.

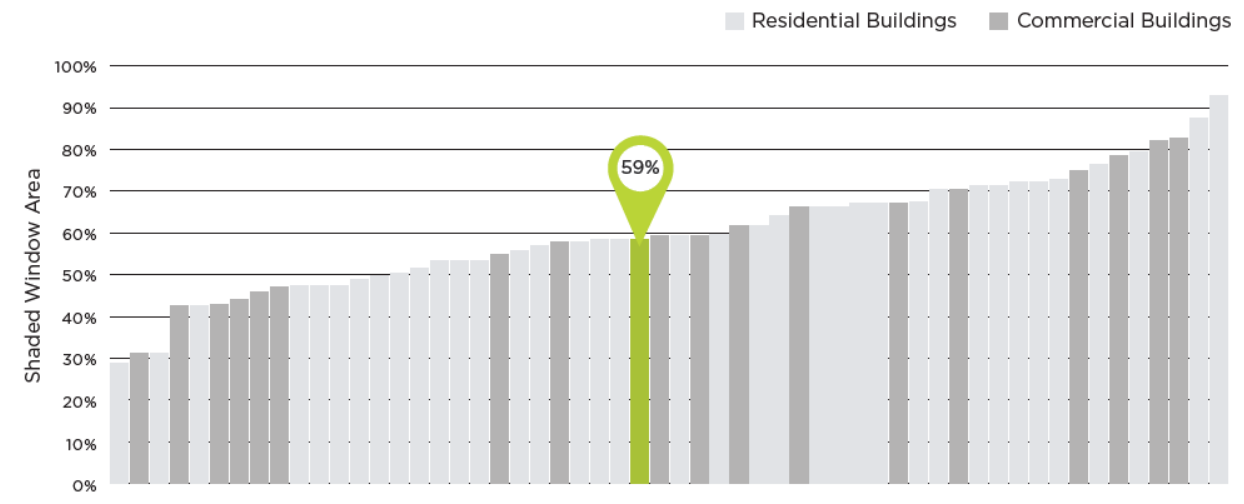

Figure 2: Shades over 59\% of Window Area of New York Buildings, US Green Building Council (2014)

Energy efficiency in buildings is influenced by the behavior of architectural spaces, part of which can be attributed to daylighting which is envelope-dominated. Designing fully-glazed façades minimizes the efficiency of the envelope, despite allowing huge amounts of daylight into a space. This does not necessarily result in good performance, since illumination levels are not optimized to fall within the acceptable range. The problem is notably experienced in south facing façades, which get the most solar exposure over the course of the day (El Sheikh, 2011). Having a lot of windows does not necessarily leads to better lighting quality and uncontrolled daylight can cause several problems for its occupants. Excessive daylight can create glare on the perimeter zone, increase the cooling load and offset the benefit of daylight. 
Tzempelikos \& Athienitis (2007) carried out an integrated thermal and daylighting study on perimeter spaces in office buildings. An office space in Montreal has been selected as a case study with clear double glazed window. Annual daylighting simulations were performed in TRNSYS and daylight Availability Ratio (DAR), also known as Daylight Autonomy (DA), was used to assess yearly illuminance levels. Seven different WWR were investigated on the four orientations. Results showed that increasing fenestrations more than $30 \%$ did not have a substantial impact on DAR levels in south-facing room.

The use of glass in office buildings has become important in the profession for transparency, visual and daylighting purposes. Although useful for allowing light into buildings, untreated windows allow more daylight into a space than required, resulting in visual problems, such as over-abundance of light in some areas, not enough in others, and glare (El Sheikh, 2011). On one hand windows are essential to enhance occupant comfort and productivity but on other hand floor to ceiling curtain walls will have significant impact on energy performance of building and will reduce positive impacts of daylighting because of the glare and high luminance level.

\subsection{External Shading Devices}

One of the important component of glazed façade that improves comfort level in building and reduces energy consumption is solar control systems. Different combinations of glass and shading devices are available for glazed building façade, but the appropriate choice of shading device is crucial as it affects both visual and thermal comfort. Exterior shadings can be either fixed or movable. Movable shadings are more efficient than fixed shadings, but they are more prone to failure and require to maintain regularly.

As Wilson (2010) stated, with effective exterior shading strategies based by orientation, it is possible

to significantly reduce the energy penalty of a high glazed facade. Exterior shading helps control solar gain, so it can reduce both total annual energy consumption and peak cooling capacity. Exterior shading is more effective in this capacity than interior shading, since the sunlight is blocked before entering the building. Once sunlight is transmitted through the glazing, most of its solar energy will be trapped in the building. Through well-designed external shading devices cooling load can be reduced and energy efficiency can be enhanced in the building. Careful designing of the shading is needed in order to maintain visual comfort and daylight.

Manzan (2014) carried out a study on south facing office room in Italy, with $4 \mathrm{~m}$ wide and $1.5 \mathrm{~m}$ high window, to design the optimal fixed shading device through genetic optimization (GO) techniques. The shading device was a flat panel positioned parallel to the window and inclined by its horizontal 
axis. Standard and high performance glazing systems have been taken into account. Lighting loads, computed by the DAYSIM code, have been considered as inputs for the code ESP-r which drives the energy computation. The results showed that impact of shading devices on building energy has always to take into account the electrical energy absorbed by the lighting system, since this load affects both heating and cooling loads. In this study, simulations did not take into account other effects related to daylighting performance such as glare and visual discomfort.

If shading devices are not designed according to sun path and functional requirements of spaces, it can fail the entire efforts of daylight design and causes extreme discomfort for its occupants, and consequently increase energy consumption of building. There are two types of shading devices. External shading devices like overhangs and internal shading devices like blinds and curtains. An internal shading device does not give the benefit in solar heat gain; moreover, the occupant pulls down the blind in unwanted situations that often will not be lifted up again for a long period of time. It can be assumed that exterior shading devices could lower or perhaps eliminate the need for cooling in northerly latitudes. To investigate this issue, Ross (2009) has performed a study to know the effect of sunshades in Toronto climate. She applies a horizontal overhang on all windows except those facing north on five distinct building geometries with WWR of $40 \%$. Only the square building has been observed with an increase in energy intensity when shading are added to the design. Cooling and fan energy are reduced, but heating energy goes up. The author explains a reason as; additional heating is needed in J anuary and February, perhaps because the overhangs shade the south windows partially, during mid-day.

\subsection{Daylighting Analysis}

Daylight is a vital element for indoor environmental quality and occupant comfort and productivity. A building's envelope plays a primary role in screening and protecting the building from external environmental factors, such as heat, light and air (Etman, Tolba $\&$ Ezzeldin, 2013). Successful daylight design requires going beyond conventional techniques of integrating large openings, skylights or light shelves into architecture (El- Sheikh \& Gerber, 2011). It encompasses thoughtful integration of design approaches addressing glare, heat gain and variation in light availability, and direct light penetration.

In a 2007 survey of 177 design practitioners leaned towards the definition of daylight being "the interplay of natural light and building form to provide a visually stimulating, healthful and productive interior environment" whereas the engineers tended towards the "the use of fenestration systems and responsive electric lighting controls to reduce overall building energy requirements (heating, 
cooling, lighting)" (Galasiu \& Reinhart, 2007). As Reinhart (2011) indicated the meaning of the term daylighting need to carefully define within the design team at the beginning of the project as well as potential for conflict between esthetics, energy efficiency and occupant comfort, since they cannot necessarily be optimized in parallel. It is the author's subjective conviction that a space that is either not energy efficient or uncomfortable cannot be called 'successfully daylit'. The hybrid definition of daylight is a space that is primarily lit with natural light and that combines high occupant satisfaction with the visual and thermal environment with low overall energy use for lighting, heating and cooling. So daylighting design becomes a balance between optimizing the annual daylight availability in a space while making sure the space is energy efficient and exhibits high occupant satisfaction.

Two commonly use approaches to measure daylight level, are Daylight Autonomy (DA) and Useful Daylight Index (UDI) (Reinhart \& Wienold, 2011). DA is defined as the percentage of the occupied hours of the year when a minimum illuminance thresholds can be met by daylight alone (Reinhart \& Walkenhorst, 2001), but it should be take into consideration that DA represent a percentage of annual daytime hours that a given point in a space is above a specific minimum targeted illumination level. It was originally proposed by the Association Suisse des Electriciens in 1989 and was improved by Christoph Reinhart between 2001- 2004. Useful Daylight Illuminance or Index (UDI) is a modification of Daylight Autonomy conceived by Mardaljevic and Nabil in 2005. This metric bins hourly time values based upon three illumination ranges, 0-100 lux, 100-2000 lux, and over 2000 lux. It provides full credit only to values between 100 lux and 2000 lux suggesting that horizontal illumination values outside of this range are not useful. There is significant debates regarding the selection of 2000 lux as an upper threshold, above which daylight is not wanted due to potential glare or overheating and there is little research to support the selection of 2000 lux as an absolute upper threshold (Reinhart, Mardaljevic \& Rogers, 2006).

Reinhart and Walkenhorst (2011), undertook a study on south facing office space using Daysim, Radiance based simulation tool, to investigate annual daylight availability, visual comfort and energy use in the space. They proposed a new metric termed 'daylight availability' to merge DA and UDI information into a single figure. Reinhart used greyscale map to divide space into a 'daylit' with DA values above $48 \%$ and a 'partially daylit' area with DA values from $0 \%$ to $48 \%$. Also three related UDI distributions of the space presented on separate greyscale maps. Then he further distinguished the 'over lit' area near the window. The 'over lit' area presented a warning that is invoked if an oversupply of daylight is assumed for at least $5 \%$ of the working year. The concept of DAmax has 
been used for this purpose which represent the percentage of time when illuminance level is 10 times above the targeted minimum illuminance level.

\subsection{Discomfort Glare}

As Collins (2002) stated 'Glare is a subjective human sensation that describes light within the field of vision that is brighter than the brightness to which the eyes are adapted.' Based on IRC, glare is too much luminance in the wrong place and should be eliminated at its source by selecting luminaires that do not emit light at angles likely to create glare directly or through reflection on work planes or computers screens. IESNA recommends that the luminance ratio between a task and immediately adjacent surroundings should not exceed 3:1, however IRC research suggests lower ratios as 1.52:1 and average computer screen to background luminance ratio of 0.8-1.2:1 (Canadian Consulting Engineer, 2015).

Glare is typically divided into disability glare and discomfort glare. Disability glare is the inability of person to see certain object in a scene due to glare, while discomfort glare is more subjective and depends on person's overall indoor environmental satisfaction. There is a widely notion that horizontal work plane illuminance is a poor predictor of discomfort since the amount of light on work plane is not completely demonstrate the person's visual experience of the space, so glare analysis should be based on illuminance distribution in the field of view of an observer (Reinhart \& Wienold, 2011). Image based lighting analysis of space through Radiance can provide better representation of overall appearance of discomfort glare in the room through the course of the year, but it is necessary to repeat the analysis for all the hours of the year using site specific climate data.

\subsection{Geometric or Ornamental Shading Screen}

One of the traditional architectural feature in Egypt and Middle East to reduce solar heat gain and diffuse natural light is Mashrabiya. Mashrabiya is the Arabic term given to a type of projecting window enclosed with carved wood latticework located on the second storey of a building or higher, often lined with stained glass. In vernacular Arabic architecture, the Mashrabiya serves several functions as shade against the sun and natural ventilation and privacy.

The Mashrabiya was initially intended as a place to cool drinking water, achieving this by enabling a convective cycle that moved air masses from a zone of high pressure to that of low pressure. The Mashrabiya gradually developed into an architectural feature which served not only to encourage airflow and passive cooling, but also to decrease solar heat gain and to diffuse natural light that penetrated through openings (Stouffs $\&$ Sariyildiz, 2013). 

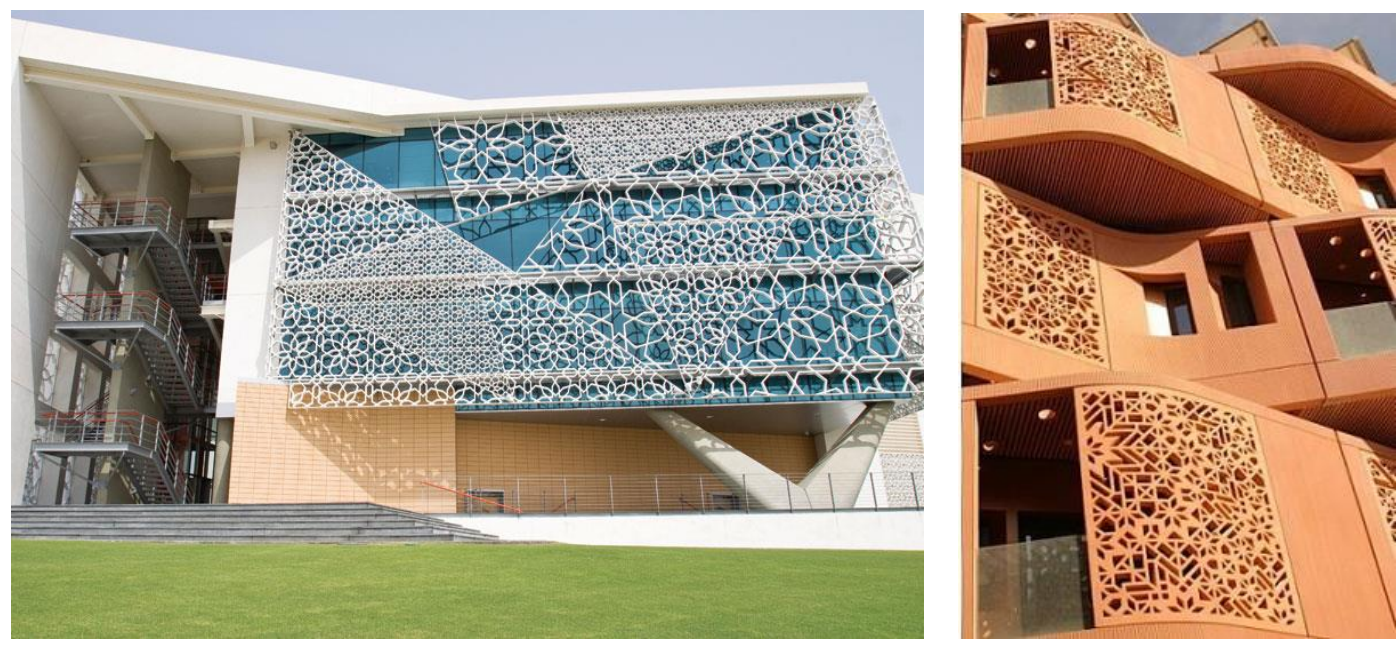

Figure 3: Modern Applications of Mashrabiya Shading Screen, Right: Masdar City, Abu Dhabi - Left: Bank Muscat, Oman

Nowadays, screens are often integrated in the building envelope. With advance technologies it is possible to build these structures in the affordable ways. Some of the available methods of constructions are scatching, miling, plasma and lase cutting and fluid forming (Lang \& Bader, 2011). A modern version of Mashrabiya can integrate into double skin façade system. A layer of shading screen can install on outer side of fully glazed façade. However unlike double skin façade system, the outer layer is shading screen which does not have any impact on natural ventilation and the focus is on provision of shading as a means of solar avoidance and environmental control. The solar control offered by this modern interpretation is more complex and a focus on solar avoidance makes it easier to quantify the benefits (Boake, 2014). So by eliminating the issues with buffer zone ventilation, impacts of shading screen on solar avoidance will be easier to quantify.

Etman, Tolba and Ezzeld in (2013), undertook a study on impacts of non-sealed double-skin facades, with various perforated outer skins, on light quality of prototypical office spaces in Egypt. The Mashrabiya was taken as an inspiration for the purpose of their research to generate different forms of perforated screens for the west facing room with 100\% WWR. Their research concluded that perforated shading screens will smooth light range that decrease the risk of potential glare and improve the distribution of acceptable indoor illumination level from $54 \%$ to $78 \%$.

With increase in digital tools to assess daylight and energy in building, a great potential is exist to optimize the performance of building façade. Modern architecture have often employed light shelves, overhangs and other passive shading techniques, however such forms are not easily applicable to highly articulated forms of contemporary architecture. Digital tools allow for parametric design of both organically and geometrically derived building skin. However such skins are largely aesthetic 
expression of the form and rarely address environmental conditions such as sun radiation control, daylighting or thermal comfort (Omidfar, 2011). Shading screens can still be part of architectural expression and aesthetic of building and at the same time improve quality of light and energy performance. Therefore shading screen or building skin is an option to be considered in order to enhance energy performance of fully glazed commercial buildings.

In order to design optimized shading structure, it is important to identify necessary parameters affecting the design of shading system. Some of these parameters are climate, location, solar geometry, building orientation and occupancy.

Also there are several parameters affecting the performance of shading screen systems such as density of the screen's pattern based on the orientation of the façade and direction the elevation faced, depth of the shading screen and reflectivity of shading materials. Based on the study by Omidfar (2011) depth of shading screen is one of the parameter affecting its performance. The study revealed that having deeper shading screen at the top of the opening is more beneficial in terms of reflecting light into the space and improving the quality of light in back of the room. Deeper parts of the shading screen act as a light shelve and by reflecting light deeper into the space, minimize the undesirable effects of direct sunlight and use of artificial lighting.

Based on reviewed literature, it is confirmed by many studies that transparent parts of the envelope, have very little ability to control heat flow and solar radiation, and high window to wall ratio and unprotected windows, do not have positive impact on space daylighting quality. Also the studies showed that effective exterior shading strategies based on orientation, can have a significant impact on energy performance of highly glazed façade.

However there is no research or real data on impacts of ornamental or geometric shading screens on energy performance or daylight quality of glazed building located in cold climate or Canadian context. 


\section{Methodology}

During the last decade with development of dynamic, climate-based simulation software, there have been multiple advances in the possibilities of numerical analysis of overall energy and lighting performance of spaces. However the design community at large is still not adapting to these techniques. Based on Reinhart (2011), some of the barriers towards adjusting to these technologies are various simulation environment and user interfaces, long simulation time, complicated simulation process, outdated rating schemes and inability to interpret simulations results. Since computerbased energy and daylighting analysis software can facilitate the design of better performing buildings, methodology of using energy and lighting simulation software have been used in this research. The following tasks were conducted on the proposed research:

- Typical glazed office building have been selected and rooms around the perimeter of the building facing south, east and west, are identified to be modeled.

- As site climatic condition has significant impact on energy use and daylight, the selection of location and climate zone was an important factor. Hence, the research is conducted in Toronto representing the context and climate of Southern Ontario.

- Simulations were conducted on archetype models using DesignBuilder energy simulation software to investigate the energy demand of different orienting rooms in terms of heating, cooling and lighting energy uses.

- In parallel to energy simulations, lighting analysis were conducted in Daysim and Radiance to explore daylight distribution in the rooms. DA, UDI and DAmax were calculated by means of the Daysim software package. Ecotect was used to create the 3D models and to assign Radiance compatible materials to each surface and then to launch Daysim to run the annual simulations.

- Various shading strategies such as overhangs, vertical fins, light shelves and diagrid screen were modeled on different orienting rooms to run energy and daylight simulation and then effect of various external shading devices was incorporated into the parametric analysis.

- After analyzing the results, the impact of various shading devices with different design parameters on energy demand and lighting were identified.

- Finally, based on the previous findings, a diagrid screen were refined to enhance its performance in terms of energy and daylight. 


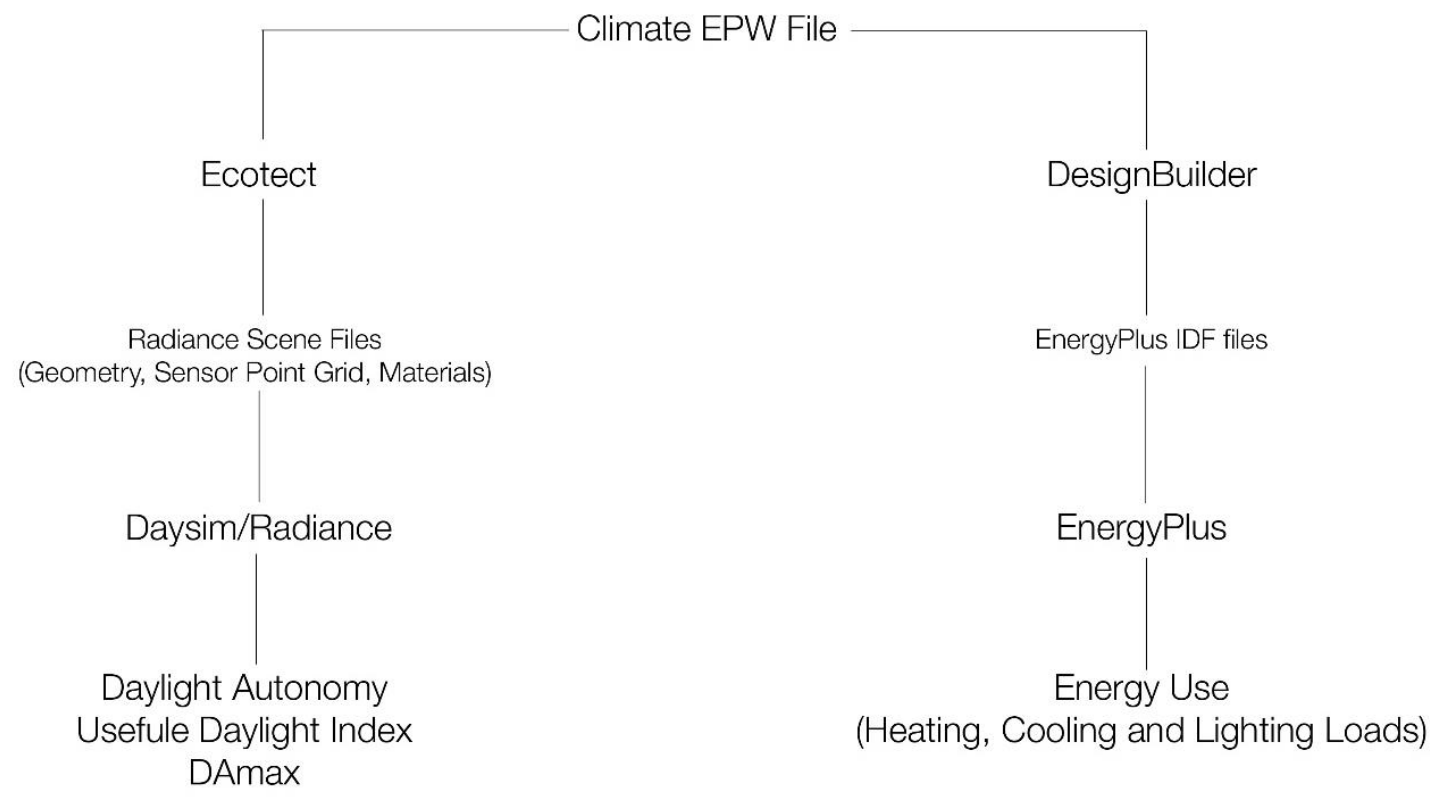

Figure 4: Methodological Framework

\subsection{Simulation Software}

Various energy and lighting simulation software are available which allow for computational analysis of energy and daylight in building. The following section is a discussion on software selected and used in this project.

\subsubsection{Energy Simulation Software}

All the energy modeling simulations were set up in DeisgnBuilder v4 and run through EnergyP lus 8.1. EnergyPlus is an energy analysis and thermal simulation program. Based on a user's description of building physical form and associated mechanical and other systems, EnergyP lus calculates heating and cooling loads necessary to maintain thermal control set points, conditions throughout a secondary HVAC system and coil loads, and the energy consumption of primary plant equipment. Simultaneous integration of these details verify that the EnergyPlus simulation performs as would the real building (DOE, 2014). Some of the EnergyPlus capabilities are as integrated and simultaneous solutions, sub-hourly and user-defined time steps, thermal comfort models, and sky model and daylighting control. EnergyPlus is a stand-alone program without a user friendly graphical interface. It reads inputs and writes outputs as text file. One of the EnergyPlus graphical interfaces is DesignBuilder. 
DesignBuilder is a fully featured EnergyPlus user interface suitable for use in any stage of design process. It first released in 2005 and allow for wide range of building types to be simulated using EnergyPlus. Building model can be assembled within the DesignBuilder modeler by drawing and positioning 3D blocks (DOE, 2014).

\subsubsection{Lighting Simulation Software and Metrics}

Lighting simulation software use various algorithms which can be classified as direct calculations, view-dependent and scene-dependent. Direct calculations are specific physical formulas and simplifications often use to cover most usual illumination situations. View-dependent algorithms computes tracing rays coming from the light source, from the observer's eyes or from light source and observer, and use for lighting calculations and renderings. Radiosity is one main example of scene-dependent algorithms which is adapted from heat transfer into lighting simulation. A scene is divided into surface elements or meshes and radiometric values are determined for each surface, independent of the view. This methods mainly use for numerical lighting calculations (Ochoa et al., 2012).

Radiance is a validated tool with a backward ray-tracer developed by Greg Ward at Lawrence Berkeley National Laboratory. It enables accurate and physically valid lighting and daylighting simulations. Daysim is also a validated tool uses radiance to calculate annual illuminance profile based on local climate data and daylight coefficient approaches (Reinhart \& Walkenhorst, 2011). This software uses EnergyPlus weather data for annual simulations and also provides luminance values and glare ratings. Similar to Radiance, it uses ray tracing algorithm and although the user interface is improved but still requires considerable expertise to properly set simulation parameters (DOE, 2011). Daysim is a Radiance-based daylighting analysis tool that has been developed at the National Research Council of Canada and the Fraunhofer Institute for Solar Energy Systems in Germany. It allows users to simulate a range of dynamic facade systems to test their daylighting performance. At the most fundamental level Daysim offers an efficient way to calculate the annual amount of daylight available in and around buildings. To do so Daysim combines a daylight coefficient approach with the Perez all weather sky model and the Radiance backward ray-tracer. Two prominent daylighting metrics which are calculated by Daysim are Daylight Autonomy (DA) and Useful Daylight Illuminance (UDI). Daylight Autonomy is now being a recommend metrics by the Illuminating Engineering Society of North America (IESNA). The daylight autonomy at a point in a building is 
defined as the percentage of occupied hours per year, when the minimum illuminance level can be maintained by daylight alone. The main advantage of the daylight autonomy over the daylight factor is that it takes facade orientation and user occupancy profiles into account and considers all possible sky conditions throughout the year. Useful Daylight llluminances or Index (UDI), proposed by Mardaljevic and Nabil in 2005, is a dynamic daylight performance measure that is also based on work plane illuminances. It aims to determine when daylight levels are 'useful' for the occupant, i.e. neither too dark ( $<100$ lux) nor too bright ( $>2000$ lux). The upper threshold is meant to detect times when an oversupply of daylight might lead to visual and/or thermal discomfort (Nabil \& Mardaljevic 2005). Climate-based metrics like UDI and DA are more precise than traditional Daylight Factor (DF) method in daylight quality assessments. DF only accounts for overcast skies and doesn't consider building orientation, location and time (Berardi \& Wang, 2014).

Maximum daylight autonomy or DAmax is reported to indicate the percentage of the occupied hour when direct sunlight or exceeding high daylight condition is presented. DAmax was defined to be a sliding level equal to ten times the design illuminance of a space. E.g. for a computer lab with a design illuminance of 150 lux DAmax corresponds to 1500 lux. This upper threshold criteria is essentially a measure of the occurrence of direct sunlight or other potentially glary conditions and can give an indication of how often and where large illuminance contrasts appear in a space (Reinhart, Mardaljevic \& Rogers, 2006).

\subsection{Typical Glazed Office Building}

A fully glazed office building located in downtown Toronto is identified as a case study. Different measures as fenestration type, building geometry and orientation have been considered prior to building selection. The Bay Adelaide Center (BAC) completed in 2009 to be downtown Toronto's first Leadership in Energy and Environmental design (LEED) Core and Shell Gold high rise office building. The average Canadian commercial or institutional buildings use approximately 400 $\mathrm{ekWh} / \mathrm{m}^{2}$ annually (Carpenter, 2011). A survey of Enermodal Engineering predicts that, the actual energy use of their monitored LEED certified projects use (on an average) just over 200ekW/m²; which is $45 \%$ less than the Canadian average (Carpenter, 2011). According to Enermodel Engineering, Bay Adelaide Center was expected to use 35\% less energy than conventional office buildings. 

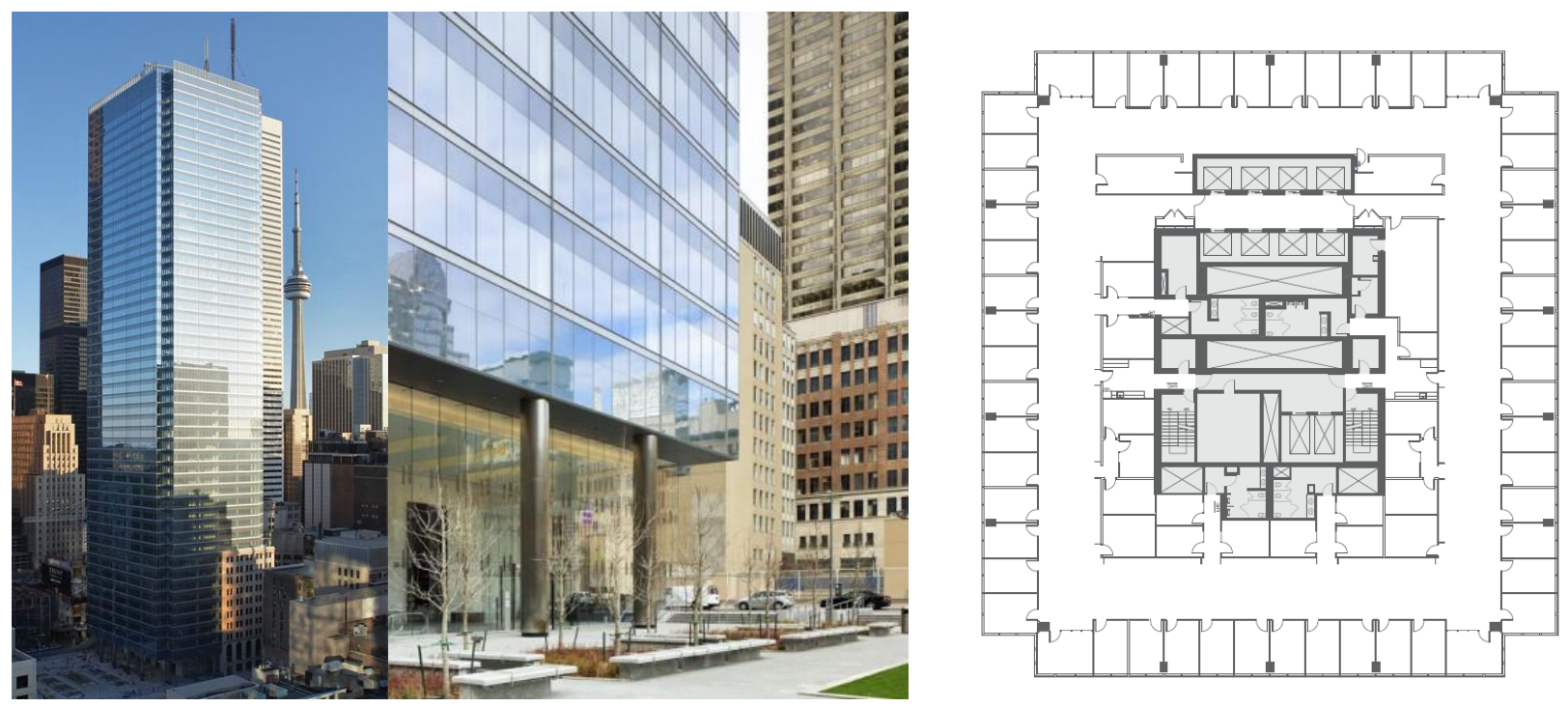

Figure 5: Bay Adelaide Center - West Tower - Typical Floor Plan

\begin{tabular}{|c|c|c|c|}
\hline 7 & \multicolumn{2}{|c|}{ Energy \& Atmosphere } & 17 \\
\hline $\bar{Y}$ & Prereq 1 & Fundamental Building Systems Commissioning & Required \\
\hline $\bar{Y}$ & Prereq 2 & Minimum Energy Performance & Required \\
\hline $\bar{Y}$ & Prereq 3 & CFC Reduction in HVAC\&R Equipment & Required \\
\hline 6 & Credit 1 & Optimize Energy Performance & 1 to 10 \\
\hline & Credit 2.1 & Renewable Energy, 5\% & 1 \\
\hline & Credit 2.2 & Renewable Energy, $10 \%$ & 1 \\
\hline & Credit 2.3 & Renewable Energy, 20\% & 1 \\
\hline & Credit 3 & Best Practice Commissioning & 1 \\
\hline & Credit 4 & Ozone Protection & 1 \\
\hline 1 & Credit 5 & Measurement \& Verification & 1 \\
\hline & Credit 6 & Green Power & 1 \\
\hline
\end{tabular}

Figure 6: LEED Credit Achieve by the Project in Energy Section

The building is covered by glass on all four elevations. The curtain wall is a fully unitized thermally broken system with four sided structural silicon bond. Since the purpose of this research is on solar heat gain and glare issues related to vision glass parts of the envelope and not the frame, the impact of mullion system and frame structure on heat loss and moisture related issues was not taken into consideration.

The selected building is just an example of typical glazed office building in Toronto and guidelines presented in this research can be applied to any other office building in Toronto with similar façade properties. 

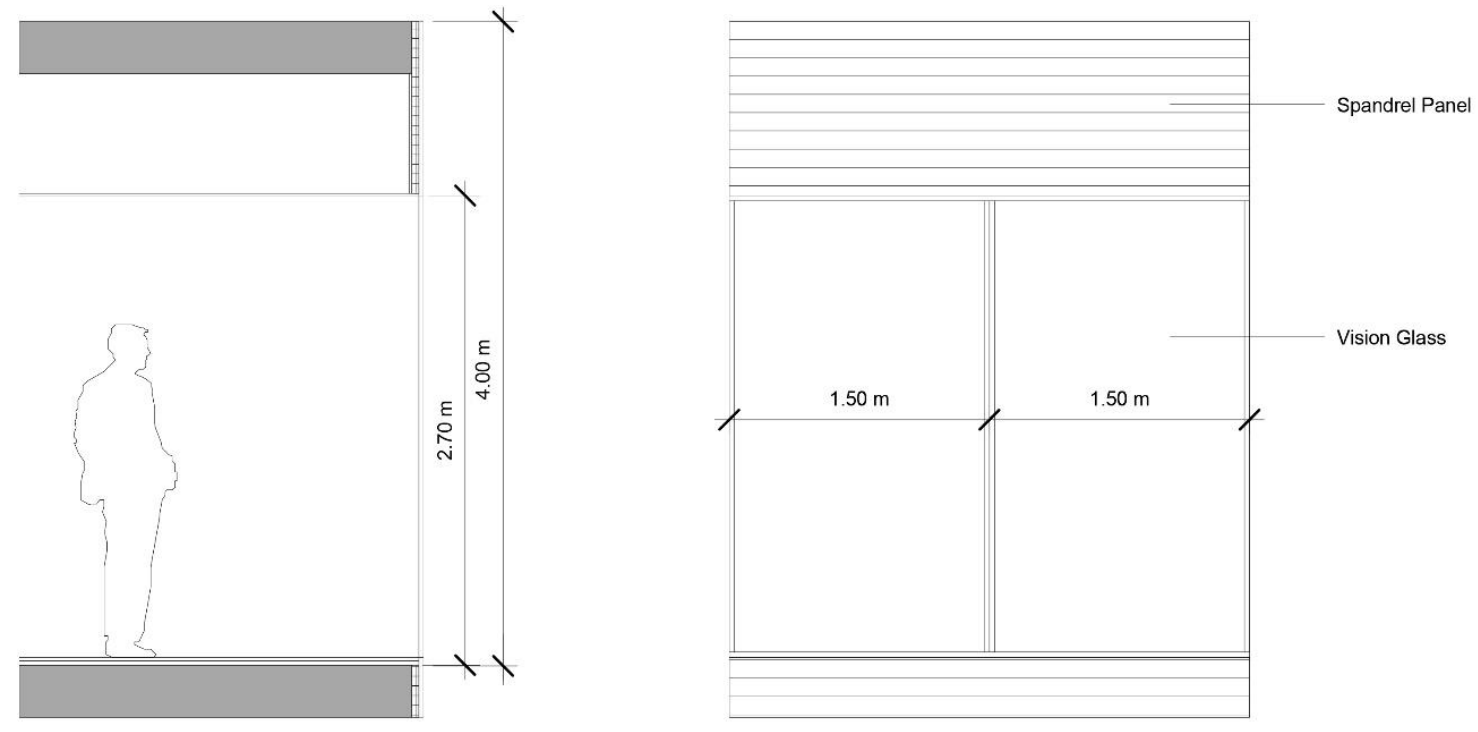

Figure 7: Curtain Wall Details

Bay Adelaide Center - West Tower Specification:

- Location: 333 Bay St, Toronto, ON

- Latitude: N 43.650370

- Longitude: W -79.38030

- Architects: Webb Zerafa Menkes Housden

- Developer: Brookfield properties

- Building Height: 51 stories

- Ceiling Heights: Slab-to-slab heights on office floors average 13'1" or $4 \mathrm{~m}$ Standard floor to ceiling height is 9' or $2.7 \mathrm{~m}$

- Mullion Spacing: $1.5 \mathrm{~m}$

Glass Specifications:

- 1" (25mm) VE1-2M Insulating Coated Glass as manufactured by Viracon;

- Exterior Glass Ply: 1/4" (6mm) Clear

- Coating: VE-2M on \#2 Surface

- Airspace: 1/2" $(13.2 \mathrm{~mm})$ argon space

- Silicone: gray

- Interior Glass Ply: 1/4" (6mm) Clear

- Performance Requirements:

- Visible Light Transmittance: $69 \%$ 
- Exterior Reflectance: $11 \%$

- Winter U-Value: $1.4 \mathrm{~W} / \mathrm{m}^{2} \mathrm{~K}\left(0.25 \mathrm{btu} / \mathrm{hr} / \mathrm{ft}^{2}-\mathrm{F}\right)$

- Summer U-Value: $1.2 \mathrm{~W} / \mathrm{m}^{2} \mathrm{~K}\left(0.21 \mathrm{btu} / \mathrm{hr} / \mathrm{ft}^{2}-\mathrm{F}\right)$

- Shading Coefficient: $43 \%$

- Solar Heat Gain Coefficient: 37\%

- Light to Solar Gain Ratio: 1.9

- Curtain Wall System:

- Type: Unitized system, 4 sided structural silicone glazed

- Frame: Thermally broken aluminum frame

- U-Value: $1.16 \mathrm{~W} / \mathrm{m}^{2} \mathrm{~K}\left(0.20 \mathrm{btu} / \mathrm{hr} / \mathrm{tt}^{2}-\mathrm{F}\right)$

- Spandrel Panel: $6 \mathrm{~mm}$ glass, $508 \mathrm{~mm}$ (2") mineral wool insulation board, $12.7 \mathrm{~mm}$ gypsum board

\subsection{Parametric Studies}

Different variables related to orientation of the room and physical characteristics of the shading strategies have been taken into consideration. The variables that changed throughout the study are as following:

- Orientation: the building has both north-south and east-west orientation with glazed façade, so orientation was treated as a variable to investigate the role of solar radiation in south, east and west facing façades.

- External shading device: various types of external shadings were modeled and impact of shading devices on lighting, heating and cooling energy demands of the rooms were studied. The shading devices variable that changed through the study are as following;

- Type: overhangs, vertical fins, light shelves and diagrid screen

- Depth: depth of shading devices will have an impact on view, amount of daylight entering the room, solar heat gain and energy demand. Shadings were studied in depths of $0.5,1$ and 1.5 meter.

- Density of diagrid screen: density or size of diagrid screen will effect view, daylight distribution and also energy use of the space. Shading screen were studied in scales of 1:1 (one floor high), 2:1 (half floor high) and 4:1 (quarter floor high). Since maintaining the view for building occupants was one of the important parameters in 
the process of diagrid screen design, diagrid screen with smaller scale (denser) and depth more than 1 meter was eliminated from the study.

- Constants parameters are glass property, curtain wall R-Value, window to wall ratio, reflectivity of the shading devices $(40 \%)$ and internal surfaces, gap between the diagrid screen and façade and rooms lay out.

All the shading devices were directly modeled in DesignB uilder for energy simulations and in Ecotect for running daylighting analysis through Radiance and Daysim. Because of the challenges of modeling the diagrid screen in energy and lighting simulation software, leaving gap between diagrid screen and building envelope was not feasible, the screen was modeled directly over the window without touching the glass.

Figure 9 is a demonstration of various shading strategies studied in the project.

\subsection{Diagrid Screen Structure}

The reason behind selection of diagrid as a shading screen structure was that diagrids are structurally efficient and architecturally significant assemblies for tall buildings. In the late 19th century early designs of tall buildings recognized the effectiveness of diagonal bracing members in resisting lateral loads. While the structural importance of diagonal is well recognized, their aesthetic potential is not explicitly appreciated (Moon, Connor \& Fernandez, 2007). So since diagrid assemblies structurally sound and have a potential to integrate with the façade of tall glazed office buildings, diagrid pattern have been selected for a purpose of this project. Example of existing buildings with similar types of diagrid screen facades, is presented in Figure 10, to better demonstrate the construction feasibility of diagrid screen assembly.

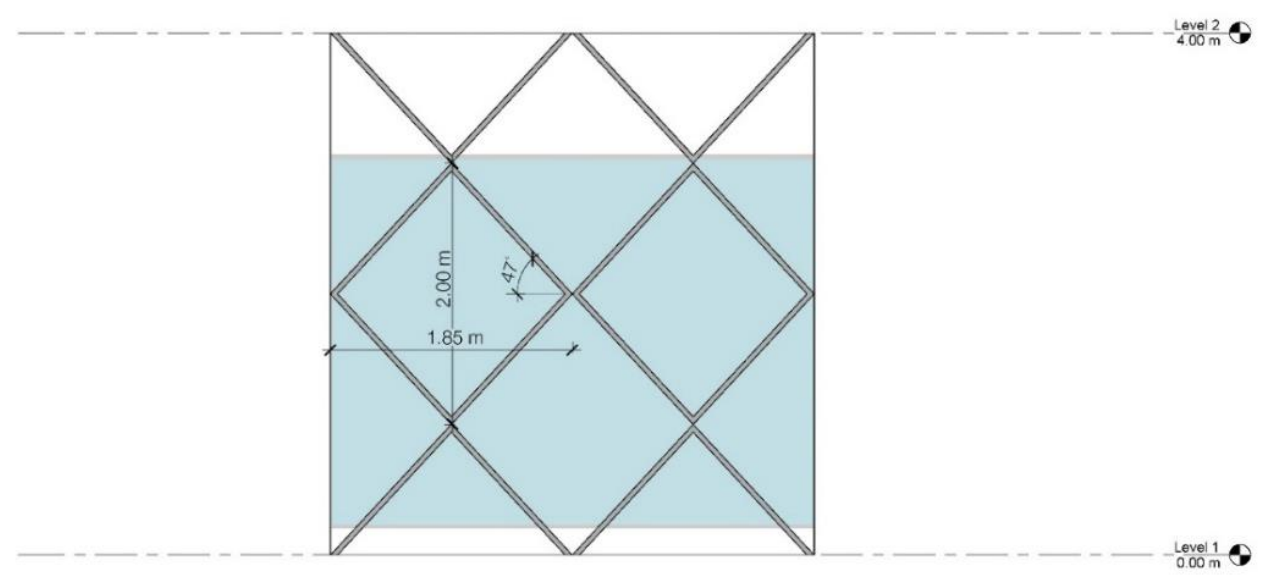

Figure 8: Diagrid Screen Details 
Room Orientation:
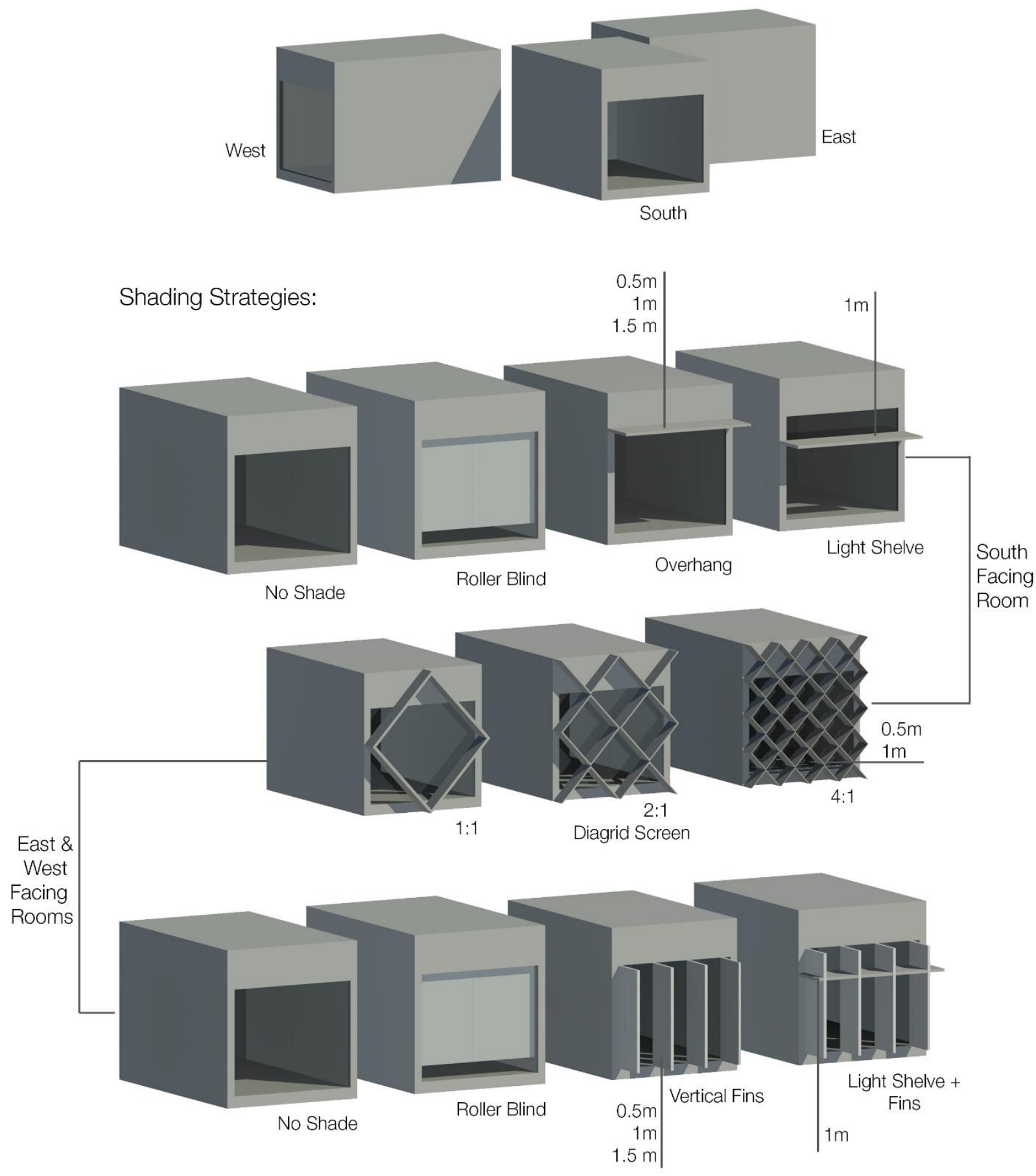

Figure 9: Parametric Study Framework 



Figure 10: Example of Buildings with Diagrid Façade - From Top Right: Varyap Merıdıan H Block,MTF Office building Project, Istanbul, Turkey - Atlas Building, Wageningen, Netherlands- Haus Dado Office Building, Dubendor, Germany - Mikrocop Data Storage Office Building , Ljubljana, Slovenia - Urban Planning Museum by Henn Architekten, Nantong, China 


\subsection{Shading Screen Materials and Implications}

External sun screens solutions bring higher added value both in terms of architecture and in terms of performance, since as mentioned earlier external shades are more effective that internal ones, however they are more expensive and subject to maintenance, since they are permanently exposed to atmospheric agents. The type of materials of screen components plays a fundamental role in its performance (Cellai, Carletti, Sciurpi \& Secchi, 2014)

Successful shading screen or building skin design, requires material selections that can last the project's life span and take into account exposure to various weather conditions, pollution and corrosive salts. Sustainable design tools also encourage the use of products that will remain in place over the project's service life (Houska, 2013).

Some possible materials to be used for shading screen are metals and polymers. Aluminum plates can be welded together and attached to the façade through different metal angles, however because of their thermal conductivity they can create thermal bridges.

Whatever material is employed, the device must ensure adequate operability and aesthetic value over time. In this regard, metals, properly treated and painted, are often used.

Stainless steel is a logical material for corrosive environments with industrial pollution, particularly when there would be minimal maintenance and expectation of 50 years of services. Stainless steel provides much higher corrosion resistance than other common architectural metals, particularly when there is pollution and chloride salt exposure (i.e., de-icing). Also stainless steel structural components should be used to support the screen, since carbon steel or aluminum structural components can cause galvanic corrosion (Houska, 2013).

The finished look, price, maintenance and durability should be considered when deciding on materials for shading assemblies.

Figure 11 shows the diagrid screen over the façade of Dado House in Germany. The thin steel swords are bonded together and to the façade with steel anchors and angles. The diagrid components are prefabricated in a factory and are attached to the façade on site.

Special fasteners are available for attaching shading screen to the structure, however Issues of fixing the screen to the façade and thermal bridges associated with it, should be taken into consideration during the early design stages. 

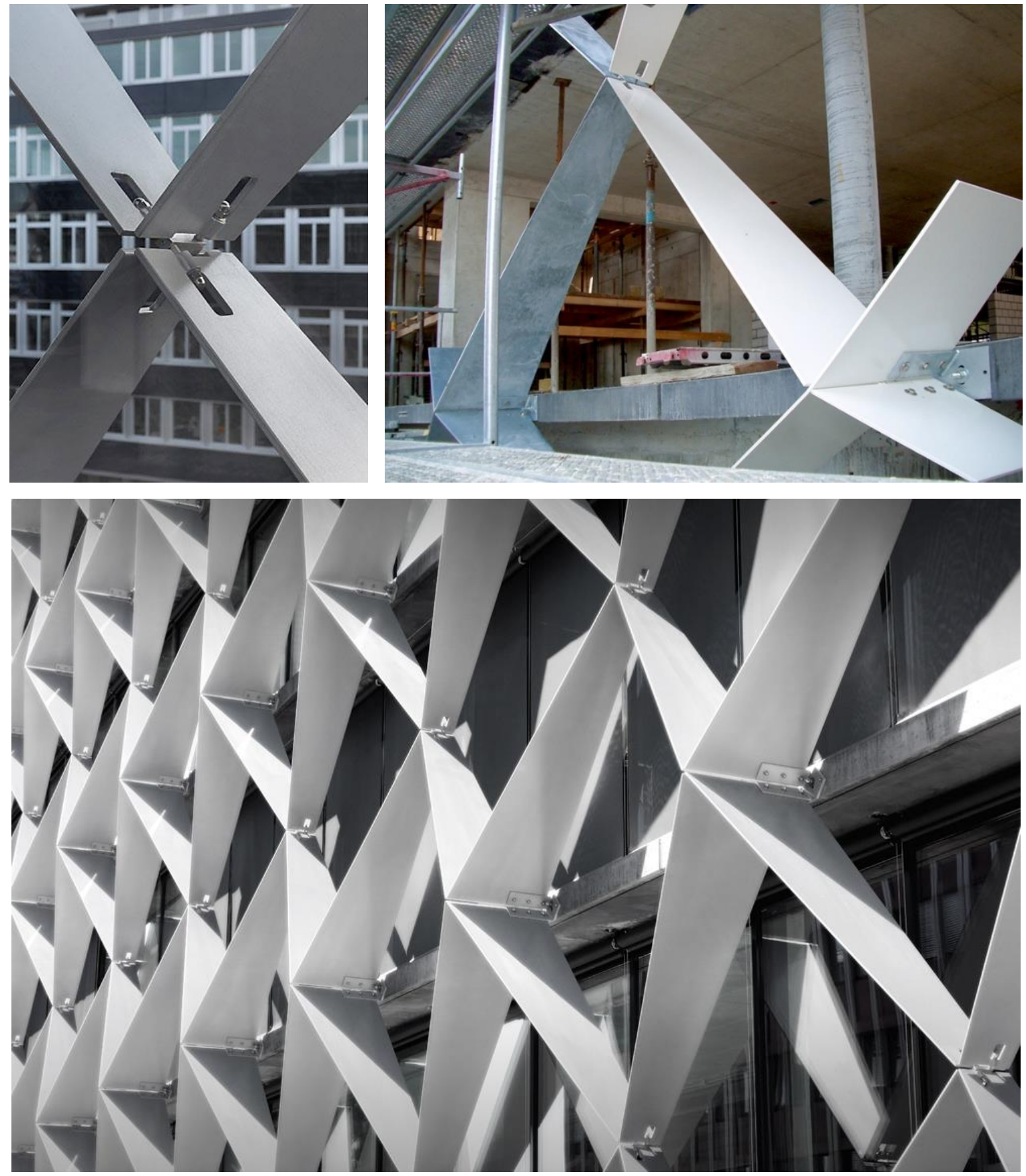

Figure 11: Diagrid Screen Connections, Dado Houese, Germany 


\subsection{Site and Weather data}

To complete energy and daylighting analysis, accurate weather file should be uploaded on simulation software. The external climate is an important factor affecting thermal and lighting performance of building. Also site location plays an important role in daylighting design, since amount of light entering the building varies from locations to orientations.

The current project uses following site data of Toronto:

Location: Toronto City

Latitude: $43.67 \mathrm{~N}$

Longitude: $79.63 \mathrm{~W}$

ASHRAE Climate Zone: $6 \mathrm{~A}$

Altitude (m): 113.0

Simulation weather file: CAN_ON_Toronto.716240_CWEC

The weather data used for the simulations were Canadian Weather Year for Energy Calculation (CWEC) Datasets which was uploaded to DesignBuilder for energy modeling simulations and later on to Daysim for daylighting analysis. CWEC is created by joining twelve Typical Meteorological Months selected from a database of, 30 years of CWEEDS data.

\subsection{Energy Simulations Assumptions}

In order to analyze the impacts of floor to ceiling windows on energy performance of glazed office buildings, rooms with openings orienting south, east and west, located around the perimeter of the building, have been selected as shown in Figure 11. All rooms are 3.5 meter wide, 5.5 meter long, with slab to slab height of 4 meter. Since the focus of this research was on impact of external shading devices on energy performance and lighting quality of spaces, north orienting room did not take into consideration.

For energy modeling simulations three selected rooms were modeled in DesignB uilder with adiabatic surfaces covering the space from five sides to avoid heat transfer. It assumes that room is bordered with thermally similar spaces and there is no heat flow between the rooms and other spaces except through the exterior wall. The exterior wall is modeled as a curtain wall system with total U-value of 
$1.16 \mathrm{~W} / \mathrm{m}^{2} \mathrm{~K}$ and $70 \%$ window to wall ratio. Glass is double pane, low-e, argon fill, with visible light transmittance of $69 \%$ and solar heat gain coefficient of $37 \%$. The space is conditioned by central dual duct VAV (Variable Air Volume) system powered by natural gas for heating and electricity for cooling. Coefficient of performance are 0.6 and 0.76 respectively. Since the selected office building is constructed in 2009, lighting power density of $12 \mathrm{~W} / \mathrm{m}^{2}$, equipment load of $12 \mathrm{~W} / \mathrm{m}^{2}$ and space occupancy of $18.6 \mathrm{~m}^{2}$ per person have been assigned to the model based on ASHRAE 2007 instructions.

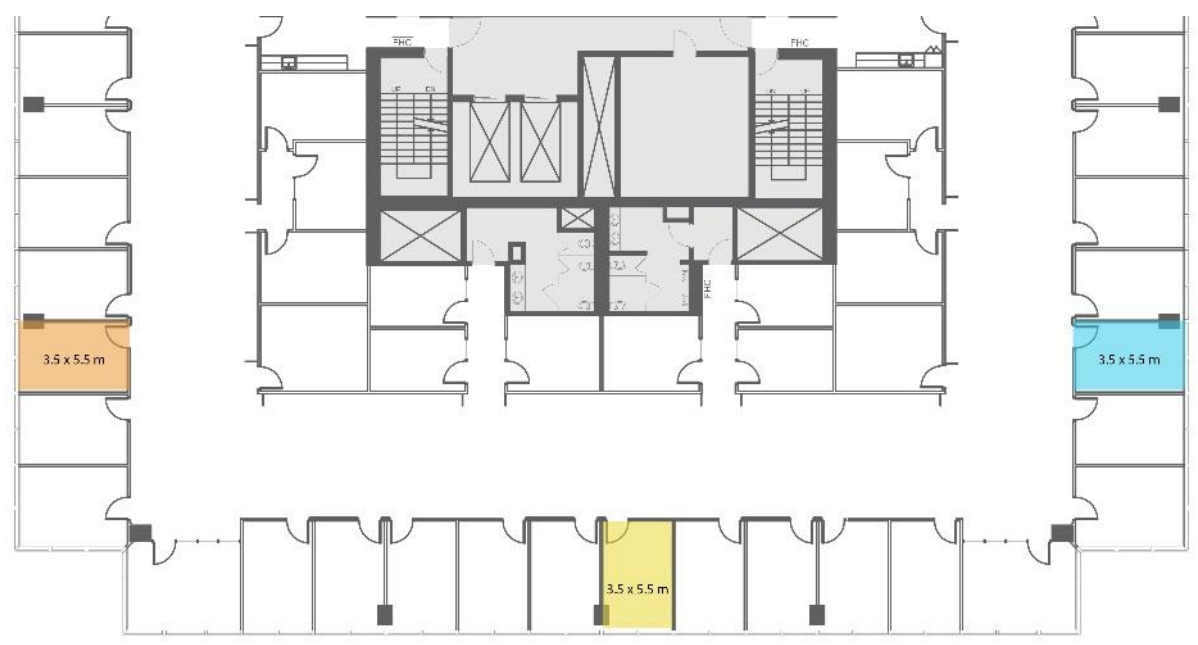

Figure 12: Selected Rooms for Energy and Daylighting Simulations

The energy modeling simulations of the rooms have been run with various shading options, such as no shade, internal blind, external shadings with different depths and diagrid screen. The regular shading strategies as overhang, light shelve and vertical fins were assigned to the model through DesignBuilder local shading components. It can be selected from opening tab in model data and will be applied to all windows of the selected wall. The depth and distance between the shading device and window from the top or sides can be modified. In terms of overhang, shading blade is exactly aligned with the top of the vision glass. The light shelve is placed with 0.7 meter offset from the top of the vision glass and vertical fins are aligned with the curtain wall mullions and have 1.5 meter spacing, as shown in figure 13 .

The internal blind was assigned to the model through the same opening tab in model data and through window shading component. It is a diffusing semi-open weave light color fabric roller blind with solar and visible transmittance of 0.45 and reflectance of 0.4 . Control type of solar and solar set point of $120 \mathrm{w} / \mathrm{m}^{2}$ was assigned to the internal blind. So internal blind is active if beam plus diffuse 
solar radiation incident on the window exceeds the solar set point. It is important to consider that actual energy use of the space with internal blind might vary from simulation results, since as discussed earlier in the real cases, once the occupant lowered the blind, since it is not automated, it will stay in that position for a long time, which for instance in terms of south facing room will increase the energy intensity of the room by decreasing the potential for passive solar heat gain.
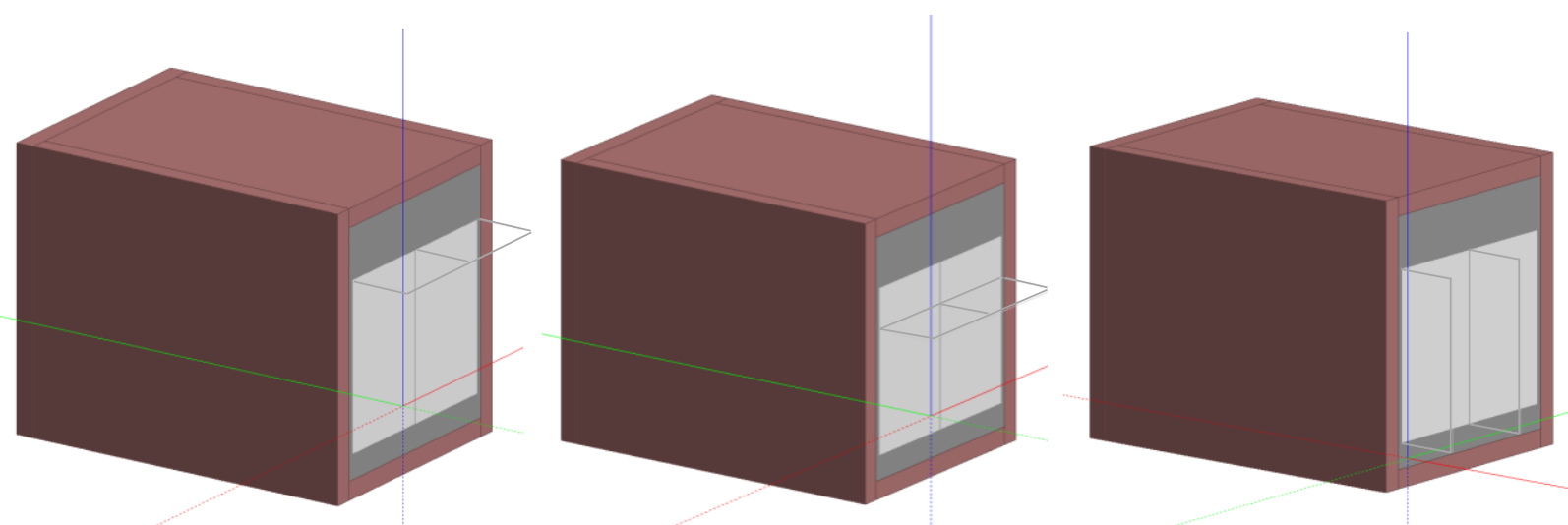

Figure 13: Local Shading Components in DesignBuilder

In terms of digrid screen, diagonal components were modeled through DesignBuilder component block. As Figure 14 shows, first 1:1 diagrid screen were modeled with diagonal blocks joining at the center of each wall, and then diagonal component blocks were added to the model to achieve diagrid screen in 2:1 and 4:1 scales. To increase the depth of diagrid screens the outer surfaces of each diagonal component blocks, have dragged through drag face command.
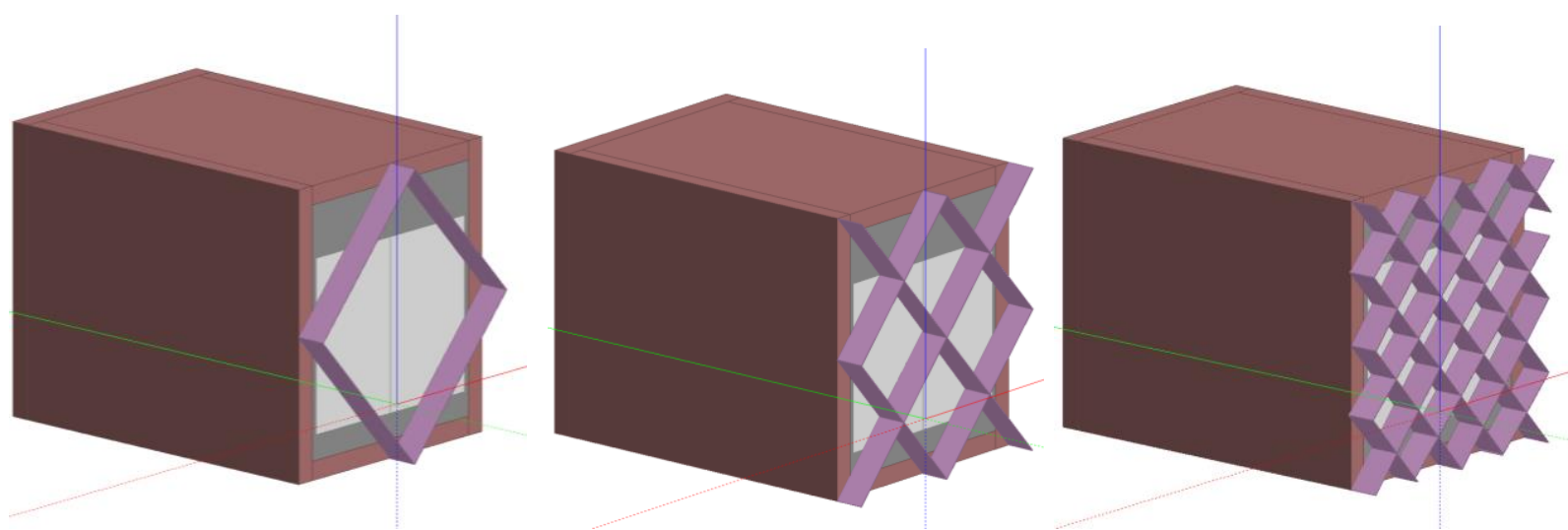

Figure 14: Diagrid Screens in DesignBuilder 


\subsection{Lighting Simulations Assumptions}

For lighting analysis each individual rooms were modeled again in Ecotect and export to Radiance and Daysim for daylighting analysis. The ceiling, walls and floor have reflectances of $70 \%, 50 \%$ and $30 \%$ respectively and the shading devices have reflectivity of $40 \%$. A horizontal analysis grid have been applied to the room with 0.8 meter distance from the floor level with sensors to measure illuminance level. The illuminance level of daylight in Lux, at three sensors located in the center of the rooms with distances of $1,2.5$ and 4 meters from the window have been measured.

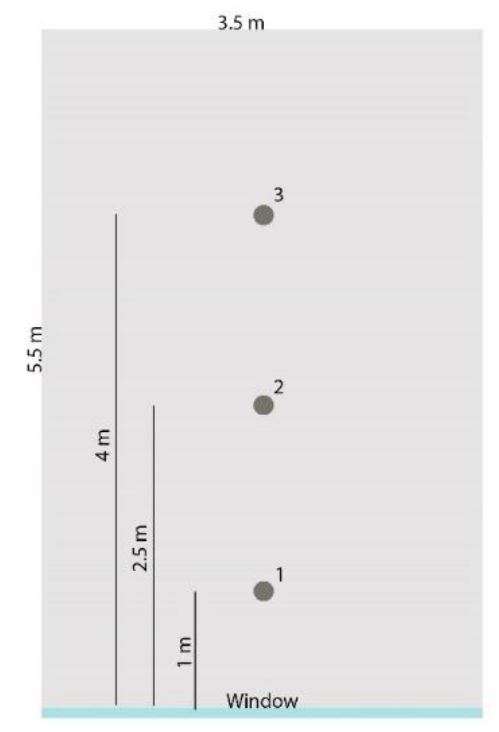

Figure 15: Lighting Sensors Locations

The shadings devices were modeled in Ecotect in a same way as explained before in energy section, through plane component. Figure 16 shows some of the different shading devices modeled in Ecotect.
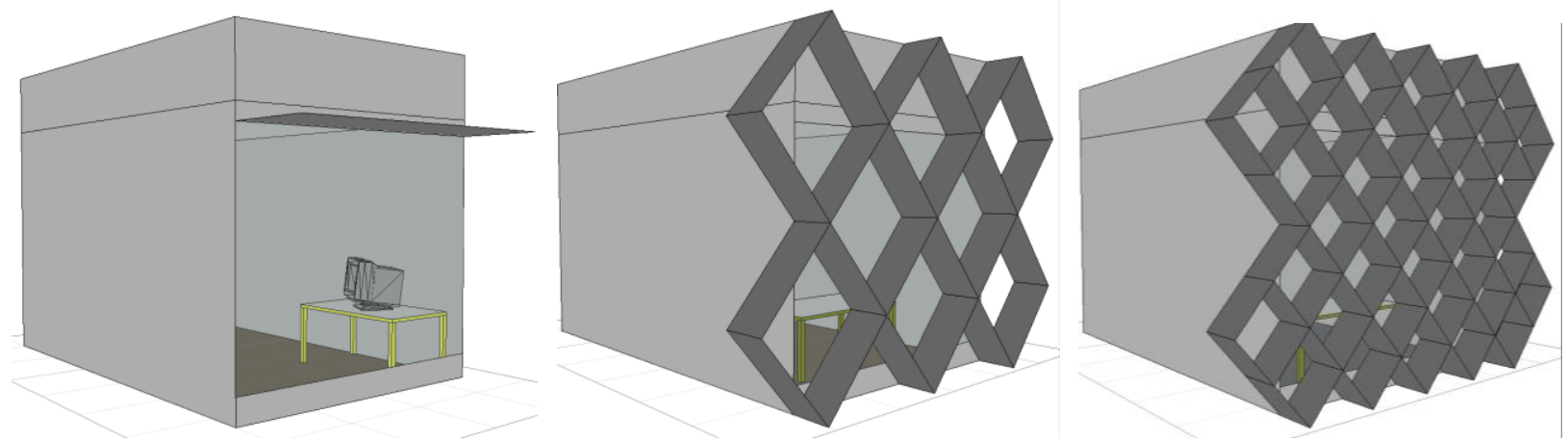

Figure 16: Shading Devices in Ecotect 
In the next stage, the models were exported to Daysim through export manager. For Daysim analysis the space is assumed to be occupied weekdays from 8 AM to 5 PM. The total annual hours of occupancy at the work place are 2349 hours. The occupant behavior was considered as equal mix of active and passive behavior with occupant avoid direct sunlight on work plane. The occupant behavior were assigned to the model based on reference work by Reinhart (2011). Based on his study the 'no blind' and 'passive user' (blinds always lowered) scenarios show the magnitude of the simulation uncertainty introduced by the occupants, and the 'true' occupant behavior is likely to lie somewhere in between these two extremes.

The next step in lighting analysis is to decide what daylight levels to consider adequate. Based on NRC/IRC Construction Technology Update No. 62 by Newsham, Veitch, Reinhart and Sander, the IESNA recommends 300 lux if computer use is intensive and 500 lux if it is intermittent. By comparison, in studies by IRC (2015) in an office set-up where occupants used dimmers to select their preferred lighting conditions, have been found that average chosen illuminances on the desk surface were in the range of 400-500 lux, even for those who are intensive computer users. So based on IRC survey research, the metric uses the target illuminance of 400 lux on work planes in this project to measure daylight level within the spaces. A point is considered to receive good daylighting if it exceeds the target illuminance for more than $50 \%$ of time (DA>50\%).

Daylight autonomy, useful daylight index and maximum daylight autonomy of the rooms were analyzed through Daysim and the quantity of daylight at selected sensor points in the rooms with various shading strategies have been reported and compared through DA, UDA and DAmax metrics. The following simulation parameters were assigned in Daysim prior to running the simulations based on reference works (Reinhart \& Walkenhorst, 2011).

\begin{tabular}{|c|c|c|c|c|c|}
\hline $\begin{array}{c}\text { Ambient } \\
\text { bounces }\end{array}$ & $\begin{array}{c}\text { Ambient } \\
\text { division }\end{array}$ & $\begin{array}{c}\text { Ambient } \\
\text { sampling }\end{array}$ & $\begin{array}{c}\text { Ambient } \\
\text { accuracy }\end{array}$ & $\begin{array}{c}\text { Ambient } \\
\text { resolution }\end{array}$ & Direct threshold \\
\hline 5 & 1000 & 20 & 0.1 & 300 & 0 \\
\hline
\end{tabular}

Table 1: Utilized Radiance Simulation Parameters 


\section{Energy Simulations Results}

A total of 36 energy simulations were performed with three archetypes rooms facing south, east and west. The simulation results are obtained for total energy use profile on annual basis. The total energy refer to heating, cooling, electrical lighting and miscellaneous equipment. Each room is analyzed with no shade and various shading strategies. The annual heating and cooling loads are defined as heating or cooling energy (in kilo watt-hours per square metre of conditioned building space) that is required to be supplied to the conditioned space by the heating or cooling systems.

Description of energy results of the rooms with and without shadings are presented below.

\subsection{South Facing Room}

Figure 17 is a demonstration of total energy use pattern in south facing room with $70 \%$ WWR and various shading strategies and Table 2 provides a summary of the energy use for various options for the south facing room.

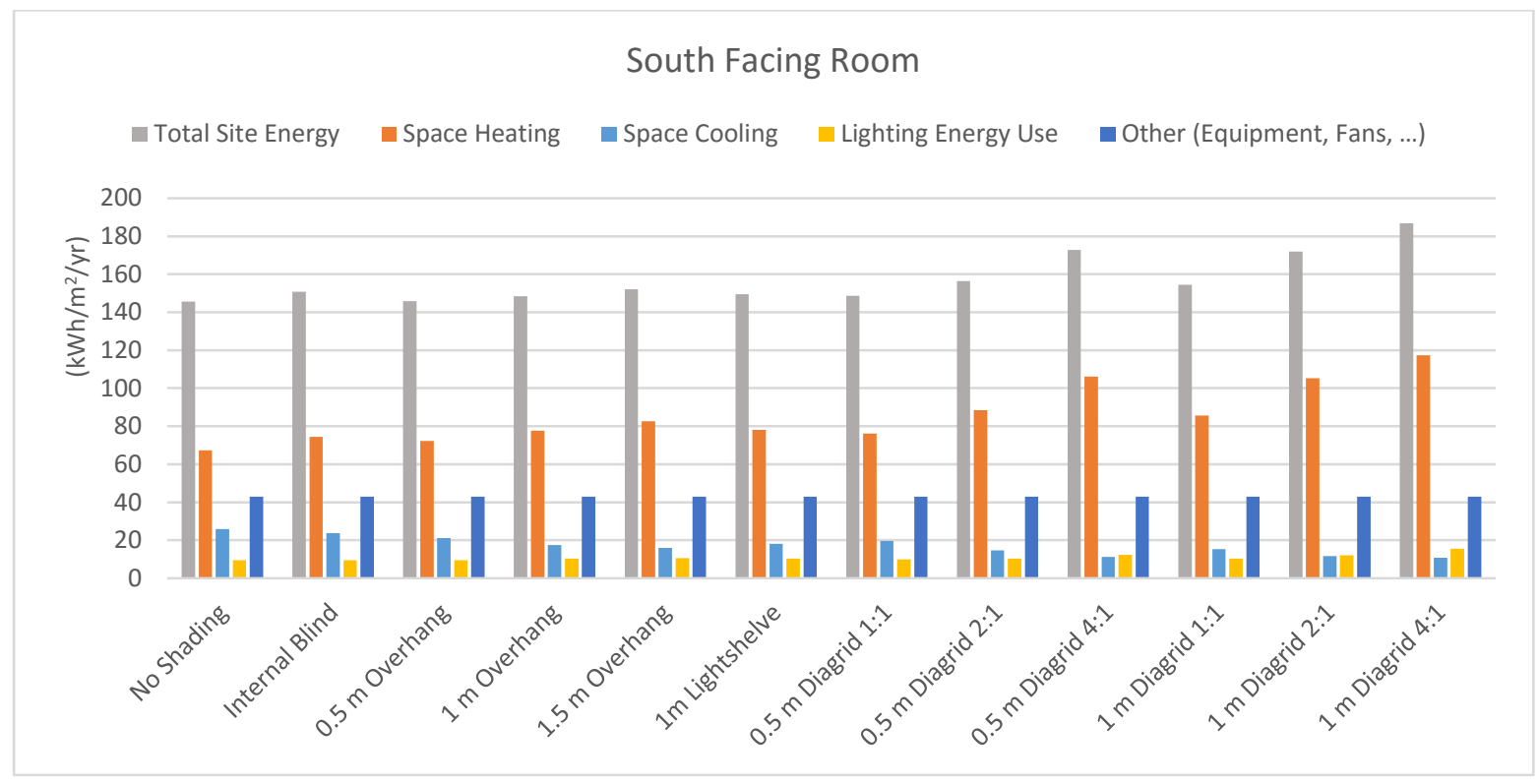

Figure 17: Energy Use Pattern of South Facing Room with Various Shading Strategies

First energy consumption of the south facing room with 70\% WWR and no shade was investigated, results are shown in the first set of bars on the left of Figure 17. The total energy consumption of the room with no shade was $145.64 \mathrm{kWh} / \mathrm{m}^{2}$, which comprised of $46 \%$ heating load, $18 \%$ cooling load, $6.5 \%$ artificial lighting and $29.5 \%$ equipment. It is clear that heating energy is major contributor to the total energy. In the next step overhang with the depths of $0.5,1$ and 1.5 meter were studied. 
The results, in Figure 17, shows that total energy intensity of the room with overhang is higher than no shade scenario. For instance, 1 meter overhang increased the total energy by $1.8 \%$. The energy use for artificial lighting is also increased with the increase in overhang depth. $0.5 \mathrm{~m}$ overhang will increase lighting intensity only by $0.95 \%, 1$ meter overhang will increase it by $8.5 \%$ and 1.5 meter overhang will cause $10.5 \%$ rise in lighting energy use.

The increase in energy use with shading is principally due to higher heating loads, since the shades reduce the passive heating benefits of the glazing. The shadings reduce cooling loads but since these are much smaller than heating loads, the overall energy use goes up. Nevertheless, the overall variations in total energy uses in small with only a $15 \%$ variation from best to worst scenarios except 4:1/1m diagrid screen, which significantly increases the space heating energy use.

The external shading is found to limit the opportunity of daylight harvesting to some extent. However, it is important to note that, conversely cooling energy gets reduced in each scenario with shading. This finding portrays the importance of carefully designed sun control devices in office buildings that maximizes daylighting while reducing both glare and cooling loads.

All the diagrid screen options regardless of their density increased the room total energy use in comparison to no shade. The screen cause a rise in heating load and since heating is the main portion of total energy use of the room, the total energy increased as well. On the other hand cooling load significantly decreased. The 4:1 diagrid pattern with depth of $0.5 \mathrm{~m}$, increases the space total energy use by $15.7 \%$, which is higher than 1 meter overhang, but it also reduce cooling load by $52 \%$.

As Figure 17 and Table 2 show, the variation between lowest and highest energy use in the room is in range of 145 to $186 \mathrm{kWh} / \mathrm{m}^{2} / \mathrm{yr}$. The room with no shade demonstrates the lowest and shading screen with depth of 1 meter and scale of 4:1 demonstrates the highest total energy use. 


\begin{tabular}{|c|c|c|c|c|c|c|}
\hline \multicolumn{7}{|c|}{ South Facing room } \\
\hline$\left(\mathrm{kWh} / \mathrm{m}^{2} / \mathrm{yr}\right)$ & $\begin{array}{c}\text { No } \\
\text { Shading }\end{array}$ & $\begin{array}{c}\text { Internal } \\
\text { Roller Blind }\end{array}$ & $\begin{array}{c}0.5 \mathrm{~m} \\
\text { Overhang }\end{array}$ & $\begin{array}{c}1 \mathrm{~m} \\
\text { Overhang }\end{array}$ & $\begin{array}{c}1.5 \mathrm{~m} \\
\text { Overhang }\end{array}$ & $\begin{array}{l}1 \text { m Light } \\
\text { Shelve }\end{array}$ \\
\hline Total Site Energy & 145.64 & 150.73 & 145.94 & 148.37 & 152.12 & 149.46 \\
\hline Space Heating & 67.24 & 74.53 & 72.35 & 77.60 & 82.71 & 78.11 \\
\hline Space Cooling & 25.99 & 23.71 & 21.17 & 17.50 & 15.89 & 18.05 \\
\hline Lighting Energy Use & 9.45 & 9.54 & 9.47 & 10.32 & 10.58 & 10.36 \\
\hline $\begin{array}{l}\text { Other (Equipment, } \\
\text { Fans, ...) }\end{array}$ & 42.95 & 42.95 & 42.95 & 42.95 & 42.95 & 42.95 \\
\hline \multicolumn{7}{|c|}{ South Facing Room - Diagrid Screen $-0.5 \mathrm{~m}$} \\
\hline$\left(\mathrm{kWh} / \mathrm{m}^{2} / \mathrm{yr}\right)$ & \multicolumn{2}{|c|}{$1: 1$} & \multicolumn{2}{|c|}{$2: 1$} & \multicolumn{2}{|c|}{$4: 1$} \\
\hline Total Site Energy & \multicolumn{2}{|c|}{148.58} & \multicolumn{2}{|c|}{156.40} & \multicolumn{2}{|c|}{172.78} \\
\hline Space Heating & \multicolumn{2}{|c|}{76.09} & \multicolumn{2}{|c|}{88.44} & \multicolumn{2}{|c|}{106.18} \\
\hline Space Cooling & \multicolumn{2}{|c|}{19.70} & \multicolumn{2}{|c|}{14.73} & \multicolumn{2}{|c|}{11.29} \\
\hline Lighting Energy Use & \multicolumn{2}{|c|}{9.85} & \multicolumn{2}{|c|}{10.28} & \multicolumn{2}{|c|}{12.36} \\
\hline $\begin{array}{l}\text { Other (Equipment, } \\
\text { Fans, ...) }\end{array}$ & \multicolumn{2}{|c|}{42.95} & \multicolumn{2}{|c|}{42.95} & \multicolumn{2}{|c|}{42.95} \\
\hline \multicolumn{7}{|c|}{ South Facing Room - Diagrid Screen - 1m } \\
\hline$\left(\mathrm{kWh} / \mathrm{m}^{2} / \mathrm{yr}\right)$ & \multicolumn{2}{|c|}{$1: 1$} & \multicolumn{2}{|c|}{$2: 1$} & \multicolumn{2}{|c|}{$4: 1$} \\
\hline Total Site Energy & \multicolumn{2}{|c|}{154.38} & \multicolumn{2}{|c|}{171.97} & \multicolumn{2}{|c|}{186.78} \\
\hline Space Heating & \multicolumn{2}{|c|}{85.70} & \multicolumn{2}{|c|}{105.35} & \multicolumn{2}{|c|}{117.38} \\
\hline Space Cooling & \multicolumn{2}{|c|}{15.29} & \multicolumn{2}{|c|}{11.61} & \multicolumn{2}{|c|}{10.81} \\
\hline Lighting Energy Use & \multicolumn{2}{|c|}{10.43} & \multicolumn{2}{|c|}{12.06} & & \\
\hline $\begin{array}{l}\text { Other (Equipment, } \\
\text { Fans, ...) }\end{array}$ & & 95 & & & & \\
\hline
\end{tabular}

Table 2: Energy Use of South Facing Room with Various Shading Strategies 


\subsection{Discussion on Individual Energy Factors - South Room}

This section further investigates the individual energy factors effecting annual total energy consumptions. Three separate graphs are generated based on energy demands of space heating, cooling and interior lighting. Although variation in total energy uses were small in previous section, variation in heating, cooling and lighting are more significant but offsets each other in some cases.

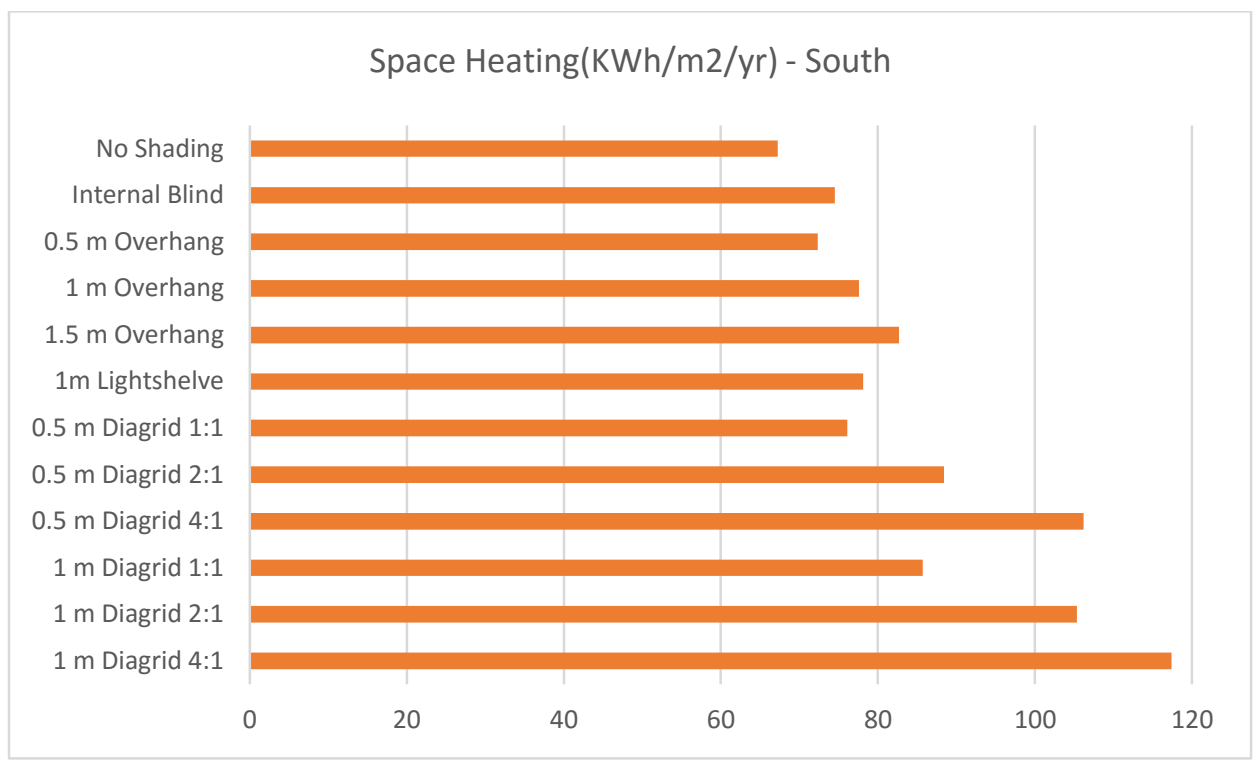

Figure 18: Space Heating of South Facing Room with Various Shading Strategies

As Figure 18 shows, the room with no shade requires the least energy for space heating in all combinations. The combinations with deeper or denser shading structures result in higher heating energy load than without shading. The heating energy increases by $13 \%$ in the room with 1 meter overhang and by $36 \%$ in the room with 0.5 meter deep, 4:1 diagrid screen. The heating load further increases in combinations with denser or deeper shading structures. So the south facing room with no shade is the best performing room in terms of space heating requirement, but it does not mean that shading should be eliminated, since glazed façade with no solar protection results in higher cooling load and more importantly occupant discomfort and glare, rather it is important to optimise the shading design to minimise increase in space heating load.

So higher potential of no shade room for passive solar heat gain causes reduction in space demand for heating. Internal blind will slightly increases heating load through blocking direct solar radiation, however its impact on heating energy rises is lower than the most of the external shading options which confirms the fact that once solar radiation enters the room most of its solar energy will be trapped in the building. 
In terms of space cooling, shading devices are more beneficial (Figure 19). Opposite to space heating, the room with no shade has higher cooling load. As shading structures getting deeper or denser the cooling load decreases further. One important note is that in general diagrid screens are more effective in terms of cooling load reduction than conventional shading devices. 1 meter overhang reduced the cooling load by $32 \%$ and $2: 1 / 1 \mathrm{~m}$ diagrid screen reduced it by $55 \%$ in comparison to no shade. The main reason is that diagrid screen provides full protection in front of the glass to block direct solar radiation in despite of the angle of the sun, but the overhang can only block the solar radiation when sun is higher in sky.

So achieving a reduction in heating and cooling loads simultaneously is challenging since fixed shading devices have diverse impact on heating and cooling loads.

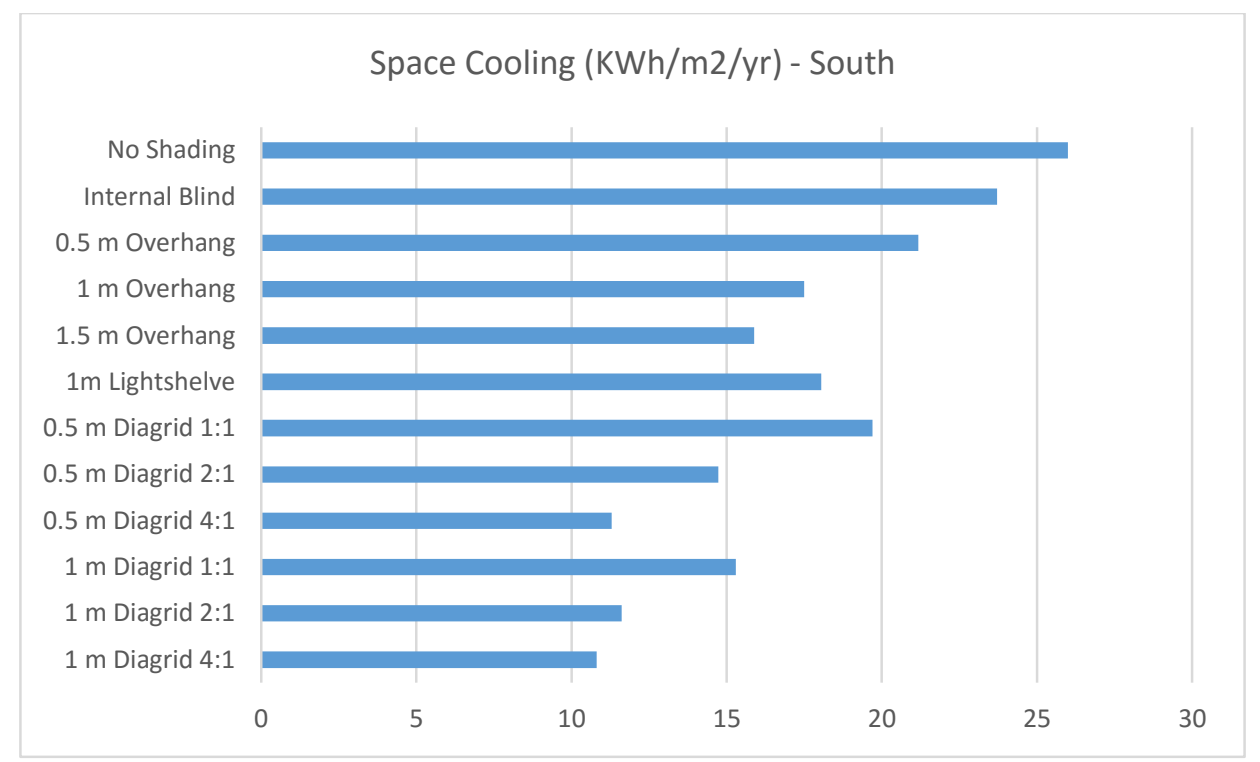

Figure 19: Space Cooling of South Facing Room with Various Shading Strategies

The lighting energy use results are presented in Figure 20. The no shade room has higher daylight harvesting potential which cause lower electrical lighting intensity, but the light entering the room might not fall in the adequate illuminance level which leads to glare and discomfort. Also as simulation results shows shading devices in general do not increase the annual lighting energy use significantly. Mainly because they block direct solar radiation during the certain times of the year but still allow diffuse light to enter the room. Especially in cases of light shelve or diagrid screens, the shading devices will reflect the light deeper into the room and enhance daylight distribution quality. However 4:1 diagrid screen with 1 meter depth seems to be too dense and causes an increase in annual lighting energy use of the space. As Figure 20 shows, the annual electrical lighting energy use of the 
room with 1 meter overhang is higher by $8.5 \%$ and by $21 \%$ with 2:1/1m diagrid screen in comparison to no shade scenario.

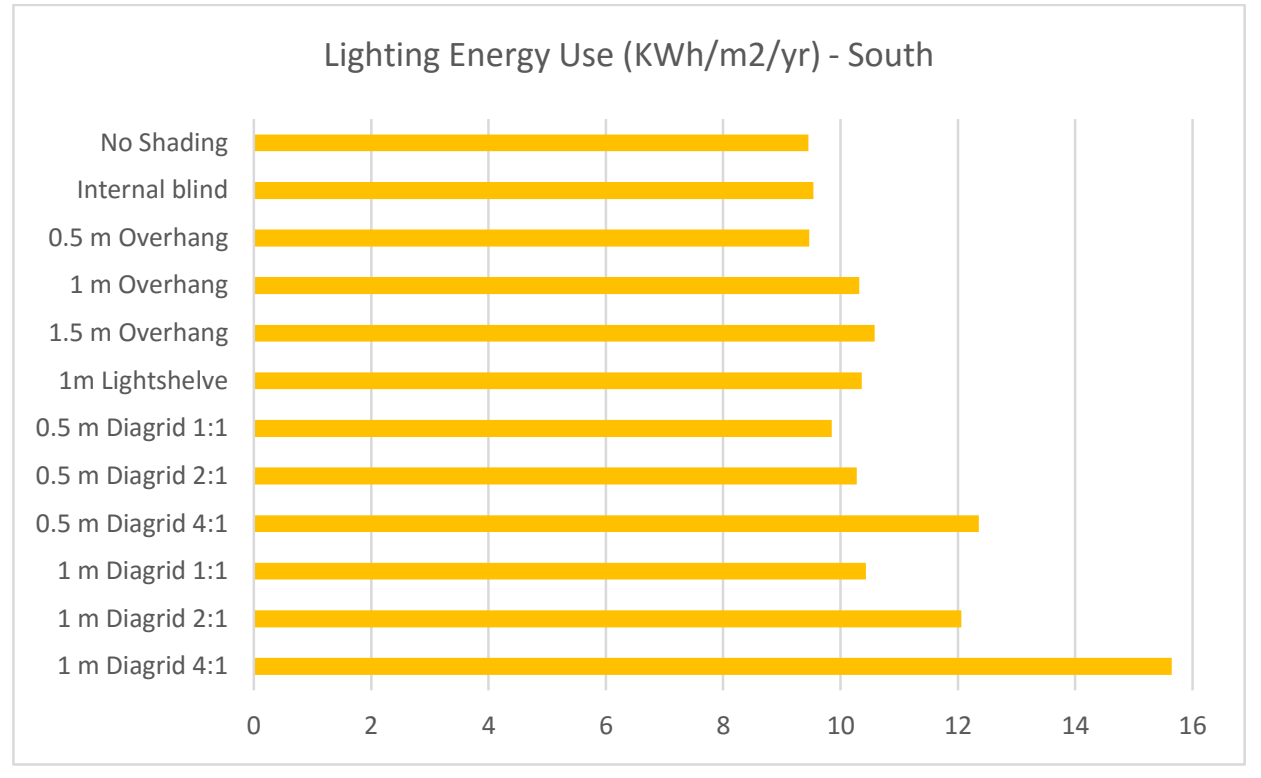

Figure 20: Artificial Annual Lighting Energy Use of South Facing Room with Various Shading Strategies

\subsection{Monthly Energy Simulations}

To develop better understanding of the process of energy use variations with various shading strategies, monthly energy simulations of the room with no shade, diagrid screen with the scale of 4:1 and 0.5 meter depth and 1 meter overhang were conducted and compared. Monthly heating simulations revealed that impact of shading screen on heating load during the whole heating season is more significant than overhang. The simulation revealed that existence of diagrid screen leads to heating load rise in winter, especially in months of J anuary, February and March. The main reason is that shading screen will block most of the solar radiations hitting the façade in mid-day, once sun is higher in sky, in winter and leads to higher heating load. Simulations show that diagrid screen is more effective in terms of blocking the direct solar radiation entering the room and minimizing the overheating potential in comparison to conventional shading strategies. To further develop the performance of shading screen in terms of energy efficiency, the screen should allow for more solar gain in winter while blocking solar radiation in summer. 


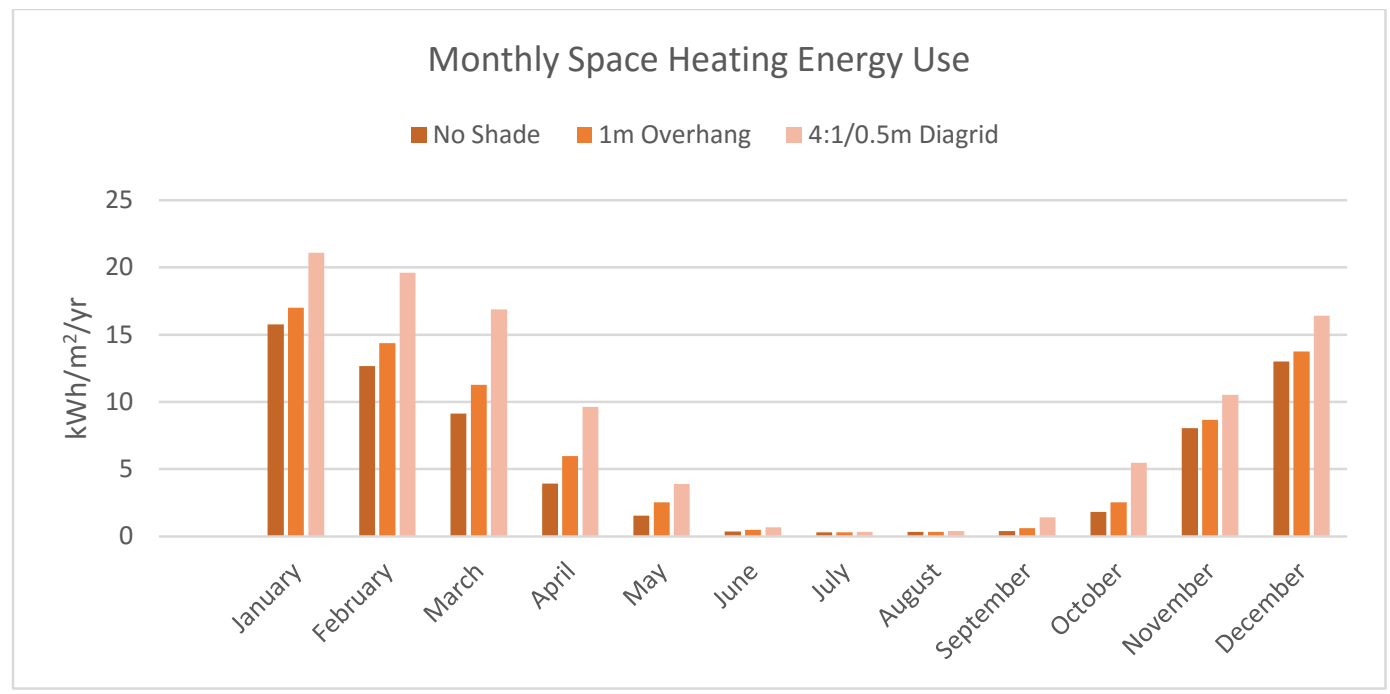

Figure 21: Monthly Space Heating Energy Use Comparison between No shade, Overhang and Diagrid Screen

One important point to note regarding the energy modeling simulation software, is that the software calculate for small amount of heating load during the summer month ( une, J uly and August), that is unlikely and cause an increase in heating load and total energy results.

The shading screen has a significant impact on cooling load reduction in comparison to overhang. As cooling graph shows in Figure 22, the diagrid screen reduces the cooling load by half in comparison to no shade scenario. This impact is more considerable in J une, J uly and August.

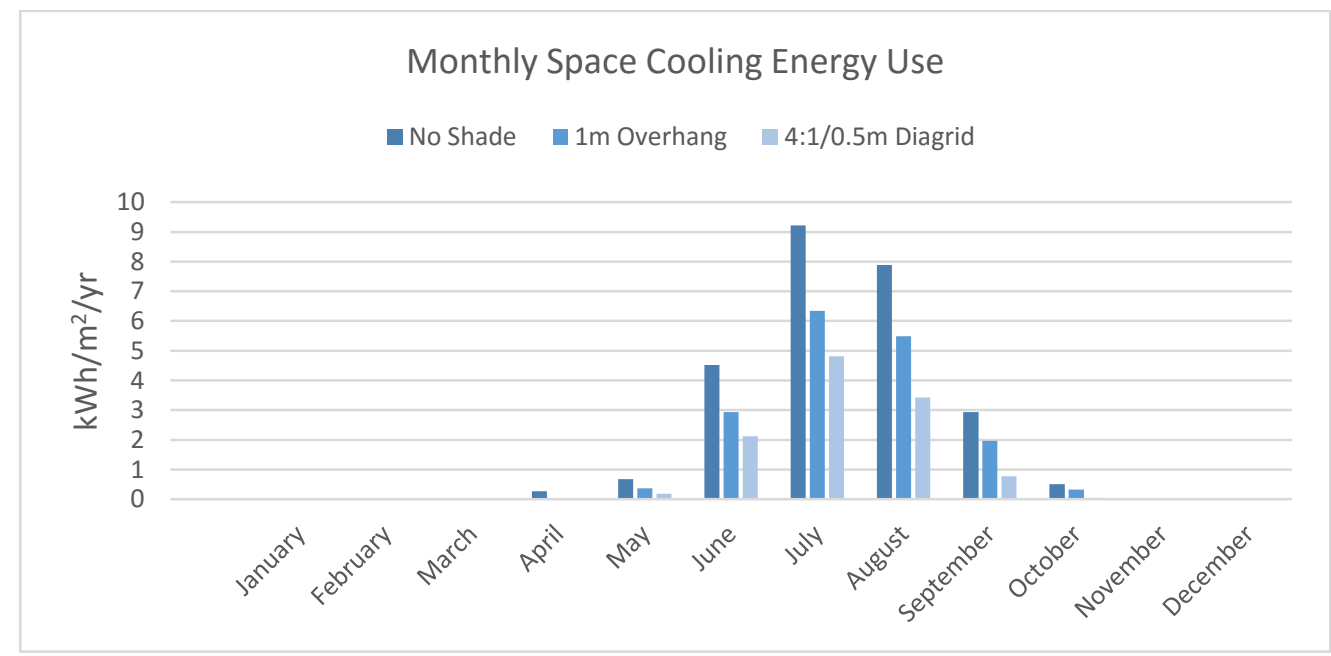

Figure 22: Monthly Space Cooling Energy Use Comparison between No shade, Overhang and Diagrid Screen 
Impact of shading devices on lighting energy use is less than their effect on heating and cooling loads. The shading devices will reduce the possibility of daylight harvesting to some extend and lighting energy uses will slightly grow in a room with external shadings, and shading screens have higher impact on this rise. However the lighting analysis in the next section confirm that they still allow for adequate level of daylight to enter the space.

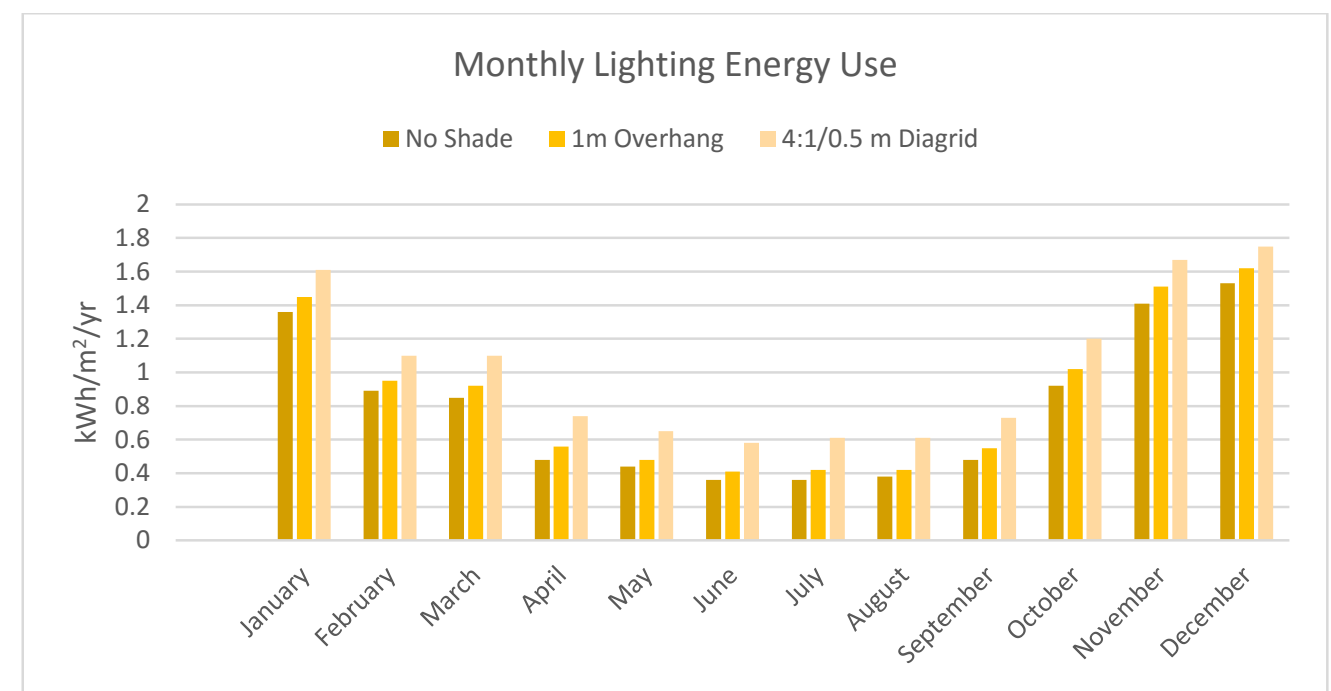

Figure 23: Monthly Lighting Energy Use Comparison between No shade, Overhang and Diagrid Screen 


\subsection{East and West Facing Rooms}

Energy use in east and west facing rooms are more consistence in comparison to south facing room. The east and west rooms have similar energy uses, but the east facing room shows slightly higher total energy use in no shade scenario. On the other hand west facing room with internal blind use more energy in comparison to east room. To explore the reason behind the east and west facing room energy variations, simulations have been run in DesignBuilder on monthly solar incidents, cooling design and heat losses and internal heat gains which is presented in the appendices section. One of the reason is that east orienting room receives higher solar incident in summer (in months of May, J une and J uly) which leads to higher cooling load in comparison to west facing room. Figure 24 and 25 demonstrate the energy use patterns in east and west facing rooms with various shading strategies.

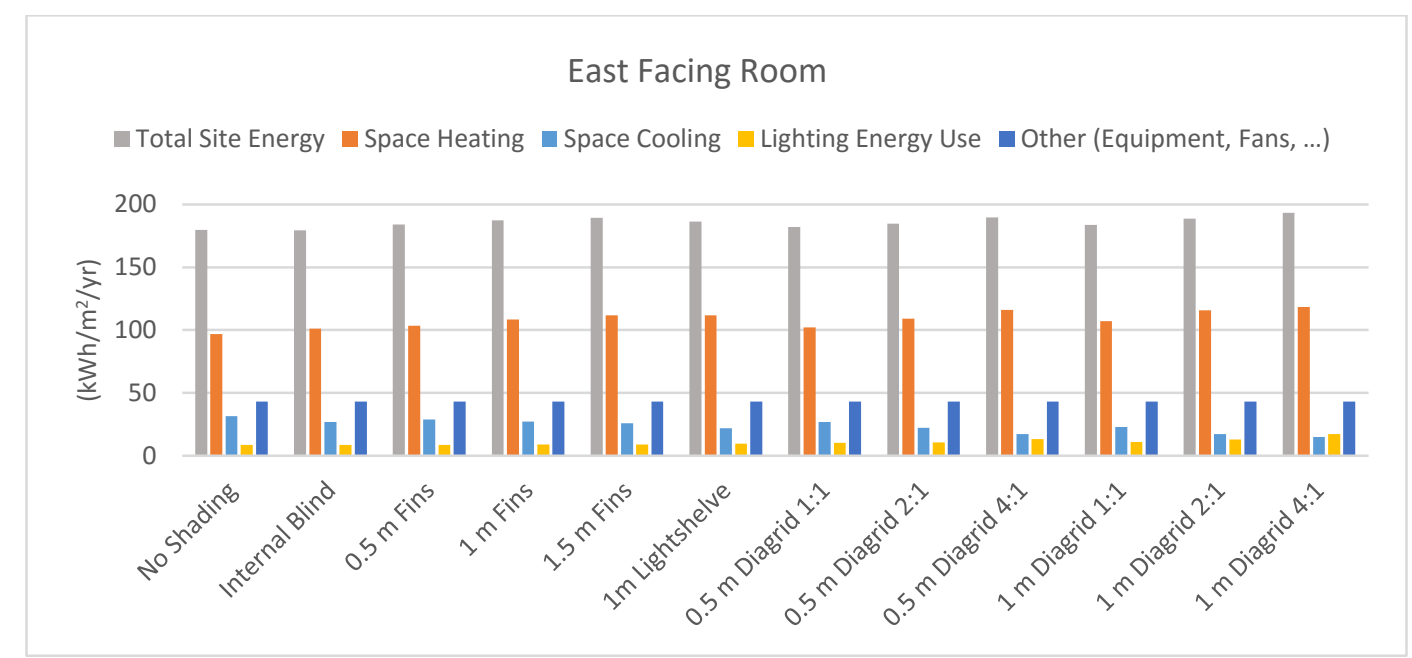

Figure 24: Energy Use Pattern of East Facing Room with Various Shading Strategies

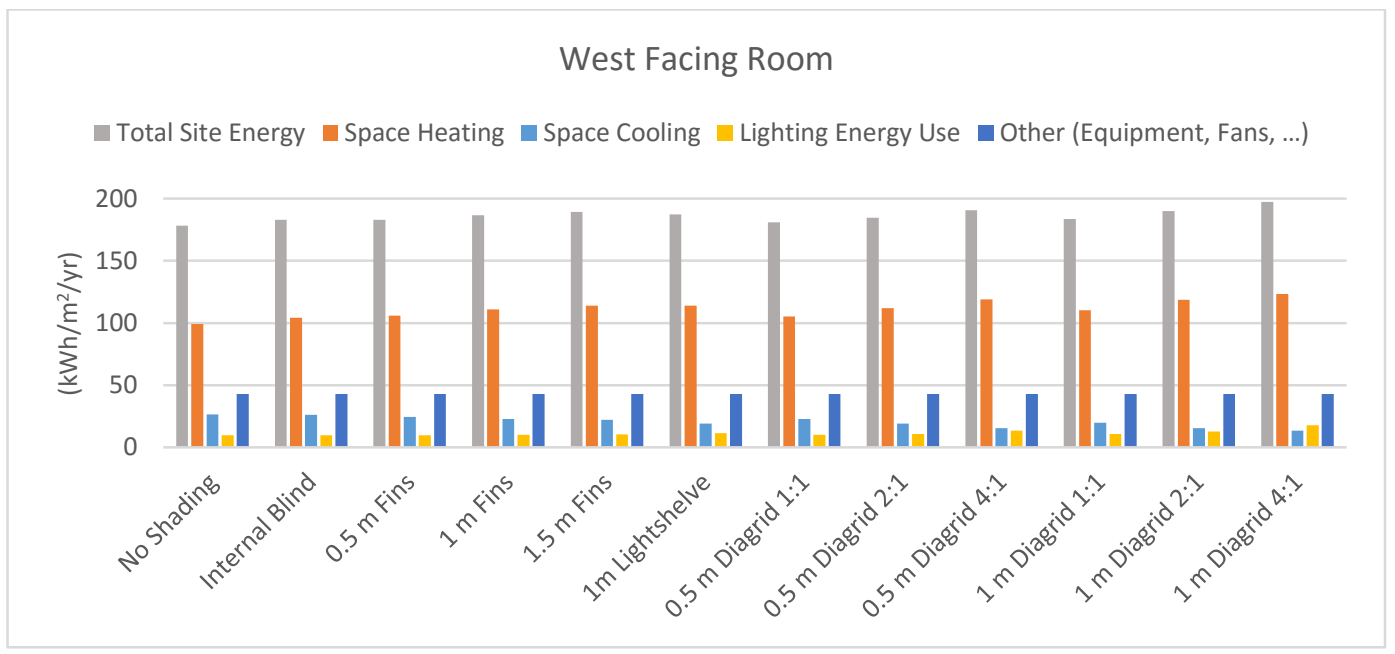

Figure 25: Energy Use Pattern of West Facing Room with Various Shading Strategies 
As Figure 24 shows the variation between highest and lowest energy intensities in the east room is in range of $179.85 \mathrm{kWh} / \mathrm{m}^{2} / \mathrm{yr}$ for no shade and $193.35 \mathrm{kWh} / \mathrm{m}^{2} / \mathrm{yr}$ for diagrid screen with 1 meter depth and density of 4:1, and in west facing room is in range of 178.23 to $197.21 \mathrm{kWh} / \mathrm{m}^{2} / \mathrm{yr}$. Similar to south orienting room, the shadings will increase the total energy use of east and west rooms, for instance 0.5 meter fins will increase the total energy intensity of the east facing room by $2.3 \%$ and the west facing room by $5.7 \%$.

Also 0.5 meter deep 4:1 diagrid screen, increases the space total energy use of east room by $5 \%$ and west room by $6.5 \%$. So in comparison to south facing room, shading screens have less negative impact on total energy use of east and west facing rooms compare to south facing room.

\subsection{Discussion on Individual Energy Factors - East/West Room}

As heating graphs shows (Figures 26 and 27), similar to south facing room, the room with no shade requires the least energy for space heating in all combinations. The room with deeper fins or denser diagrid screens demontrates higher heating energy use in both the east and west facing rooms. The heating energy use of both east and west facing rooms with 0.5 meter fins will increase by $6 \% .0 .5$ meter deep, 4:1 diagrid screen will increase heating energy by $16.6 \%$ in east and west facing rooms. One instresting point is that even though the enrgy intensities are slightly different in east and west rooms, but impact of shading strategies on energy consumptions is equal.

West facing room in overall demonstrates higher heating load compare to east facing room.

As mentioned earlier, room with no shade demonstrates the best performing room in terms of space heating requirements, but it does not mean that shading devices should be eliminated, since lack of solar protection can lead to glare and occupant discomfort. 


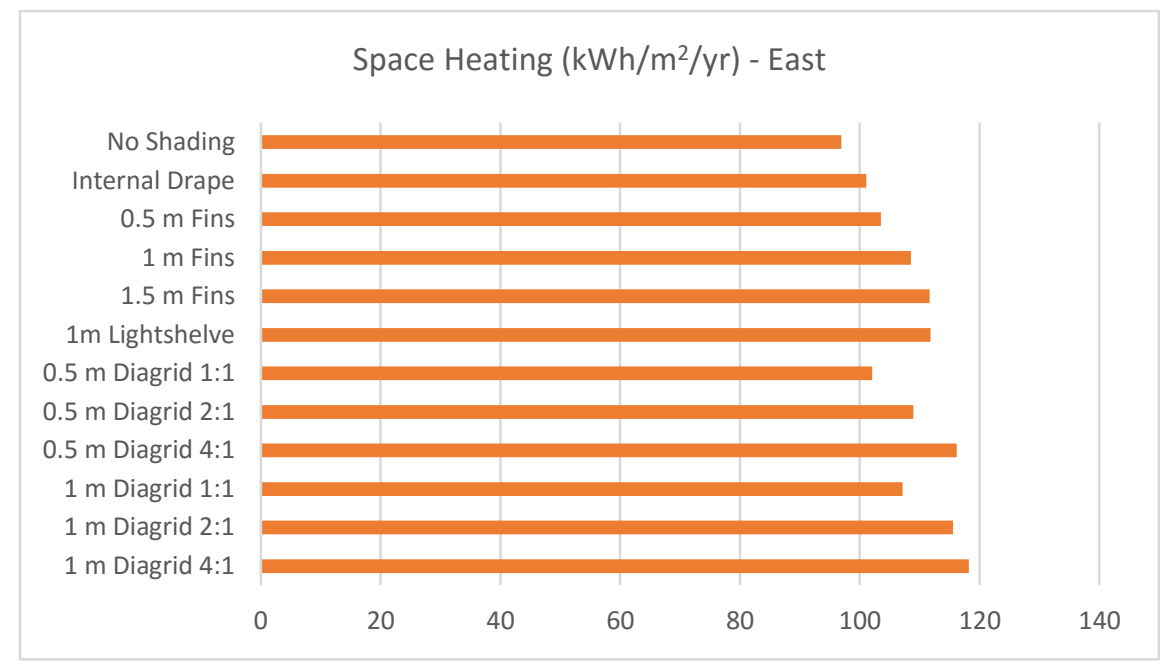

Figure 26: Space Heating of East Facing Room with Various Shading Strategies

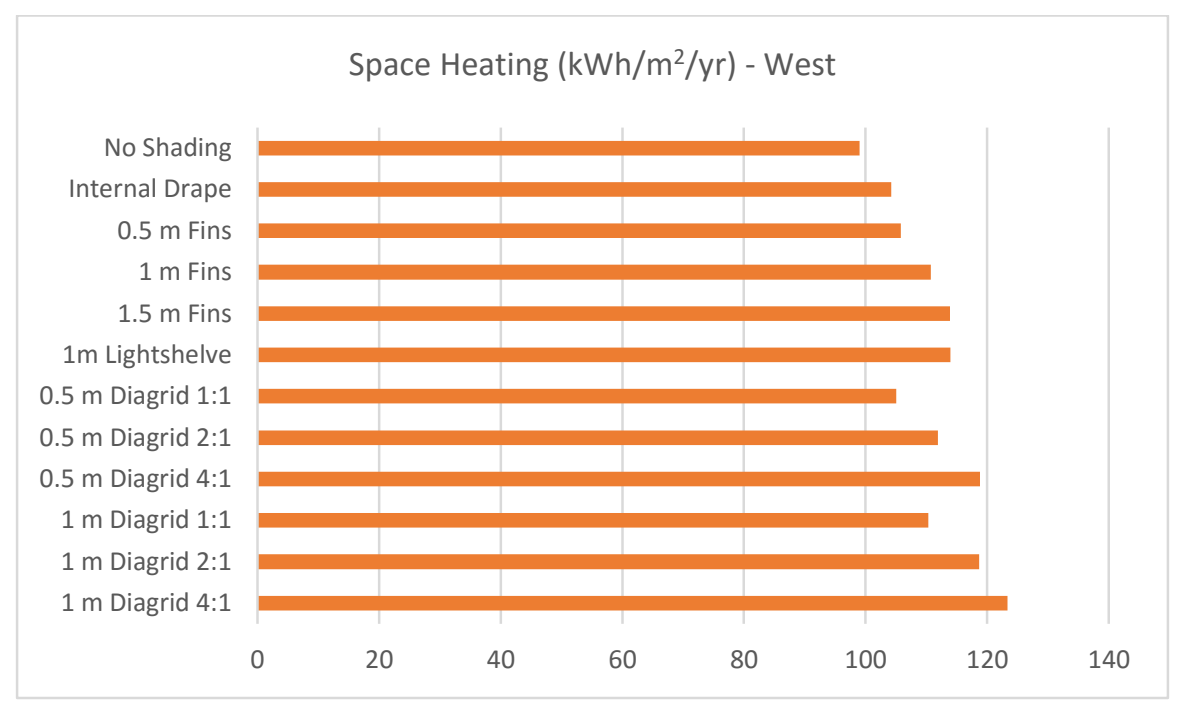

Figure 27: Space Heating of West Facing Room with Various Shading Strategies

In regards to space cooling loads, Figures 28 and 29 , the room with no shade has considerably higher cooling energy use than some of the shading options. Deeper or denser shading devices will decrease the cooling energy use further. 0.5 meter fins will decrease cooling energy use by $8 \%$ in both east and west facing rooms, and 0.5 meter, $4: 1$ diagrid screen will decrease it by $45 \%$. So similar to south facing room, shading screen is significantly more effective than conventional shading strategies in terms of space cooling energy use reduction.

Also in contrast with heating load, west facing room in overall demonstrates lower cooling load than east facing room. 


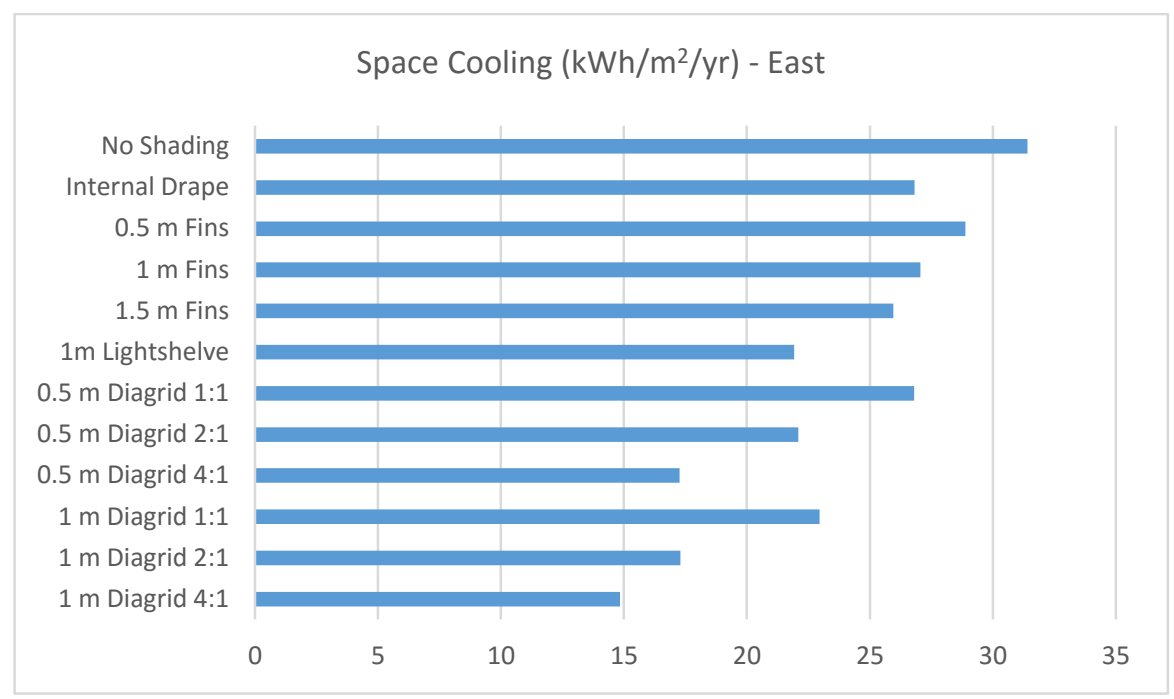

Figure 28: Space Cooling of East Facing Room with Various Shading Strategies

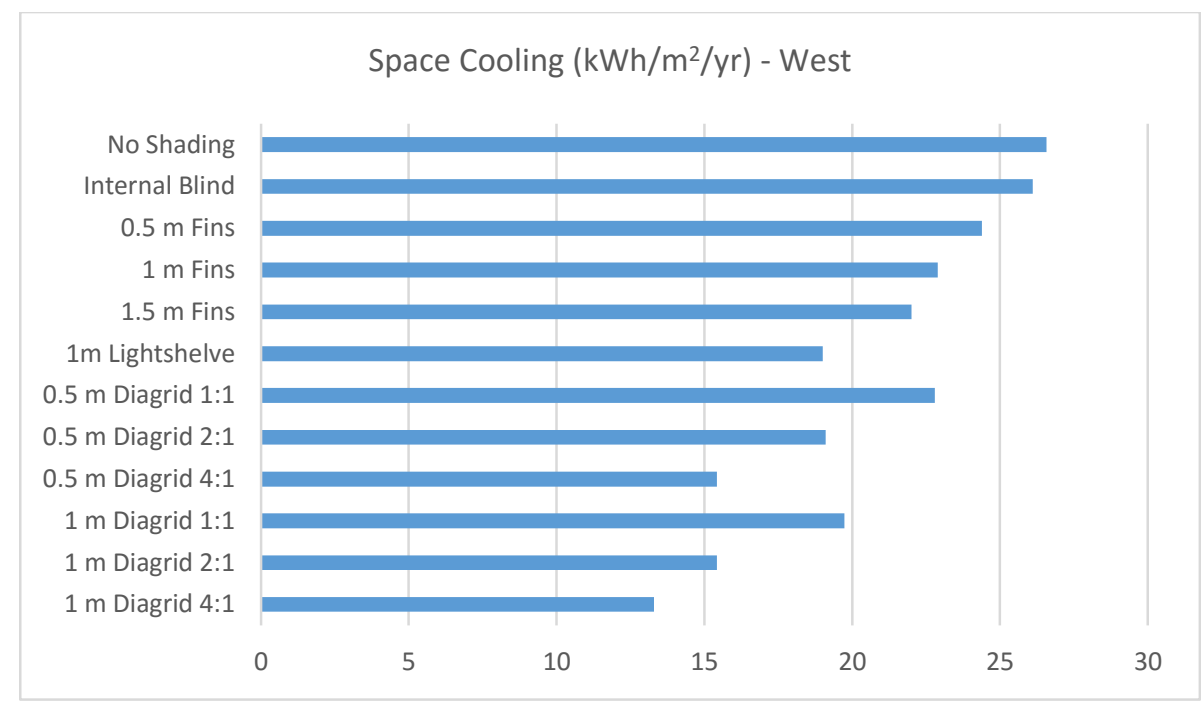

Figure 29: Space Cooling of West Facing Room with Various Shading Strategies

So cooling load in east facing room is $15.4 \%$ higher and the heating is $2.1 \%$ lower than west facing room, which in overall cause east room to consume more energy in total.

One key conclusion is that in terms of space heating there is much less variation between the various options, and the shading systems seem to have less effect in reducing passive heating. This is likely due to the fact that in the winter months there is little direct solar gain on these elevations. On the other hand the shading strategies have higher impact on cooling energy use reduction which is desirable. 
Regarding the lighting energy use, as shown in Figures 30 and 31, the room with no shade has higher potential for daylight harvesting than the rooms with shading devices, which leads to lower electrical lighting energy use. But in overall impact of shading strategies on lighting energy use is not significant, except the room with dense and deep shading screen which block most of the solar radiations. The lighting energy use of the room with 0.5 meter fins is $2.6 \%$ higher than the room with no shade. Diagrid screen will increase lighting energy use by $35 \%$ in east room and by $28 \%$ in west facing room.

In overall west facing room demonstrates higher electrical lighting intensity than east facing room.

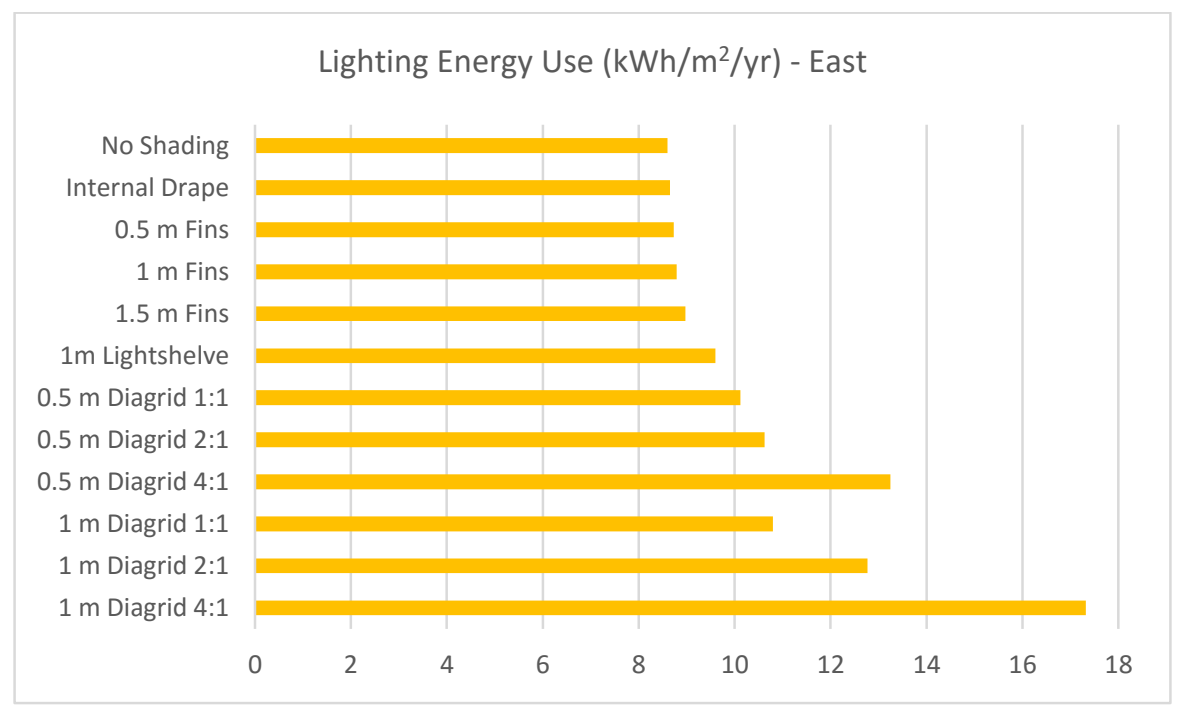

Figure 30: Lighting Energy Use Intensity of East Facing Room with Various Shading Strategies

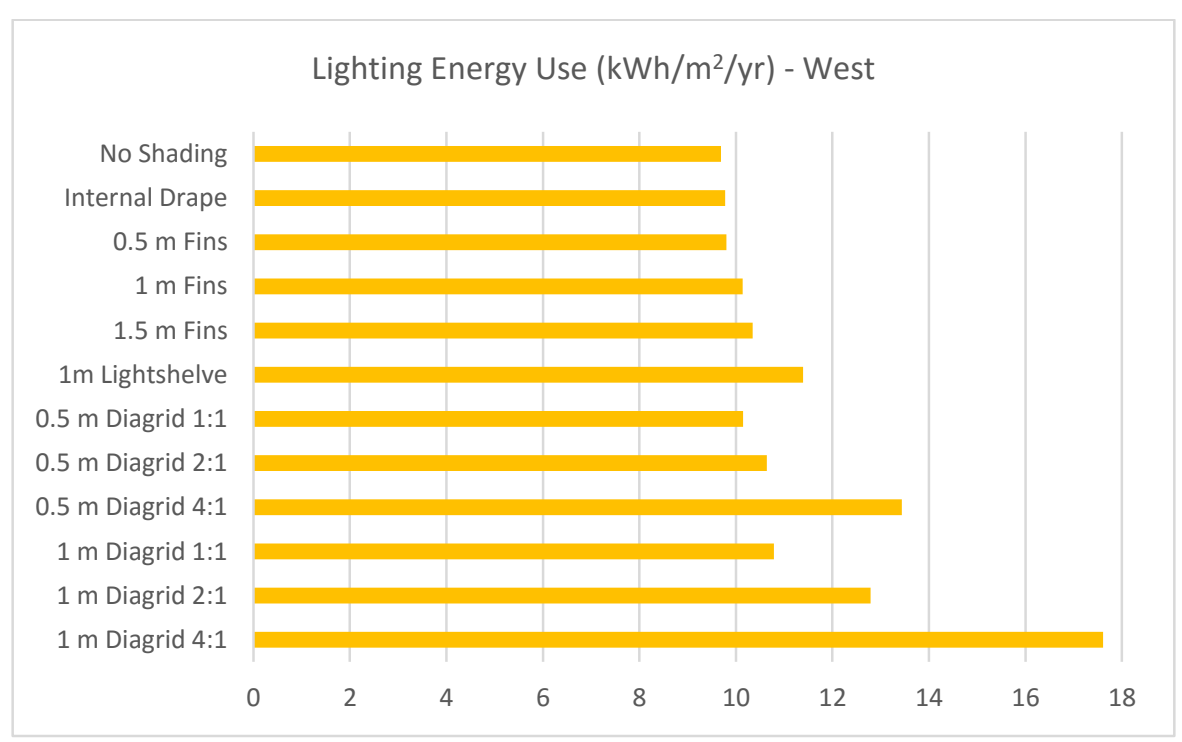

Figure 31: Lighting Energy Use of West Facing Room with Various Shading Strategies 


\begin{tabular}{|c|c|c|c|c|c|c|}
\hline \multicolumn{7}{|c|}{ East Facing Room } \\
\hline$\left(\mathrm{kWh} / \mathrm{m}^{2} / \mathrm{yr}\right)$ & $\begin{array}{c}\text { No } \\
\text { Shading }\end{array}$ & $\begin{array}{c}\text { Internal } \\
\text { Roller Blind }\end{array}$ & $0.5 \mathrm{~m}$ Fins & $1 \mathrm{~m}$ Fins & $1.5 \mathrm{~m}$ Fins & $\begin{array}{c}1 \mathrm{~m} \\
\text { Light Shelve }\end{array}$ \\
\hline $\begin{array}{l}\text { Total Site } \\
\text { Energy }\end{array}$ & 179.85 & 179.52 & 184.08 & 187.34 & 189.51 & 186.30 \\
\hline $\begin{array}{l}\text { Space } \\
\text { Heating }\end{array}$ & 96.88 & 101.11 & 103.51 & 108.54 & 111.63 & 111.82 \\
\hline Space Cooling & 31.42 & 26.82 & 28.88 & 27.06 & 25.96 & 21.92 \\
\hline $\begin{array}{c}\text { Lighting } \\
\text { Energy Use }\end{array}$ & 8.60 & 8.65 & 8.73 & 8.79 & 8.97 & 9.60 \\
\hline $\begin{array}{c}\text { Other } \\
\text { (Equipment, } \\
\text { Fans, ...) } \\
\end{array}$ & 42.95 & 42.95 & 42.95 & 42.95 & 42.95 & 42.95 \\
\hline \multicolumn{7}{|c|}{ East Facing Room - Diagrid Screen $-0.5 \mathrm{~m}$} \\
\hline$\left(\mathrm{kWh} / \mathrm{m}^{2} / \mathrm{yr}\right)$ & \multicolumn{2}{|c|}{$1: 1$} & \multicolumn{2}{|c|}{$2: 1$} & \multicolumn{2}{|c|}{$4: 1$} \\
\hline $\begin{array}{c}\text { Total Site } \\
\text { Energy }\end{array}$ & \multicolumn{2}{|c|}{181.93} & \multicolumn{2}{|c|}{184.63} & \multicolumn{2}{|c|}{189.60} \\
\hline $\begin{array}{l}\text { Space } \\
\text { Heating }\end{array}$ & \multicolumn{2}{|c|}{102.05} & \multicolumn{2}{|c|}{108.96} & \multicolumn{2}{|c|}{116.15} \\
\hline Space Cooling & \multicolumn{2}{|c|}{26.81} & \multicolumn{2}{|c|}{22.10} & \multicolumn{2}{|c|}{17.26} \\
\hline $\begin{array}{c}\text { Lighting } \\
\text { Energy Use }\end{array}$ & \multicolumn{2}{|c|}{10.12} & \multicolumn{2}{|c|}{10.62} & \multicolumn{2}{|c|}{13.25} \\
\hline $\begin{array}{c}\text { Other } \\
\text { (Equipment, } \\
\text { Fans, ...) } \\
\end{array}$ & \multicolumn{2}{|c|}{42.95} & \multicolumn{2}{|c|}{42.95} & \multicolumn{2}{|c|}{42.95} \\
\hline \multicolumn{7}{|c|}{ East Facing Room - Diagrid Screen - 1m } \\
\hline$\left(\mathrm{kWh} / \mathrm{m}^{2} / \mathrm{yr}\right)$ & \multicolumn{2}{|c|}{$1: 1$} & \multicolumn{2}{|c|}{$2: 1$} & \multicolumn{2}{|c|}{$4: 1$} \\
\hline $\begin{array}{l}\text { Total Site } \\
\text { Energy }\end{array}$ & \multicolumn{2}{|c|}{183.85} & \multicolumn{2}{|c|}{188.60} & \multicolumn{2}{|c|}{193.35} \\
\hline $\begin{array}{l}\text { Space } \\
\text { Heating }\end{array}$ & \multicolumn{2}{|c|}{107.16} & \multicolumn{2}{|c|}{115.58} & \multicolumn{2}{|c|}{118.23} \\
\hline Space Cooling & \multicolumn{2}{|c|}{22.95} & \multicolumn{2}{|c|}{17.30} & \multicolumn{2}{|c|}{14.85} \\
\hline $\begin{array}{c}\text { Lighting } \\
\text { Energy Use }\end{array}$ & \multicolumn{2}{|c|}{10.80} & \multicolumn{2}{|c|}{12.77} & & \\
\hline $\begin{array}{c}\text { Other } \\
\text { (Equipment, } \\
\text { Fans, ...) }\end{array}$ & & .95 & & & & \\
\hline
\end{tabular}




\begin{tabular}{|c|c|c|c|c|c|c|}
\hline \multicolumn{7}{|c|}{ West Facing Room } \\
\hline$\left(\mathrm{kWh} / \mathrm{m}^{2} / \mathrm{yr}\right)$ & $\begin{array}{c}\text { No } \\
\text { Shading }\end{array}$ & $\begin{array}{c}\text { Internal } \\
\text { Roller Blind }\end{array}$ & $0.5 \mathrm{~m}$ Fins & $1 \mathrm{~m}$ Fins & $1.5 \mathrm{~m}$ Fins & $\begin{array}{c}1 \mathrm{~m} \\
\text { Light Shelve }\end{array}$ \\
\hline $\begin{array}{c}\text { Total Site } \\
\text { Energy }\end{array}$ & 178.23 & 183.03 & 182.96 & 186.76 & 189.17 & 187.28 \\
\hline Space Heating & 99.02 & 104.20 & 105.81 & 110.77 & 113.87 & 113.94 \\
\hline Space Cooling & 26.57 & 26.11 & 24.39 & 22.90 & 22.01 & 19.00 \\
\hline $\begin{array}{c}\text { Lighting } \\
\text { Energy Use }\end{array}$ & 9.69 & 9.78 & 9.8 & 10.14 & 10.35 & 11.39 \\
\hline $\begin{array}{c}\text { Other } \\
\text { (Equipment, } \\
\text { Fans, ...) }\end{array}$ & 42.95 & 42.95 & 42.95 & 42.95 & 42.95 & 42.95 \\
\hline \multicolumn{7}{|c|}{ West Facing Room - Diagrid Screen $-0.5 \mathrm{~m}$} \\
\hline$\left(\mathrm{kWh} / \mathrm{m}^{2} / \mathrm{yr}\right)$ & \multicolumn{2}{|c|}{$1: 1$} & \multicolumn{2}{|c|}{$2: 1$} & \multicolumn{2}{|c|}{$4: 1$} \\
\hline $\begin{array}{c}\text { Total Site } \\
\text { Energy }\end{array}$ & \multicolumn{2}{|c|}{180.95} & \multicolumn{2}{|c|}{184.64} & \multicolumn{2}{|c|}{190.66} \\
\hline Space Heating & \multicolumn{2}{|c|}{105.06} & \multicolumn{2}{|c|}{111.94} & \multicolumn{2}{|c|}{118.85} \\
\hline Space Cooling & \multicolumn{2}{|c|}{22.79} & \multicolumn{2}{|c|}{19.11} & \multicolumn{2}{|c|}{15.43} \\
\hline $\begin{array}{c}\text { Lighting } \\
\text { Energy Use }\end{array}$ & \multicolumn{2}{|c|}{10.15} & \multicolumn{2}{|c|}{10.64} & \multicolumn{2}{|c|}{13.44} \\
\hline $\begin{array}{c}\text { Other } \\
\text { (Equipment, } \\
\text { Fans, ...) }\end{array}$ & \multicolumn{2}{|c|}{42.95} & \multicolumn{2}{|c|}{42.95} & \multicolumn{2}{|c|}{42.95} \\
\hline \multicolumn{7}{|c|}{ West Facing Room - Diagrid Screen - 1m } \\
\hline$\left(\mathrm{kWh} / \mathrm{m}^{2} / \mathrm{yr}\right)$ & \multicolumn{2}{|c|}{$1: 1$} & \multicolumn{2}{|c|}{$2: 1$} & \multicolumn{2}{|c|}{$4: 1$} \\
\hline $\begin{array}{c}\text { Total Site } \\
\text { Energy }\end{array}$ & \multicolumn{2}{|c|}{183.79} & \multicolumn{2}{|c|}{189.87} & \multicolumn{2}{|c|}{197.21} \\
\hline Space Heating & \multicolumn{2}{|c|}{110.31} & \multicolumn{2}{|c|}{118.69} & \multicolumn{2}{|c|}{123.36} \\
\hline Space Cooling & \multicolumn{2}{|c|}{19.74} & \multicolumn{2}{|c|}{15.43} & \multicolumn{2}{|c|}{13.30} \\
\hline $\begin{array}{c}\text { Lighting } \\
\text { Energy Use }\end{array}$ & \multicolumn{2}{|c|}{10.79} & \multicolumn{2}{|c|}{12.79} & & \\
\hline $\begin{array}{c}\text { Other } \\
\text { (Equipment, } \\
\text { Fans, ...) }\end{array}$ & & 95 & & & & \\
\hline
\end{tabular}

Table 4: Energy Use of West Facing Room with Various Shading Strategies 


\section{Lighting Simulations Results}

A total of 30 daylighting analysis were performed in Daysim on three archetypes rooms facing south, east and west. The lighting analysis results were obtained for annual daylight autonomy (DA), useful daylight index (UDI) and DAmax. Similar to energy simulations, each room is analyzed with no shade and various shading strategies as mentioned in energy section.

Description of daylighting analysis results of the rooms with and without shadings are presented below.

\subsection{South Facing Room}

Figures 32, 33 and 34 are demonstrations of DA, UDI and DAmax along the sensors of the south facing room and Table 5 summarises the results. Comparing cases with no shade and with shadings show that level of DA in all cases except the room with $4: 1 / 1 \mathrm{~m}$ diagrid screen, is above $68 \%$. As daylight autonomy graph shows, percentage of the time with lighting level of 400 lux or above is not significantly affected by shading devices and shading strategies mostly reduce the amount of time when lighting level goes above adequate illuminance level. So other than diagrid 4:1 with 1 meter depth, other options do not have negative impact on daylight autonomy. It is important to note that Daylight Autonomy does not have any threshold or upper limit and is demonstration of percentage of times that daylight level is at or above 400 lux, so higher DA does not necessary means that the room has better daylight quality as it does not address glare and high illuminance level.

Amount of daylight autonomies at three sensors confirm that having shading devices will not significantly reduce the amount of useful light entering the space.

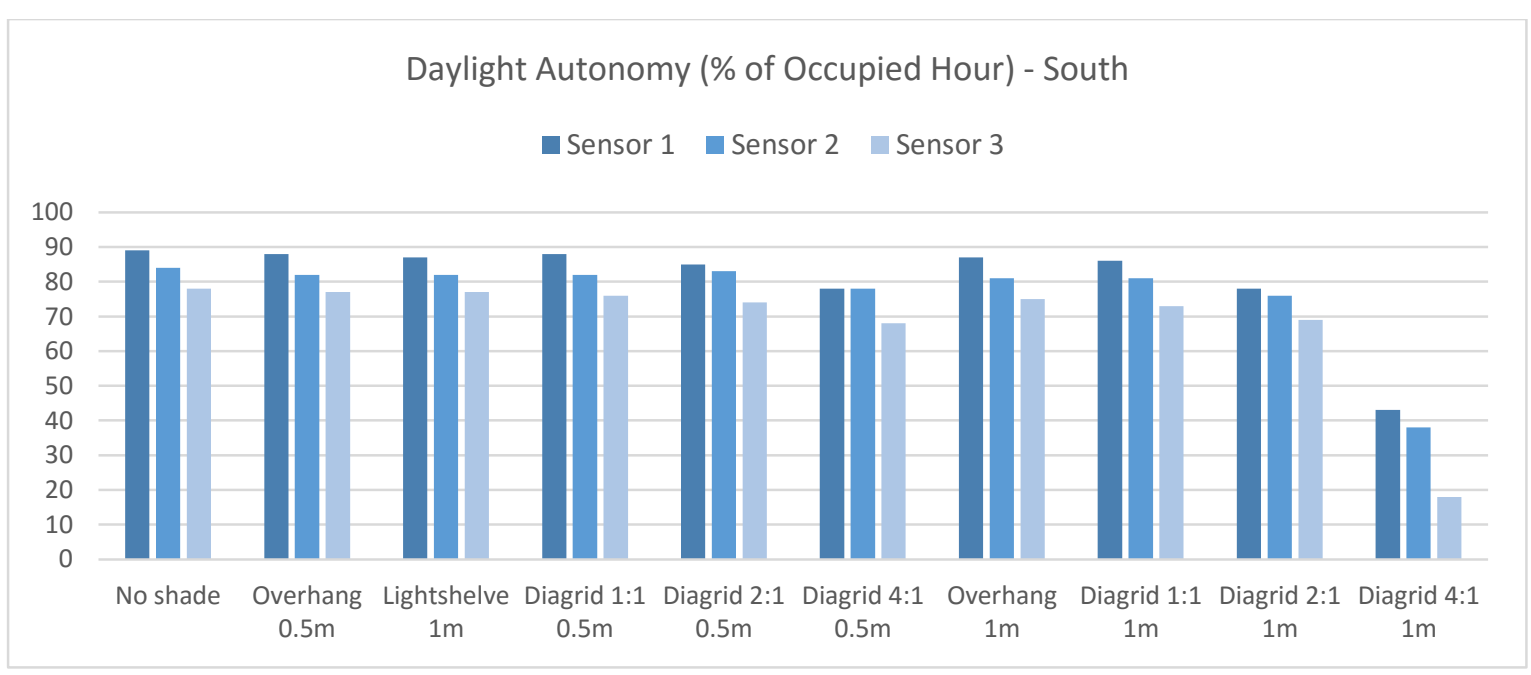

Figure 32: Daylight Autonomy (DA) in South Room 
UDI metric have been used in the next step to better quantify the quality of daylight entering the room. In terms of useful daylight index, shading strategies will increase the percentage of time with UDI between 100 and 2000 lux. As Figure 33 shows diagrid screens are more beneficial in this regard in comparison to conventional shading strategies. $4: 1 / 0.5 \mathrm{~m}$ and $2: 1 / 1 \mathrm{~m}$ diagrid screens demonstrate the best performance in introducing daylight level in the adequate range of 100-2000 lux.

The low UDI for sensor 1 (1 meter from the window) for the no shade and overhangs indicates that too much light is getting to this spaces and lighting level is often above the 2000 lux, maximum desirable level. This supports the idea that high level of glazing (70\% WWR) are unnecessary for lighting comfort.

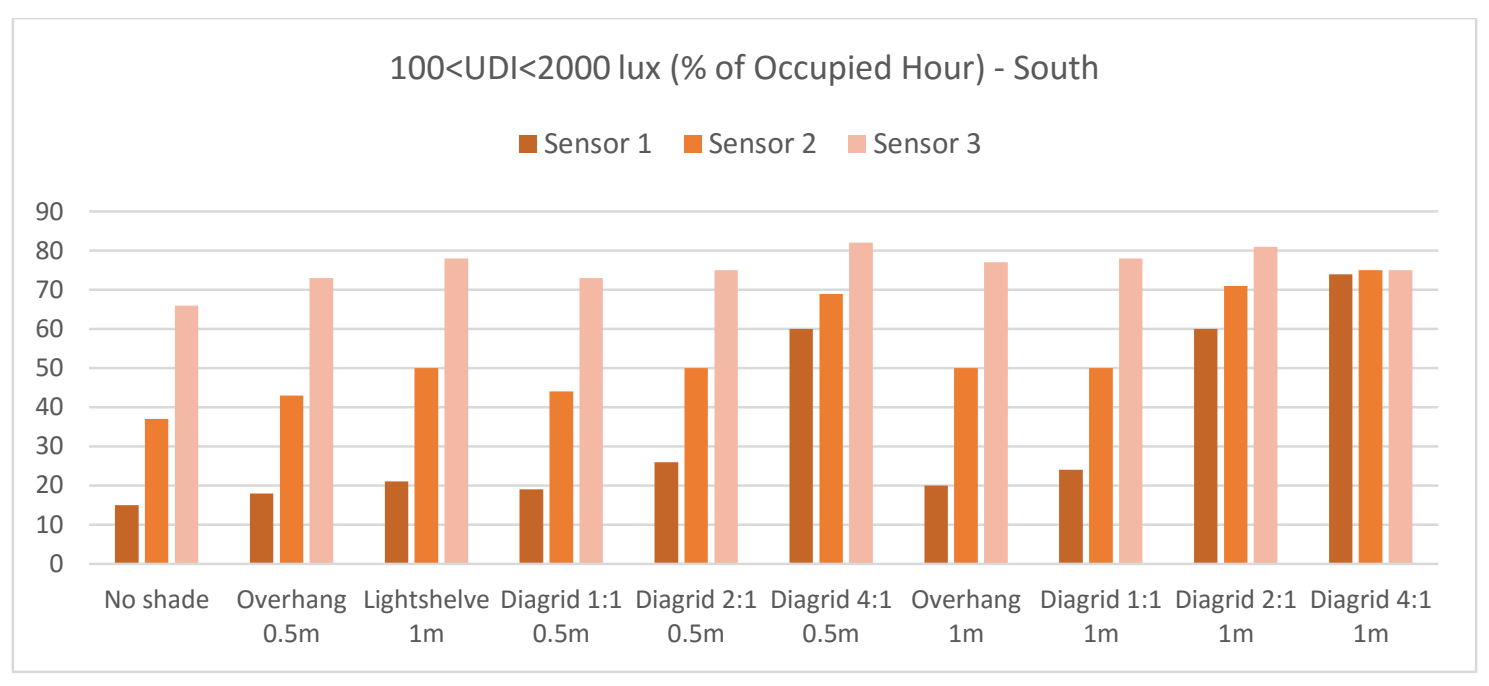

Figure 33: Useful Daylight Index in South Room

The main concern with high lighting level is glare. DAmax is a metric developed through Daysim which quantify the percentage of time that lighting level is 10 times higher than minimum targeted level, which also presents the possibility of glare during those periods. As Figure 34 shows with conventional shading strategies percentage of time with possibility of having glare especially close to window is very high and diagrid screen $2: 1 / 1 \mathrm{~m}$ is a best option to reduce the glare possibility in the room. Diagrid 2:1/1m reduces DAmax close to window by $88 \%$ in comparison to no shade. 


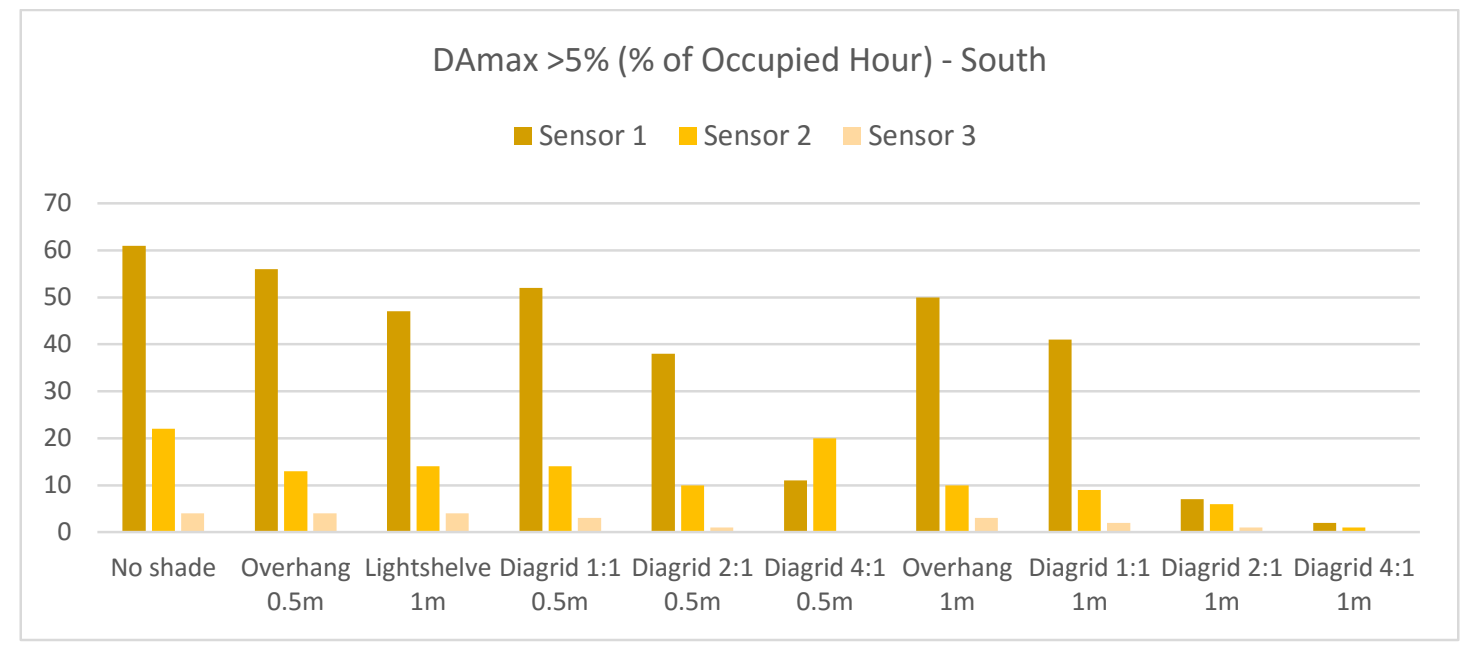

Figure 34: DAmax in South Room

Figures 35-37 demonstrate various UDI categories as UDI $<100$ and UDI>2000 lux. UDI less than 100 lux in all the rooms either with no shade or various shading options are close and very low for all three sensors along the rooms. It confirms that adding shading devices will not increase the percentage of time with very low lighting level, but it still allow for adequate amount of light to penetrate into the space. On the other hand the room with no shade has a high percentage of time with illuminance level over 2000 lux for sensors 1 and 2. The 2:1/1m and 4:1/0.5m diagrid screens have more significant impact on reducing the percentage of time with the UDI 2000 even on sensor 1.

The Figures also show that in all different combinations, even for sensor 3 UDI between 100 and 2000 lux is still high and it improves with some of the shading solutions such as $2: 1 / 1 \mathrm{~m}$ and $4: 1 / 0.5 \mathrm{~m}$ diagrid screens.

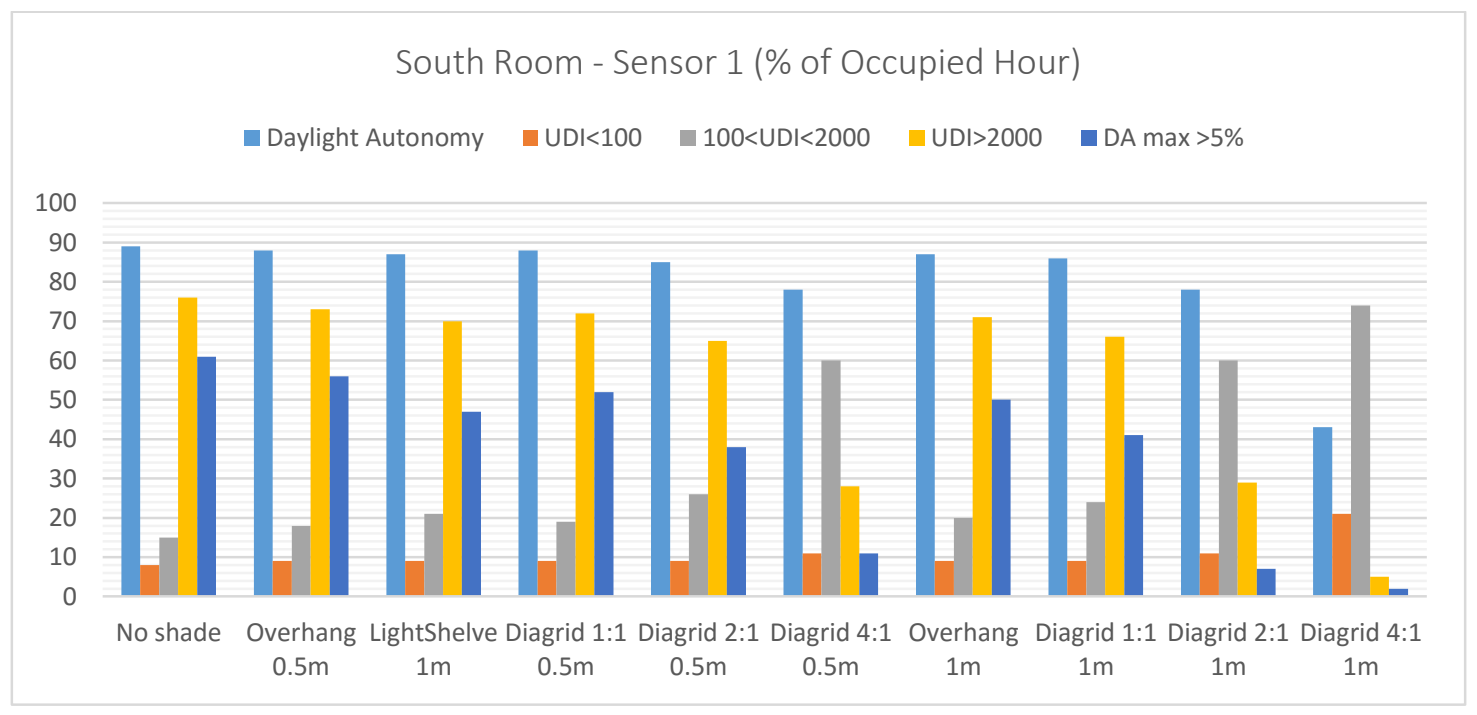

Figure 35: Demonstration of DA, UDI and DAmax in South Room - Sensor 1 


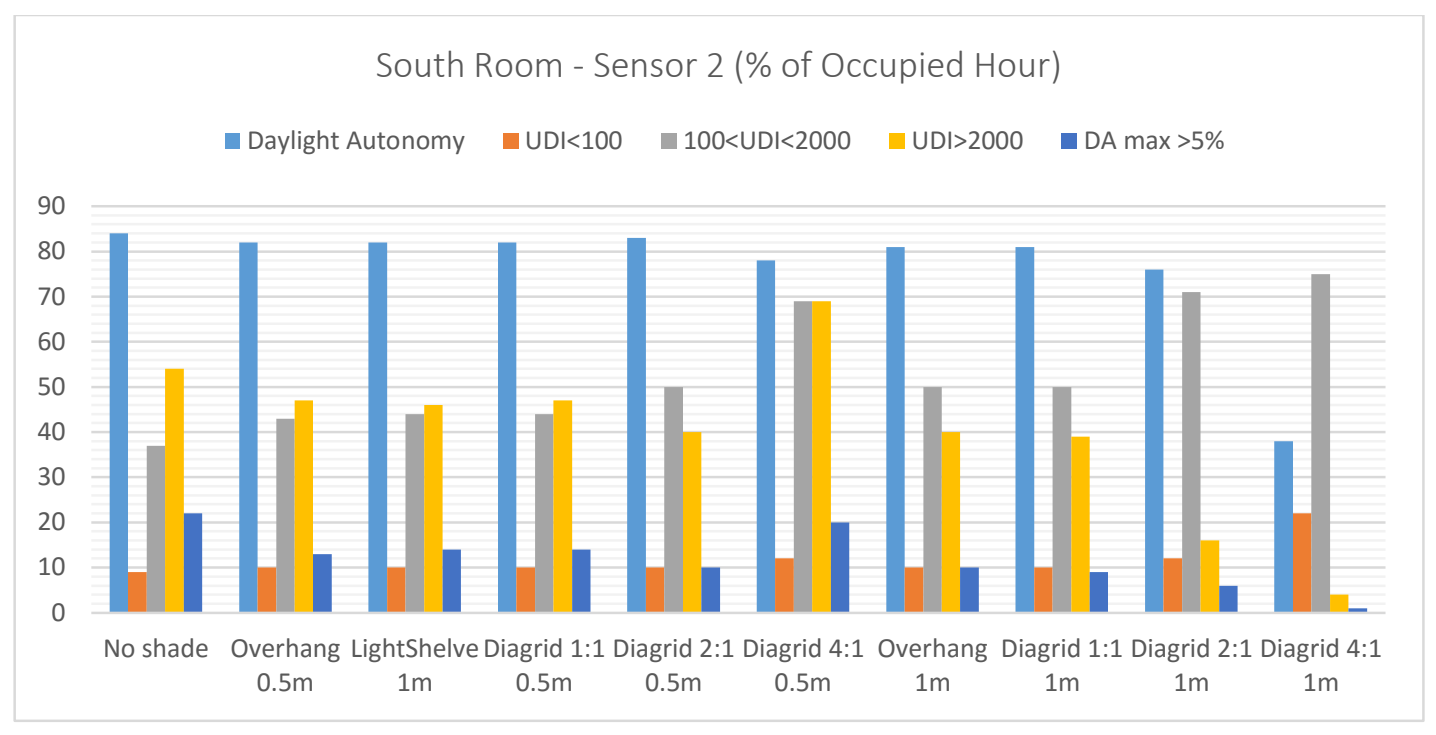

Figure 36: Demonstration of DA, UDI and DAmax in South Room - Sensor 2

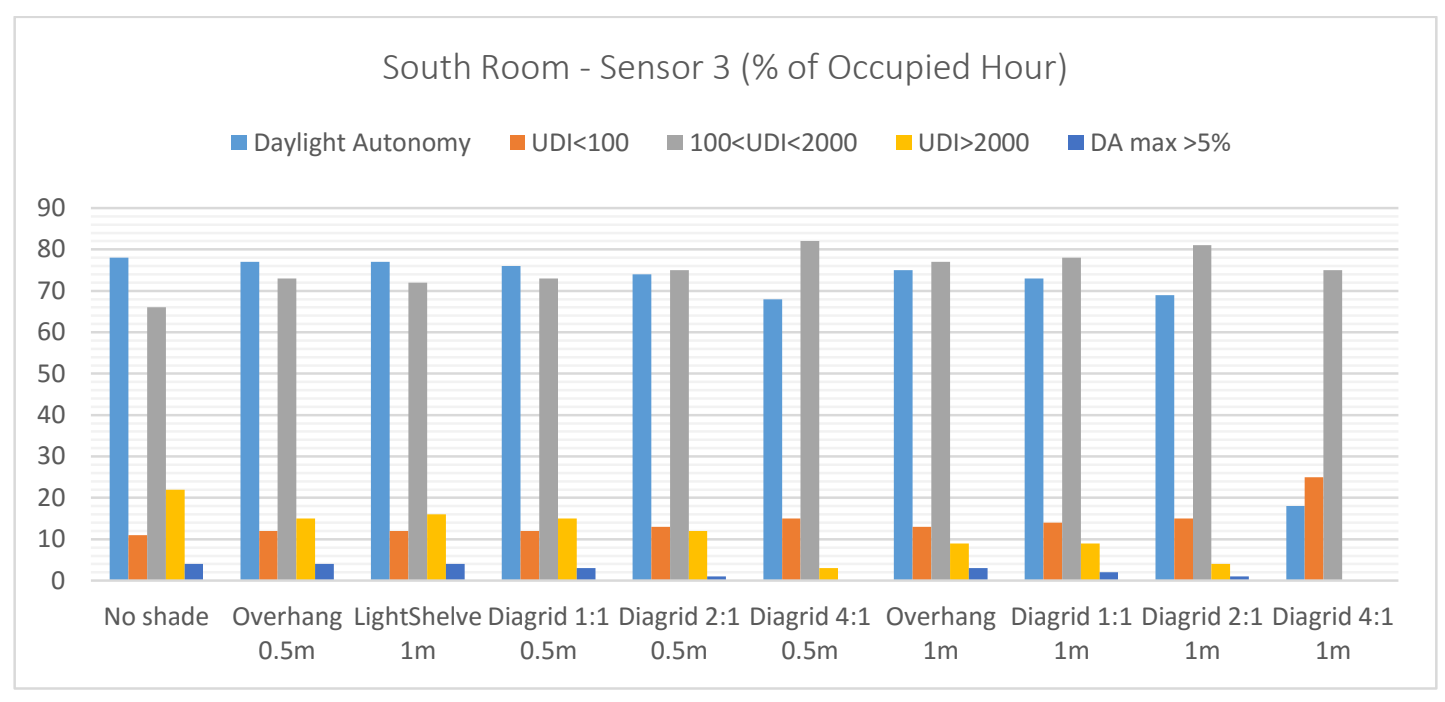

Figure 37: Demonstration of DA, UDI and DAmax in South Room - Sensor 3 


\begin{tabular}{|c|c|c|c|c|c|}
\hline \multicolumn{6}{|c|}{ South Facing room $-0.5 \mathrm{~m}$ Shade (\% of Occupied Hour) } \\
\hline & $\begin{array}{c}\text { Daylight } \\
\text { Autonomy }\end{array}$ & UDI $<100$ & $100<U D \mid<2000$ & UDI $>2000$ & DA $\max >5 \%$ \\
\hline \multicolumn{6}{|c|}{ No Shade } \\
\hline Sensor 1 & 89 & 8 & 15 & 76 & 61 \\
\hline Sensor 2 & 84 & 9 & 37 & 54 & 22 \\
\hline Sensor 3 & 78 & 11 & 66 & 22 & 4 \\
\hline \multicolumn{6}{|c|}{ Overhang } \\
\hline Sensor 1 & 88 & 9 & 18 & 73 & 56 \\
\hline Sensor 2 & 82 & 10 & 43 & 47 & 13 \\
\hline Sensor 3 & 77 & 12 & 73 & 15 & 4 \\
\hline \multicolumn{6}{|c|}{ Diagrid Screen 1:1 } \\
\hline Sensor 1 & 88 & 9 & 19 & 72 & 52 \\
\hline Sensor 2 & 82 & 10 & 44 & 47 & 14 \\
\hline Sensor 3 & 76 & 12 & 73 & 15 & 3 \\
\hline \multicolumn{6}{|c|}{ Diagrid Screen 2:1 } \\
\hline Sensor 1 & 85 & 9 & 26 & 65 & 38 \\
\hline Sensor 2 & 83 & 10 & 50 & 40 & 10 \\
\hline Sensor 3 & 74 & 13 & 75 & 12 & 1 \\
\hline \multicolumn{6}{|c|}{ Diagrid Screen $4: 1$} \\
\hline Sensor 1 & 78 & 11 & 60 & 28 & 11 \\
\hline Sensor 2 & 78 & 12 & 69 & 20 & 4 \\
\hline Sensor 3 & 68 & 15 & 82 & 3 & 0 \\
\hline \multicolumn{6}{|c|}{ South Facing room - 1m Shade (\% of Occupied Hour) } \\
\hline & $\begin{array}{c}\text { Daylight } \\
\text { Autonomy }\end{array}$ & UDI $<100$ & $100<U D \mid<2000$ & UDI>2000 & DA $\max >5 \%$ \\
\hline \multicolumn{6}{|c|}{ Overhang } \\
\hline Sensor 1 & 87 & 9 & 20 & 71 & 50 \\
\hline Sensor 2 & 81 & 10 & 50 & 40 & 10 \\
\hline Sensor 3 & 75 & 13 & 77 & 9 & 3 \\
\hline \multicolumn{6}{|c|}{ Lightshelve } \\
\hline Sensor 1 & 87 & 9 & 21 & 70 & 47 \\
\hline Sensor 2 & 82 & 10 & 44 & 46 & 14 \\
\hline Sensor 3 & 77 & 12 & 72 & 16 & 4 \\
\hline \multicolumn{6}{|c|}{ Diagrid Screen 1:1 } \\
\hline Sensor 1 & 86 & 9 & 24 & 66 & 41 \\
\hline Sensor 2 & 81 & 10 & 50 & 39 & 9 \\
\hline Sensor 3 & 73 & 14 & 78 & 9 & 2 \\
\hline \multicolumn{6}{|c|}{ Diagrid Screen 2:1 } \\
\hline Sensor 1 & 78 & 11 & 60 & 29 & 7 \\
\hline Sensor 2 & 76 & 12 & 71 & 16 & 6 \\
\hline Sensor 3 & 69 & 15 & 81 & 4 & 1 \\
\hline \multicolumn{6}{|c|}{ Diagrid Screen 4:1 } \\
\hline Sensor 1 & 43 & 21 & 74 & 5 & 2 \\
\hline Sensor 2 & 38 & 22 & 75 & 4 & 1 \\
\hline Sensor 3 & 18 & 25 & 75 & 0 & 0 \\
\hline
\end{tabular}




\subsection{East and West Facing Rooms}

Comparing DA in cases of no shade and with shades in east and west facing rooms, confirms that similar to south room level of DA in the rooms with shading devices is not significantly lower than no shade scenarios and DA in all cases except diagrid $4: 1 / 1 \mathrm{~m}$ is above $57 \%$ in the east and west rooms. So percentage of time with lighting level of 400 lux or above is not significantly affected by shading devices and shading strategies mostly reduce the percentage of time that lighting level goes above adequate illuminance level.

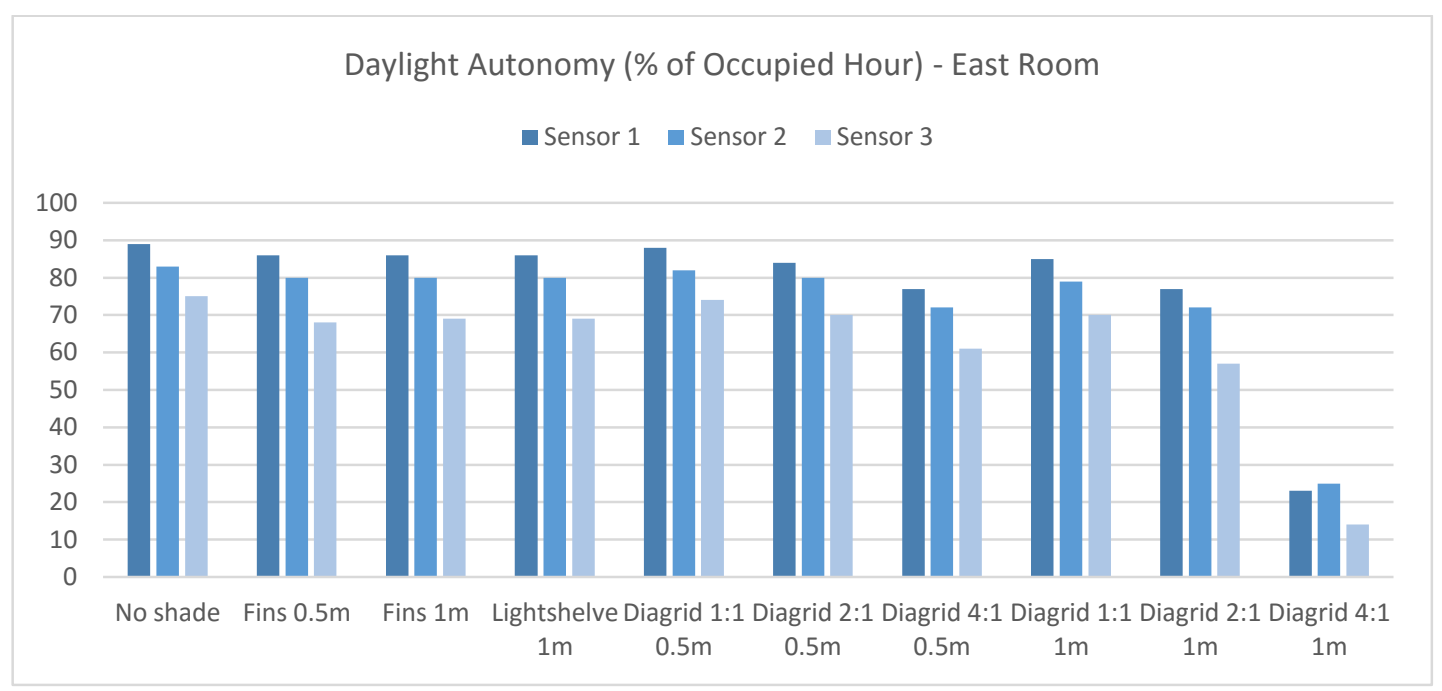

Figure 38: Daylight Autonomy (DA) in East Room

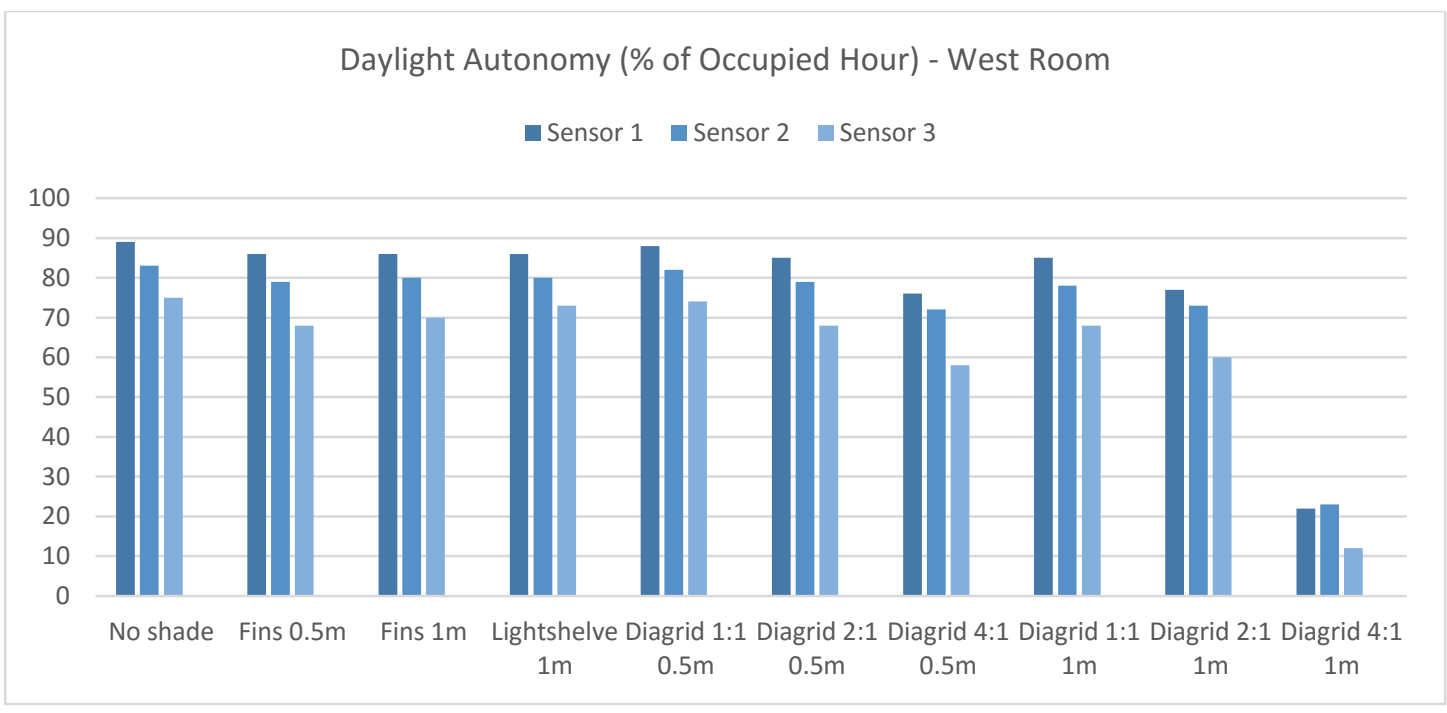

Figure 39: Daylight Autonomy (DA) in West Room

The shading strategies have the largest impact on the lighting level of the room close to window. As Figures 40 and 41 show 0.5 meter vertical fins will increase the UDI level close to window (Sensor 1) by $52 \%$ compare to no shade and 1 meter fins will increase it by $47 \%$. Similar to south facing room, 
$2: 1 / 1 \mathrm{~m}$ and $4: 1 / 0.5 \mathrm{~m}$ diagrid screens are the best performing shading strategies to increase the UDI along the room. Diagrid $2: 1 / 1 \mathrm{~m}$ and $4: 1 / 0.5 \mathrm{~m}$ will enhance useful daylight by $74 \%$ in comparison to no shade scenario.

Even though diagrid 4:1/1m shows the highest UDI at all three sensors in comparison to other options, but DA graphs demonstrates the lowest level of DA for it which means that most of lighting level is below 400 lux which is not sufficient for office space activities.

Amount of useful daylight at the middle or back portions of the room is less affected by shading strategies, but interesting point is that shading devices will not decrease the amount of useful light in that areas and through reflecting diffuse light deeper into the room even enhance it slightly.

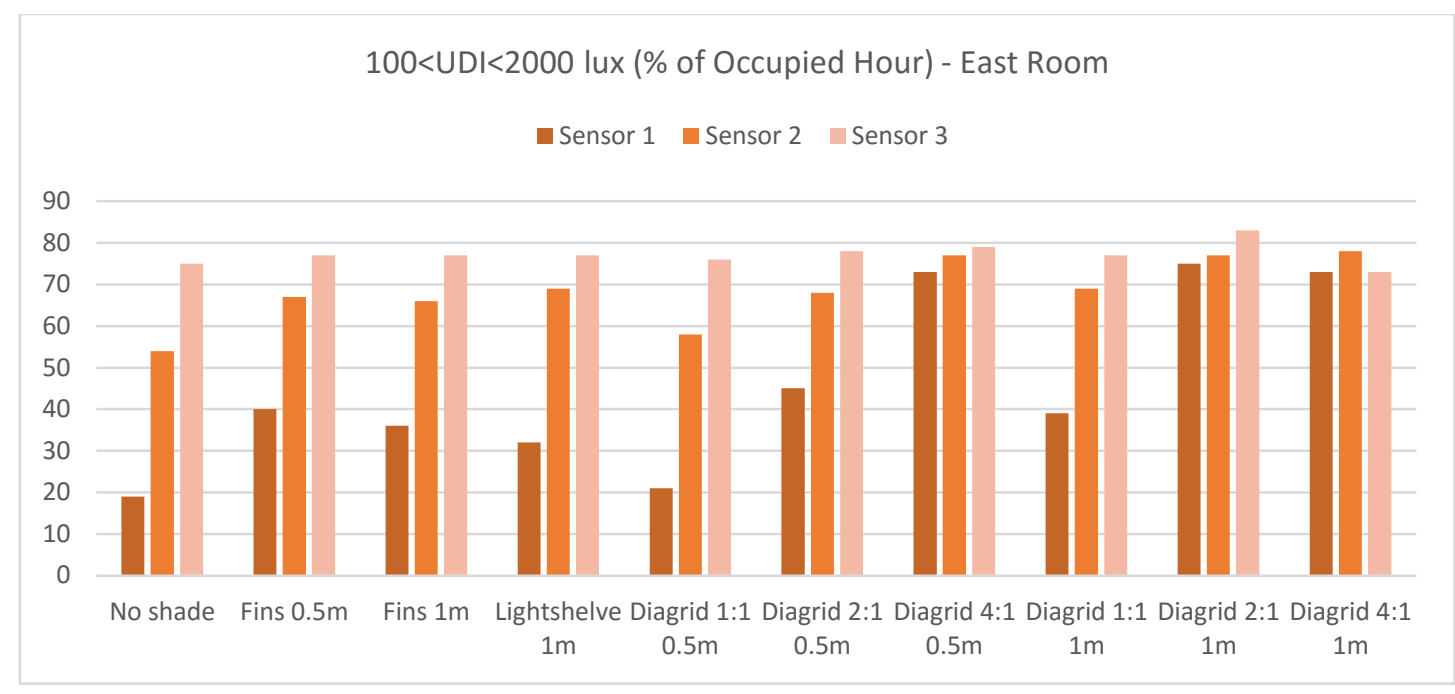

Figure 40: Useful Daylight Index in East room with Various Shading Strategies

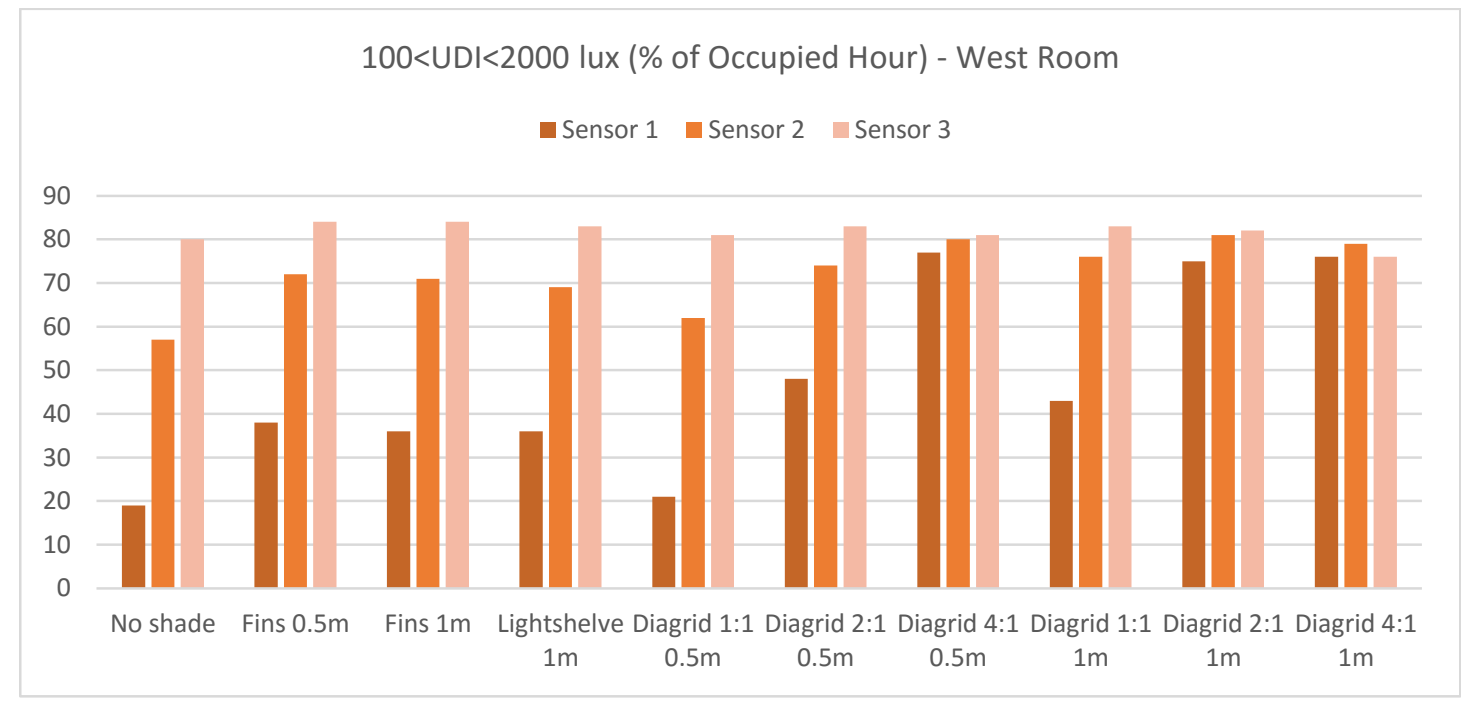

Figure 41: Useful Daylight Index in West room with Various Shading Strategies 
The percentage of time with daylight level 10 times higher than minimum in the rooms with no shade is high and around $39-45 \%$ of the time at sensor 1 close to window. This amount will reduce as we move deeper in the room. 1 meter fins will reduce DAmax by $46 \%$ and $2: 1 / 1 \mathrm{~m}$ diagrid screen will reduce it by $88 \%$ in comparison to no shade scenario. Similar to south facing room $2: 1 / 1 \mathrm{~m}$ is a best option in terms of reducing the excessive lighting level and glare possibility in the room.

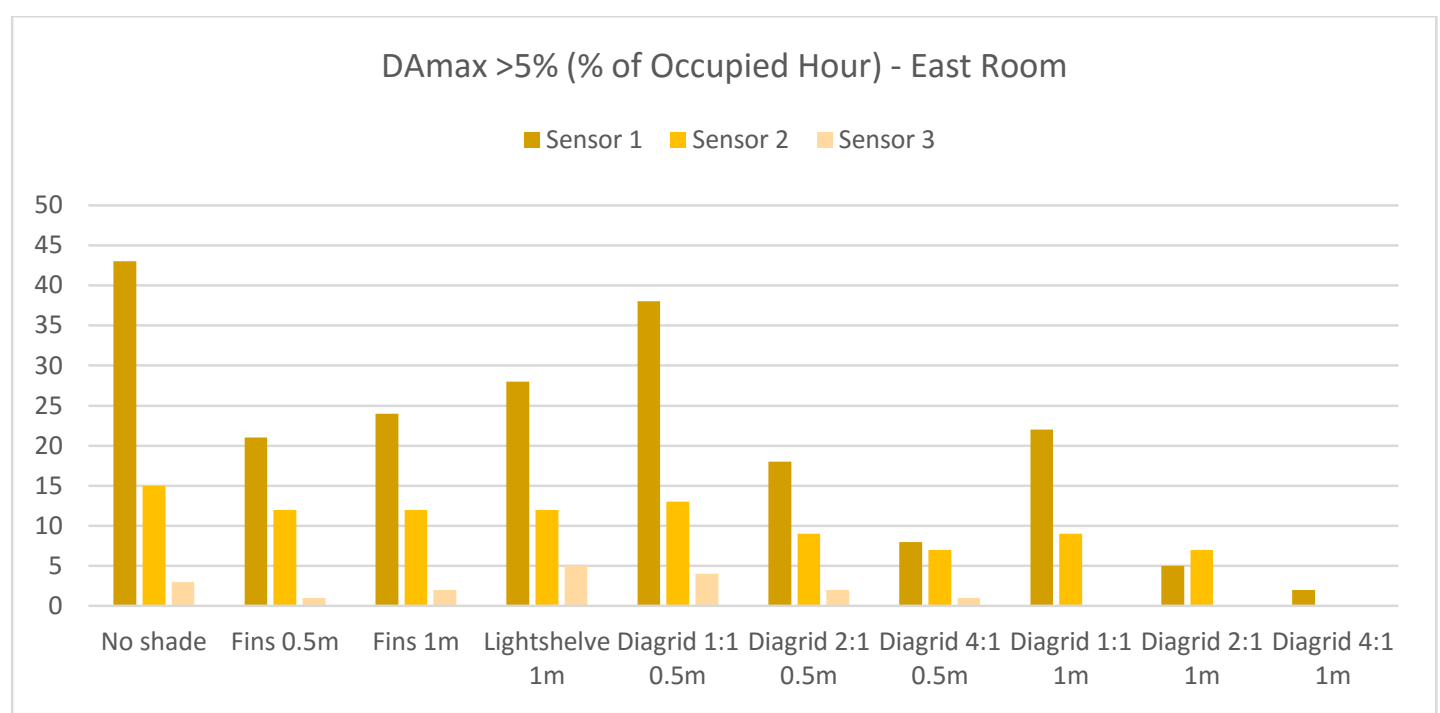

Figure 42: DAmax in East room with Various Shading Strategies

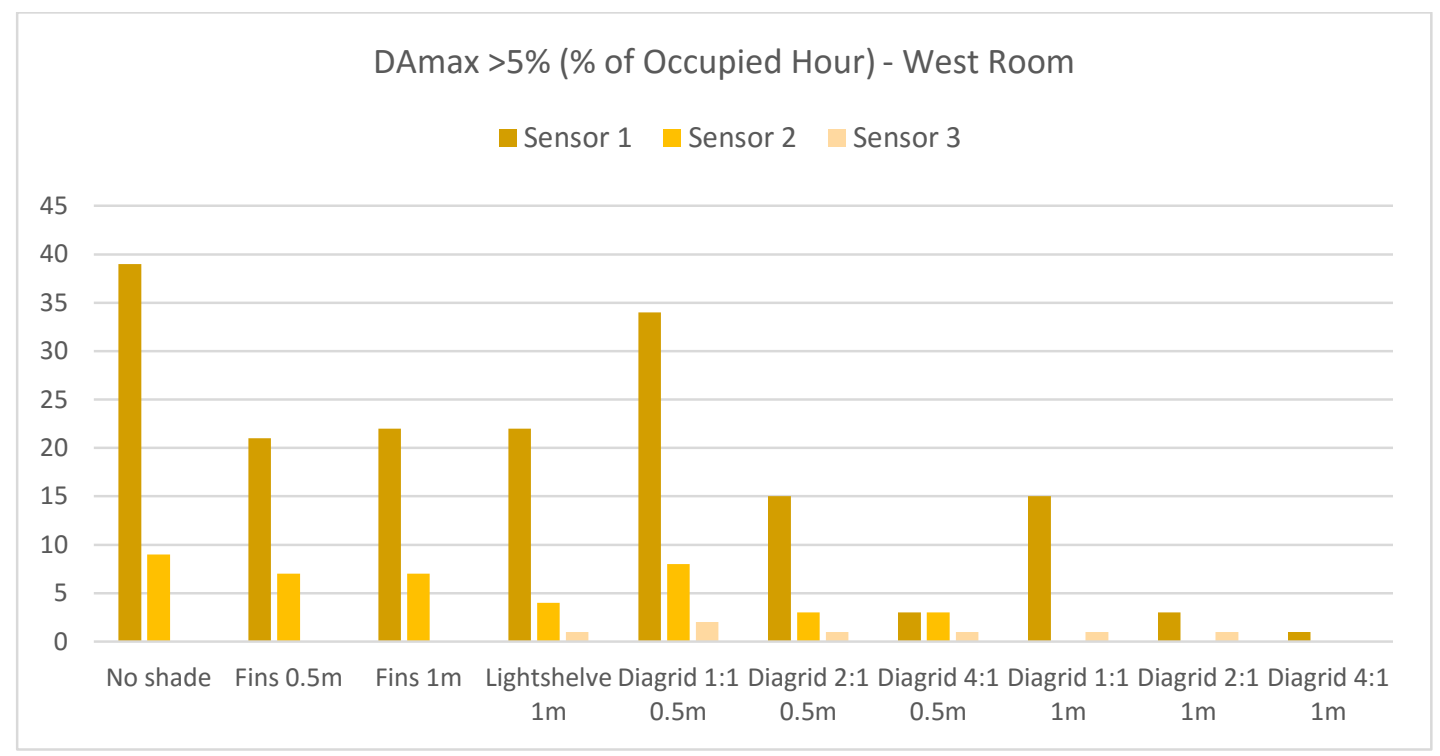

Figure 43: DAmax in West room with Various Shading Strategies

Since the Figures 42 and 43 are representation of DA max in east and west facing room from 8 am to $5 \mathrm{pm}$, the west facing room shows less glare possibility compare to east room. To achieve more accurate results, daylight analysis were repeated in east and west facing rooms with no shade in a 
time frame of 8 am to $8 \mathrm{pm}$. Figures 44 demonstrates DAmax in east and west facing rooms with no shade. As Figure 44 shows with considering longer afternoon, east and west rooms having almost similar DAmax percentage at sensor 1, close to window. However as we move further from the window, the percentage of DAmax in the east room increases, which means sun is lower in sky and getting deeper into the room during the morning.

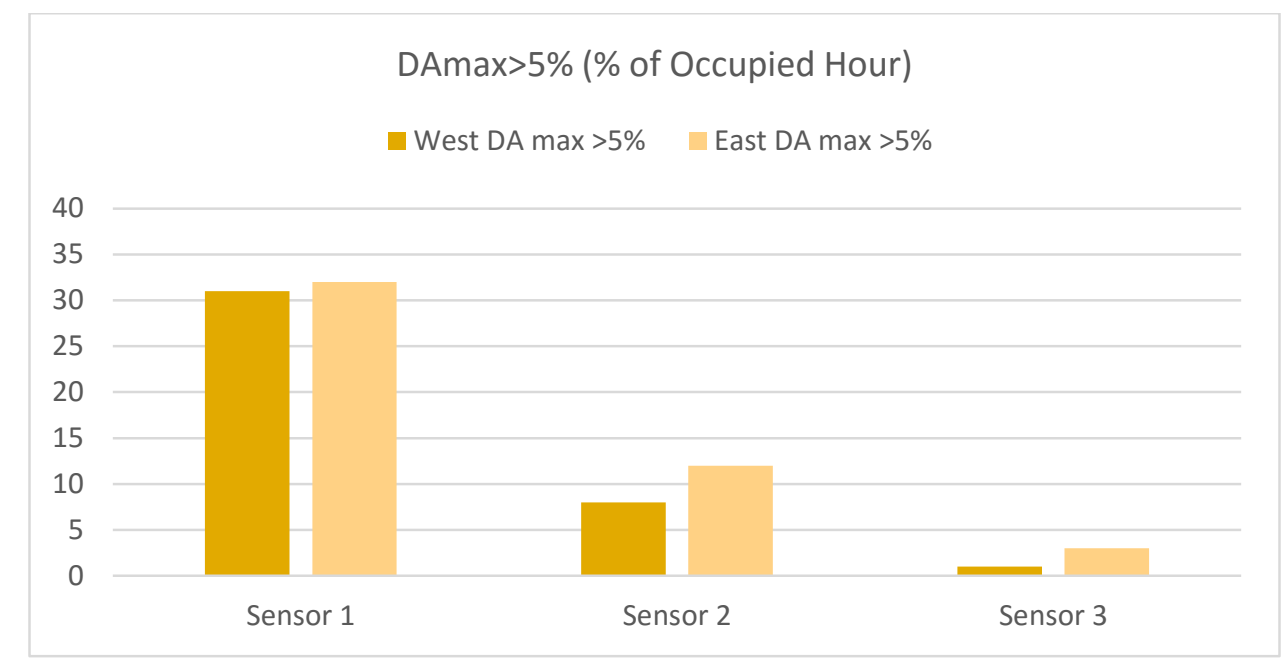

Figure 44: Comparison of DAmax in the East and West Facing rooms with No Shade

Figure 45 to 50 are representation of DA, DAmax and different categories of UDI for three sensors of east and west facing rooms. The percentage of time with UDI between 100 and 2000 lux in east and west facing rooms are higher than south facing room, since the space is less expose to direct solar radiation in comparison to south facing room. The percentage of time with UDI over 2000 lux for sensor 1 in the room with no shade and even in the rooms with conventional shading strategies is high and over $50 \%$. Similar to south facing room amount of useful daylight index in the rooms with 2:1/1m and 4:1/0.5m diagrid screens are significantly increased. They also caused UDI over 2000 lux to decrease considerably. So adequate solar protection strategies can be as beneficial in east and west rooms as south facing room. 


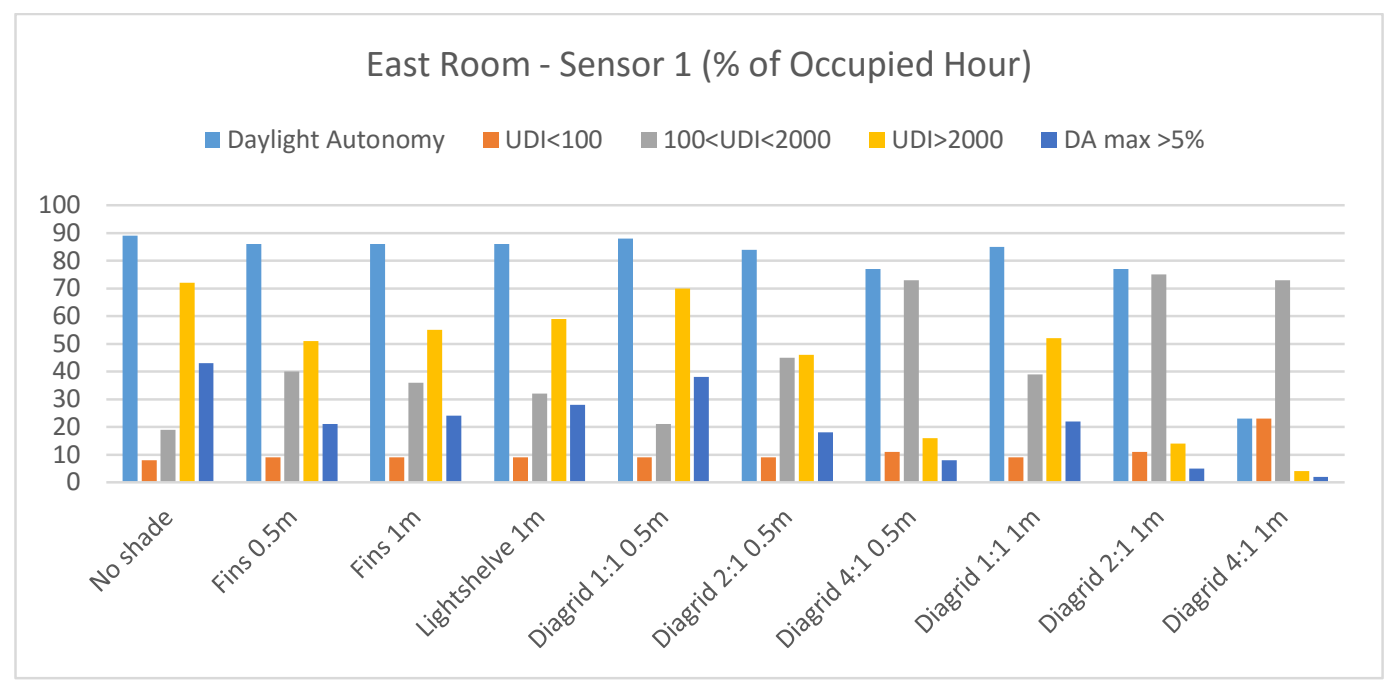

Figure 45: Demonstration of DA, UDI and DAmax in East Room - Sensor 1

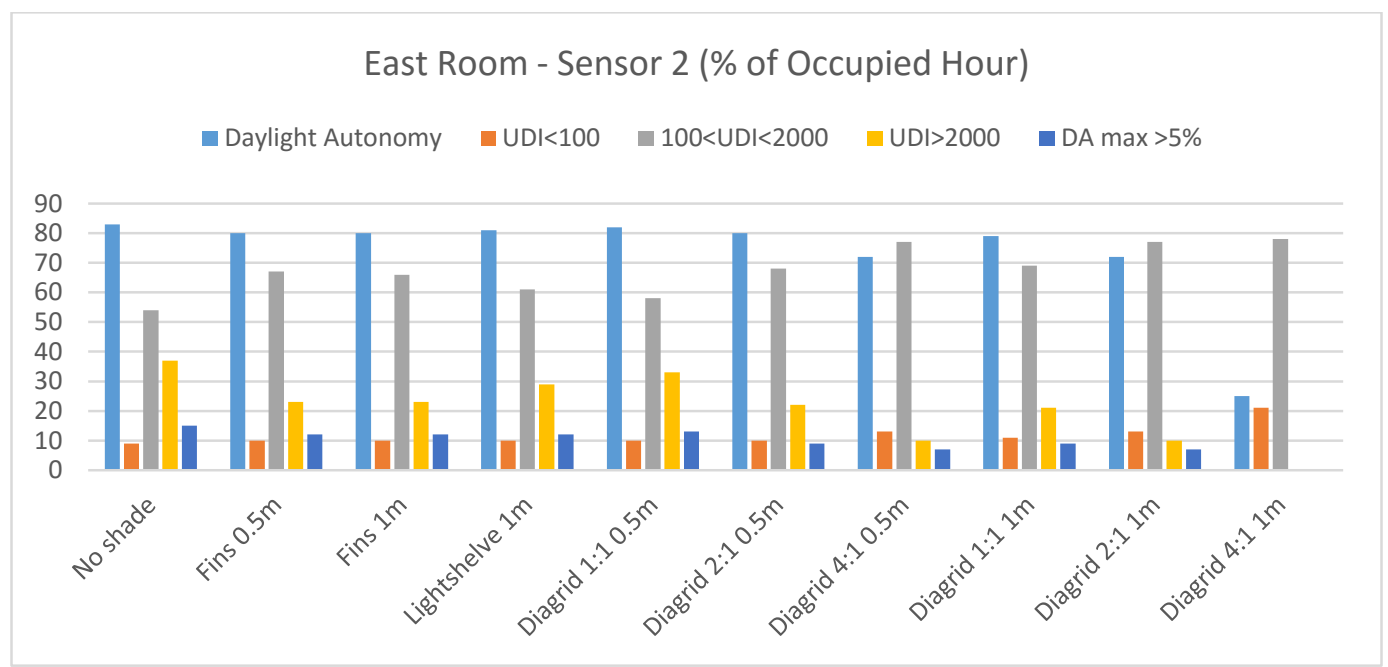

Figure 46: Demonstration of DA, UDI and DAmax in East Room - Sensor 2

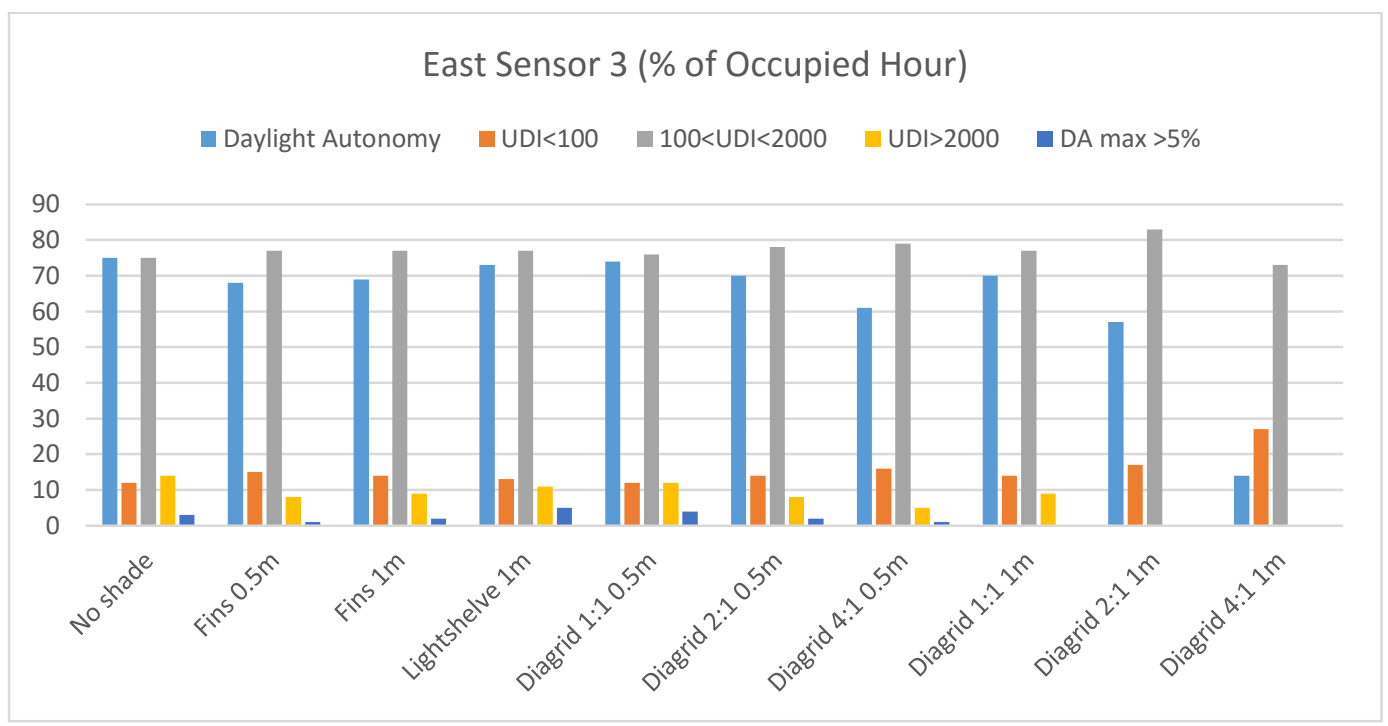

Figure 47: Demonstration of DA, UDI and DAmax in East Room - Sensor 3 


\begin{tabular}{|c|c|c|c|c|c|}
\hline \multicolumn{6}{|c|}{ East Facing room $-0.5 \mathrm{~m}$ Shade (\% of Occupied Hour) } \\
\hline & $\begin{array}{c}\text { Daylight } \\
\text { Autonomy }\end{array}$ & UDI $<100$ & $100<U D \mid<2000$ & UDI>2000 & DA $\max >5 \%$ \\
\hline \multicolumn{6}{|c|}{ No Shade } \\
\hline Sensor 1 & 89 & 8 & 19 & 72 & 43 \\
\hline Sensor 2 & 83 & 9 & 54 & 37 & 15 \\
\hline Sensor 3 & 75 & 12 & 75 & 14 & 3 \\
\hline \multicolumn{6}{|c|}{ Vertical Fins } \\
\hline Sensor 1 & 86 & 9 & 40 & 51 & 21 \\
\hline Sensor 2 & 80 & 10 & 67 & 23 & 12 \\
\hline Sensor 3 & 68 & 15 & 77 & 8 & 1 \\
\hline \multicolumn{6}{|c|}{ Diagrid Screen 1:1 } \\
\hline Sensor 1 & 88 & 9 & 21 & 70 & 38 \\
\hline Sensor 2 & 82 & 10 & 58 & 33 & 13 \\
\hline Sensor 3 & 74 & 12 & 76 & 12 & 4 \\
\hline \multicolumn{6}{|c|}{ Diagrid Screen 2:1 } \\
\hline Sensor 1 & 84 & 9 & 45 & 46 & 18 \\
\hline Sensor 2 & 80 & 10 & 68 & 22 & 9 \\
\hline Sensor 3 & 70 & 14 & 78 & 8 & 2 \\
\hline \multicolumn{6}{|c|}{ Diagrid Screen 4:1 } \\
\hline Sensor 1 & 77 & 11 & 73 & 16 & 8 \\
\hline Sensor 2 & 72 & 13 & 77 & 10 & 7 \\
\hline Sensor 3 & 61 & 16 & 79 & 5 & 1 \\
\hline \multicolumn{6}{|c|}{ East Facing room - $1 \mathrm{~m}$ Shade (\% of Occupied Hour) } \\
\hline & $\begin{array}{c}\text { Daylight } \\
\text { Autonomy }\end{array}$ & UDI $<100$ & $100<U D \mid<2000$ & UDI>2000 & DA $\max >5 \%$ \\
\hline \multicolumn{6}{|c|}{ Vertical Fins } \\
\hline Sensor 1 & 86 & 9 & 36 & 55 & 24 \\
\hline Sensor 2 & 80 & 10 & 66 & 23 & 12 \\
\hline Sensor 3 & 69 & 14 & 77 & 9 & 2 \\
\hline \multicolumn{6}{|c|}{ Lightshelve } \\
\hline Sensor 1 & 86 & 9 & 32 & 59 & 28 \\
\hline Sensor 2 & 81 & 10 & 61 & 29 & 12 \\
\hline Sensor 3 & 73 & 13 & 77 & 11 & 5 \\
\hline \multicolumn{6}{|c|}{ Diagrid Screen 1:1 } \\
\hline Sensor 1 & 85 & 9 & 39 & 52 & 22 \\
\hline Sensor 2 & 79 & 11 & 69 & 21 & 9 \\
\hline Sensor 3 & 70 & 14 & 77 & 9 & 0 \\
\hline \multicolumn{6}{|c|}{ Diagrid Screen 2:1 } \\
\hline Sensor 1 & 77 & 11 & 75 & 14 & 5 \\
\hline Sensor 2 & 72 & 13 & 77 & 10 & 7 \\
\hline Sensor 3 & 57 & 17 & 83 & 0 & 0 \\
\hline \multicolumn{6}{|c|}{ Diagrid Screen 4:1 } \\
\hline Sensor 1 & 23 & 23 & 73 & 4 & 2 \\
\hline Sensor 2 & 25 & 21 & 78 & 0 & 0 \\
\hline Sensor 3 & 14 & 27 & 73 & 0 & 0 \\
\hline
\end{tabular}

Table 6: Percentage of Occupied Hour with Daylight Metrics of DA, UDI and DAmax - East Room 


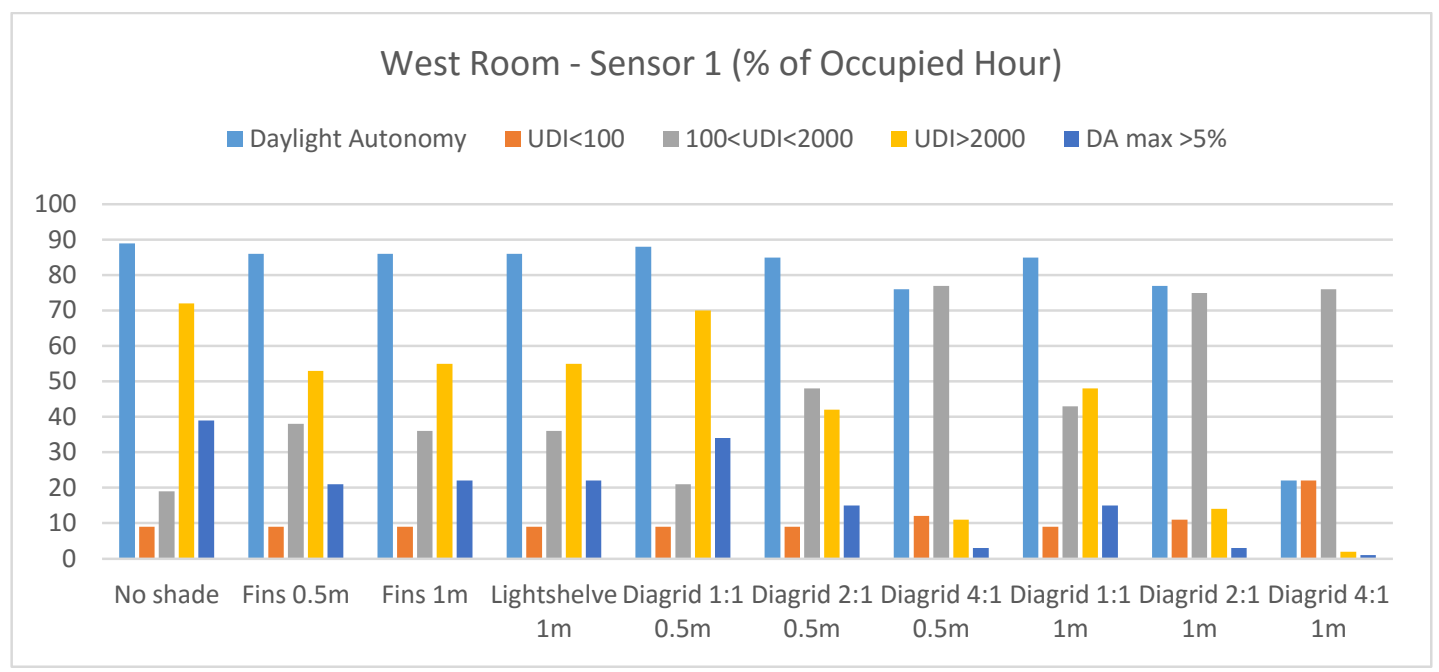

Figure 48: Demonstration of DA, UDI and DAmax in West Room - Sensor 1

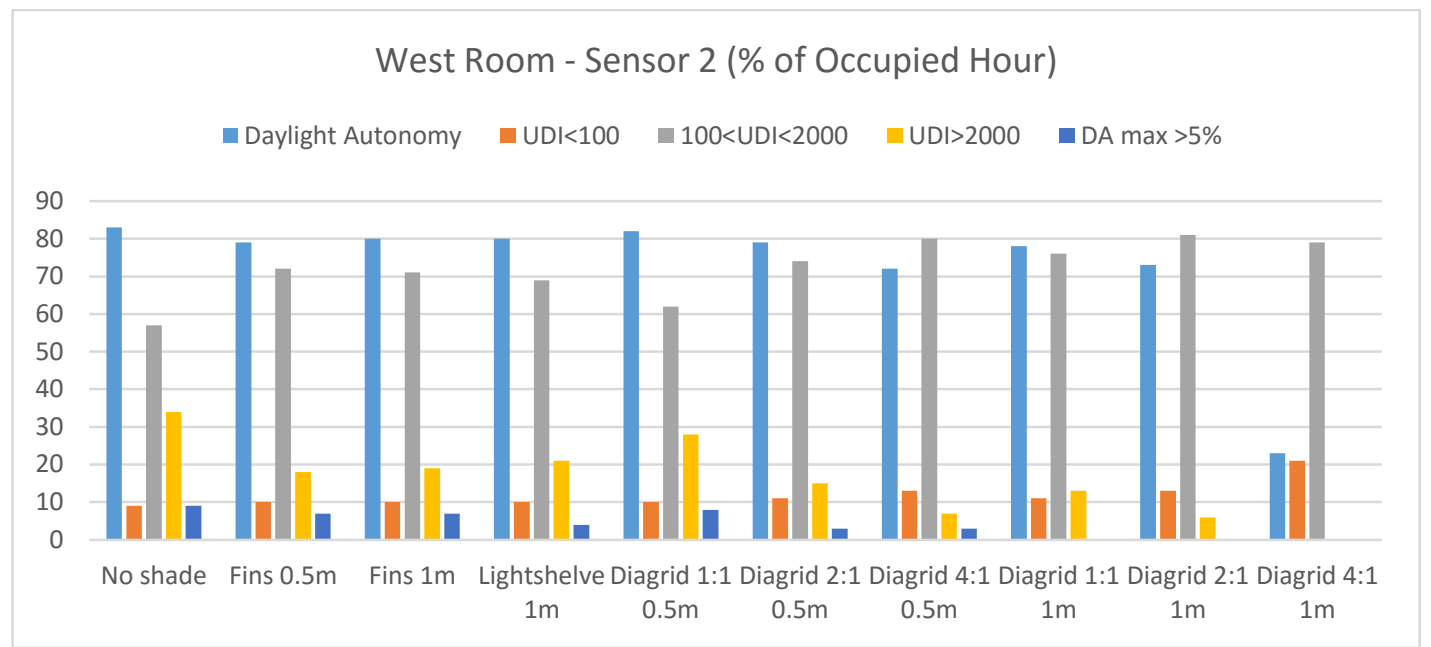

Figure 49: Demonstration of DA, UDI and DAmax in West Room - Sensor 2

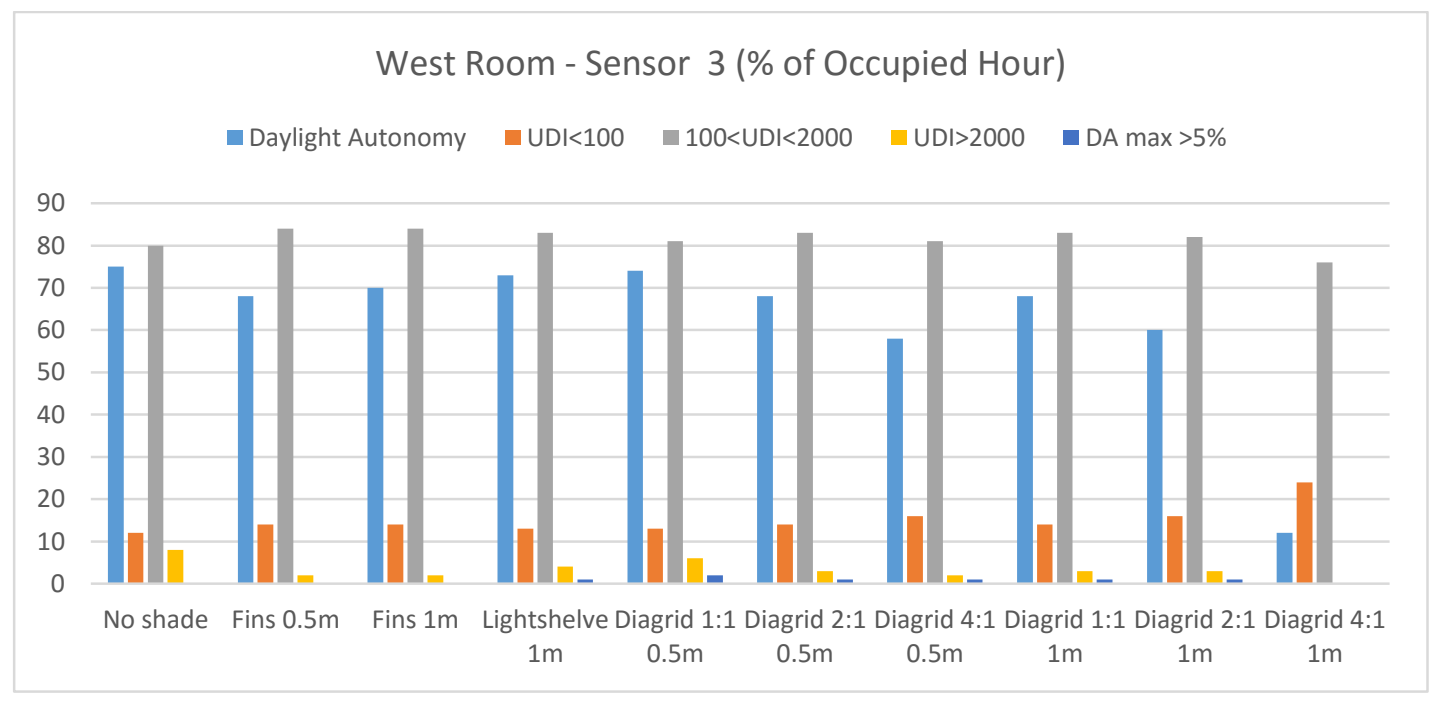

Figure 50: Demonstration of DA, UDI and DAmax in West Room - Sensor 3 


\begin{tabular}{|c|c|c|c|c|c|}
\hline \multicolumn{6}{|c|}{ West Facing room $-0.5 \mathrm{~m}$ Shade (\% of Occupied Hour) } \\
\hline & $\begin{array}{c}\text { Daylight } \\
\text { Autonomy }\end{array}$ & UDI<100 & $100<U D \mid<2000$ & UDI>2000 & DA $\max >5 \%$ \\
\hline \multicolumn{6}{|c|}{ No Shade } \\
\hline Sensor 1 & 89 & 9 & 19 & 72 & 39 \\
\hline Sensor 2 & 83 & 9 & 57 & 34 & 9 \\
\hline Sensor 3 & 75 & 12 & 80 & 8 & 0 \\
\hline \multicolumn{6}{|c|}{ Vertical Fins } \\
\hline Sensor 1 & 86 & 9 & 38 & 53 & 21 \\
\hline Sensor 2 & 79 & 10 & 72 & 18 & 7 \\
\hline Sensor 3 & 68 & 14 & 84 & 2 & 0 \\
\hline \multicolumn{6}{|c|}{ Diagrid Screen 1:1 } \\
\hline Sensor 1 & 88 & 9 & 21 & 70 & 34 \\
\hline Sensor 2 & 82 & 10 & 62 & 28 & 8 \\
\hline Sensor 3 & 74 & 13 & 81 & 6 & 2 \\
\hline \multicolumn{6}{|c|}{ Diagrid Screen 2:1 } \\
\hline Sensor 1 & 85 & 9 & 48 & 42 & 15 \\
\hline Sensor 2 & 79 & 11 & 74 & 15 & 3 \\
\hline Sensor 3 & 68 & 14 & 83 & 3 & 1 \\
\hline \multicolumn{6}{|c|}{ Diagrid Screen 4:1 } \\
\hline Sensor 1 & 76 & 12 & 77 & 11 & 3 \\
\hline Sensor 2 & 72 & 13 & 80 & 7 & 3 \\
\hline Sensor 3 & 58 & 16 & 81 & 2 & 1 \\
\hline \multicolumn{6}{|c|}{ West Facing room - 1m Shade (\% of Occupied Hour) } \\
\hline & $\begin{array}{c}\text { Daylight } \\
\text { Autonomy }\end{array}$ & UDI $<100$ & $100<U D \mid<2000$ & UDI>2000 & DA $\max >5 \%$ \\
\hline \multicolumn{6}{|c|}{ Vertical Fins } \\
\hline Sensor 1 & 86 & 9 & 36 & 55 & 22 \\
\hline Sensor 2 & 80 & 10 & 71 & 19 & 7 \\
\hline Sensor 3 & 70 & 14 & 84 & 2 & 0 \\
\hline \multicolumn{6}{|c|}{ Lightshelve } \\
\hline Sensor 1 & 86 & 9 & 32 & 59 & 22 \\
\hline Sensor 2 & 81 & 10 & 69 & 21 & 4 \\
\hline Sensor 3 & 73 & 13 & 83 & 4 & 1 \\
\hline \multicolumn{6}{|c|}{ Diagrid Screen 1:1 } \\
\hline Sensor 1 & 85 & 9 & 43 & 48 & 15 \\
\hline Sensor 2 & 78 & 11 & 76 & 13 & 0 \\
\hline Sensor 3 & 68 & 14 & 83 & 3 & 1 \\
\hline \multicolumn{6}{|c|}{ Diagrid Screen 2:1 } \\
\hline Sensor 1 & 77 & 11 & 75 & 14 & 3 \\
\hline Sensor 2 & 73 & 13 & 81 & 6 & 0 \\
\hline Sensor 3 & 60 & 16 & 82 & 3 & 1 \\
\hline \multicolumn{6}{|c|}{ Diagrid Screen 4:1 } \\
\hline Sensor 1 & 22 & 22 & 76 & 2 & 1 \\
\hline Sensor 2 & 23 & 21 & 79 & 0 & 0 \\
\hline Sensor 3 & 12 & 24 & 76 & 0 & 0 \\
\hline
\end{tabular}

Table 7: Percentage of Occupied Hour with Daylight Metrics of DA, UDI and DAmax - West Room 


\section{Importance of Parallel Analysis of Energy and Daylight}

In the last two sections impacts of glazed façade and various shading strategies on energy and daylight of the rooms facing south, east and west were reported and compared. The results show that only considering energy as a main factor in designing the façade can lead to occupants discomfort and glare, and looking at daylight quality and not considering energy performance, can cause unnecessary energy rise of the building. For instance based on previous analysis, dense diagrid screen can enhance daylight quality but it can also significantly increase heating load and consequently total energy intensity of a building located in a cold climate region.

Designing the screen only based on aesthetic properties, can have negative impacts on building performance and occupant's thermal and visual comfort. It can cause heating energy to grow through blocking passive solar heat gain in winter and cooling energy grow as a result of inadequate solar protection. Also it can lead to glare as a result of reflecting the light in the wrong direction.

Looking at energy and daylighting simulation results, the rooms with no shade had the lowest energy consumptions in comparison to the rooms with shading strategies. The shading devices increased the space heating energy use and as a result increased the total energy. However this rise is not that significant in comparison to the daylight benefits of shading devices.

The percentage of time with useful daylight in the rooms with shading strategies was considerably higher than the room with no shade. Also daylighting analysis revealed that amount of UDI in all the combinations with or without shadings were still high and some shading strategies as 2:1/1m and $4: 1 / 0.5 \mathrm{~m}$ diagrid screens even enhance it further through reflecting the light deeper into the rooms.

It is important to note that impact of conventional shading devices such as overhangs and vertical fins, on daylight quality improvement was lower than diagrid screens. The regular shadings still allow for high possibility of glare and UDI over 2000 lux close to window. Diagrid screen 2:1/1m and $4: 1 / 0.5 \mathrm{~m}$ were the most beneficial options in enhancing the space daylight quality. On the other hand they had the highest impact on space cooling energy use reduction.

The increase in energy use with shading is principally due to higher heating loads, since the shades reduce the passive heating benefits of the glazing. The shadings reduce cooling loads but since these are much smaller that heating loads, the overall energy use goes up. Nevertheless, the overall variation in total energy uses is small with only a $15 \%$ variation from best to worst scenarios except with 4:1 diagrid screen with 1 meter depth. This result shows that increasing density and depth of 
the screen pattern simultaneously causes total energy use to grow without significant performance benefits.

So conventional shading options offered some benefits in terms of enhancing daylight quality of spaces and reducing glare on work stations, but impacts of diagrid screens on this enhancement were more significant.

Parametric analysis of parameters such as depth of the screen, density of the pattern, rotation angle of the screen assembly, reflectivity of the shading material and distance between shading screen and building façade, can be useful in the process of performance based design of shading screens. In the process of designing the shading screens on glazed buildings, both daylight quality and energy efficiency should be taken into consideration from the early design stages simultaneously. The main pattern of the screen can be developed at the beginning according to aesthetic preferences of the design team and then impact of designed screen on energy intensity and daylight quality can be enhanced through parametric studies and validated energy and daylighting simulation software. 


\section{Diagrid Screen Design Modification on South Façade}

In the previous sections the energy intensity of the south facing room with horizontal overhang, light shelve and diagrid screens were investigated. These studies provided us with better ideas of how various shading strategies will impact energy and daylight performance of the spaces. Based on these findings it is possible to further develop the diagrid screen to enhance its impact on energy efficiency and at the same time on daylight distribution quality. The important point to consider is that all external shading devices will increase heating load in heating dominated climates, since they block solar heat gain in certain periods of time in the year based on their design, but the aim is to reduce this impact as much as possible to not over increase total energy intensity.

So far, diagrid screen $2: 1 / 1 \mathrm{~m}$ and $4: 1 / 0.5 \mathrm{~m}$ were the best options to improve the quality of daylight in the rooms. Also they had highest impact on cooling load reduction. However since the largest portion of total energy intensity of a building located in cold climate is heating, both configurations causing an increase in heating load and as a result total energy use of the building.

So to further enhance the screen's performance based on previous outcomes, the screen was modified to allow for more solar heat gain in winter, to decrease heating load and at the same time keep the cooling load as low as possible.

\subsection{Step One - Variable Depth}

In a first step, based on the fact that sun is lower in sky in winter and to increase the solar heat gain in this period, the 2:1 diagrid screen remodeled in DesignBuilder with higher depth at the top and lower depth at the bottom. The top portion had a depth of 1 meter and lower portion 0.5 meter.

After each modification energy and daylight simulations were conducted to investigate the impact of that revision. The change in screen depth, reduced the total energy intensity from 171.97 to 165.60 $\mathrm{kWh} / \mathrm{m}^{2} / \mathrm{yr}$, which is reduced by $3.7 \%$. This modification reduced the heating load by $5.6 \%$ and also reduced lighting load by $9 \%$. This is caused by the fact that deeper section of the screen acts as a light shelve and through reflecting the light deeper into the room reduces electrical lighting intensity.

On the other hand this causes cooling load to increase by $4.9 \%$. So having an uneven depth for the shading screen is one of the parameters affecting its performance and by strategically modification of the depth, positive impacts of shading screen on energy and daylight can be enhanced. Table 8 compares the variations in energy uses during the modification process. 

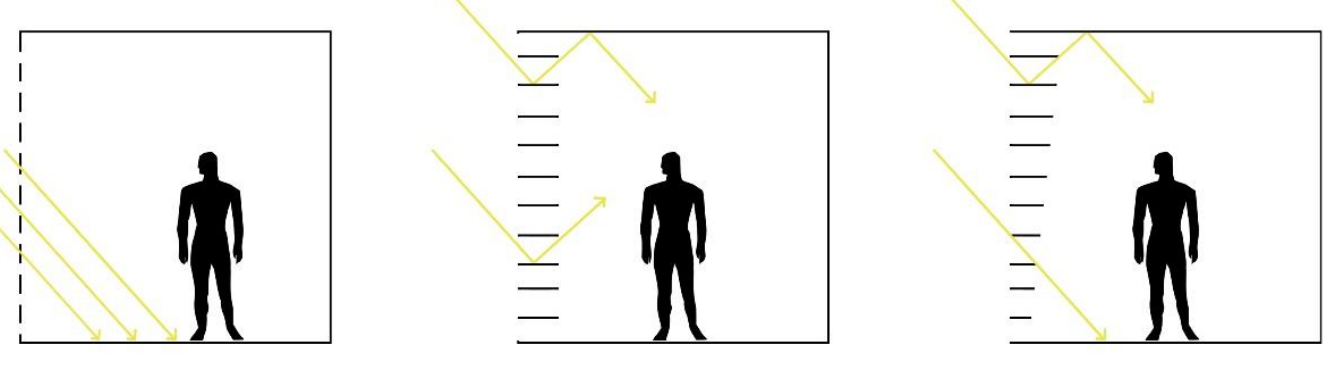

Figure 51: Benefits of Diagrid Screen in Redirecting Light into the Space

\subsection{Step Two - Rotation Angle}

Since the heating load is dominated portion of total energy consumption, in the next stage to even further reduce the heating load, based on the sun's altitude in winter and summer each diagonal block have been rotated by 15 degree at the top, to allow for more passive solar heat gain in winter and still allow the screen to shade the room during the summer. This change caused the upper point of each grid to move up and allow for more solar heat gain and diffuse light to the room, Figures 53 and 54 .

This modification brought the total energy from 165.60 down to $158.70 \mathrm{kWh} / \mathrm{m}^{2} / \mathrm{yr}$, with $4.1 \%$ reduction in comparison to first step and $7.7 \%$ reduction in comparison to regular 2:1 diagrid screen. Heating load decreases from 105.35 to $92.22 \mathrm{kWh} / \mathrm{m}^{2} / \mathrm{yr}$, which is decreased by $12.5 \%$. However this cause cooling load to increase slightly (from 12.21 to $13.35 \mathrm{kWh} / \mathrm{m}^{2} / \mathrm{yr}$ ).

\subsection{Step Three - Density + Depth}

To maintain a balance between heating and cooling loads and reduce cooling load increase in the previous stage, the upper part of the screen subdivided into diagrid with denser pattern. This blocks most of the direct solar radiations in summer and still allow for solar heat gain in winter when sun is lower. This change causes cooling load to decrease but increased heating load and as a result increased total energy intensity. So increasing the density and depth at the same time will cause the total site energy to increase. However it will reduce cooling load significantly compared to regular shading devices, but the higher rise in heating load was the main reason behind total energy upturn.

The aim is to provide a balance between heating and cooling loads and to reduce the increase on total energy intensity as far as possible. To achieve this, depth of the whole diagrid screen from top to bottom reduced by 0.2 meter. So upper part is 0.8 meter deep and lower part 0.3 meter. This 
modification reduced total energy to $157.99 \mathrm{kWh} / \mathrm{m}^{2} / \mathrm{yr}$ which is decreased by $0.44 \%$ in comparison to step 2 and by $8.2 \%$ in comparison to regular $2: 1 / 1 \mathrm{~m}$ diagrid screen.

Figure 52 is demonstration of energy pattern of the room with modified screen compare with some previous shading options. As graph shows, the total energy of the room with the modified shading screen is $6 \%$ higher than the room with regular 1 meter overhang, which is not significant compare to benefits of the screen in terms of daylight quality, glare reduction and occupant comfort.

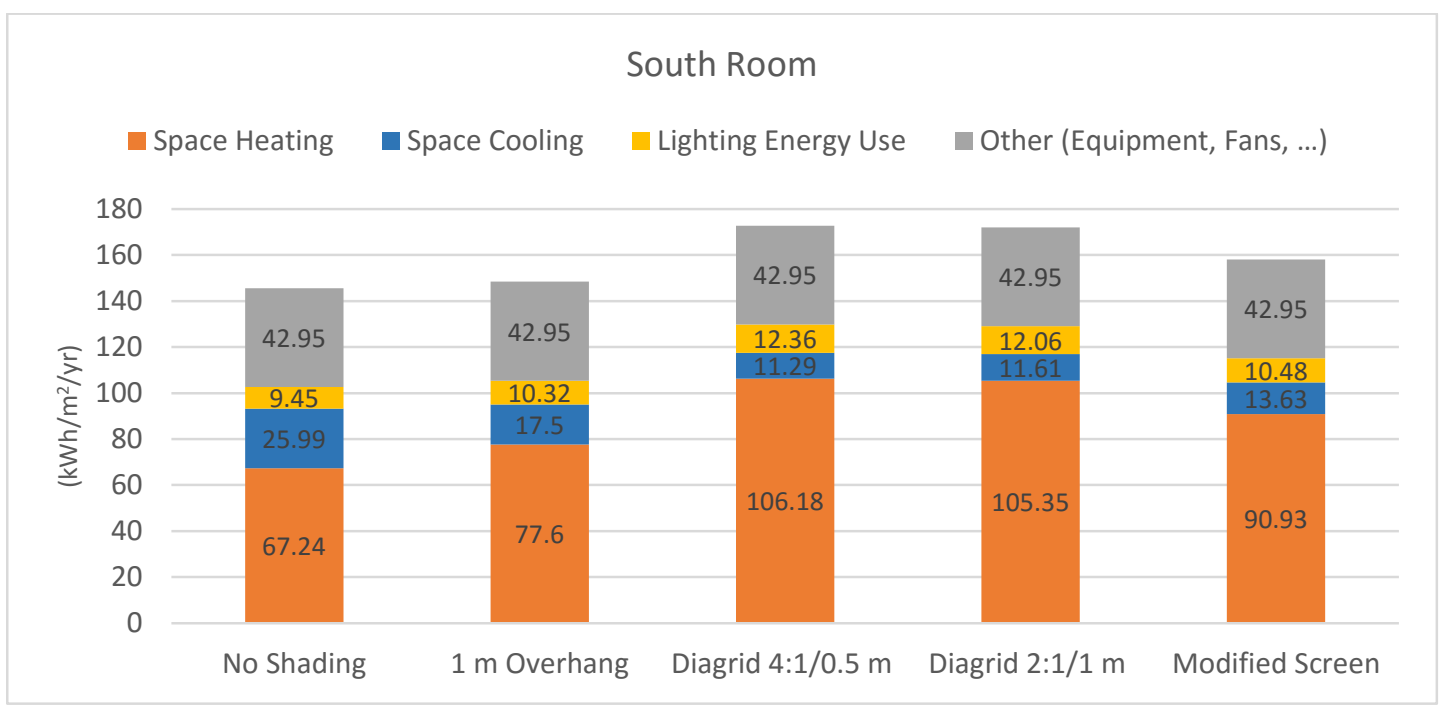

Figure 52: Comparison of Energy Use Pattern of Modified Shading Screen with Various Shading Strategies

\begin{tabular}{|c|c|c|c|}
\hline \multirow{2}{*}{$\begin{array}{l}\text { Diagrid } \\
\text { Screen } \\
\text { Unit: } \\
\text { (kWh/m²/yr) }\end{array}$} & & & \\
\hline & & & \\
\hline $\begin{array}{c}\text { Total Site } \\
\text { Energy }\end{array}$ & 165.60 & 158.70 & 157.99 \\
\hline $\begin{array}{l}\text { Space } \\
\text { Heating }\end{array}$ & 99.46 & 92.22 & 90.93 \\
\hline $\begin{array}{l}\text { Space } \\
\text { Cooling }\end{array}$ & 12.21 & 13.35 & 13.63 \\
\hline $\begin{array}{l}\text { Lighting } \\
\text { Energy Use }\end{array}$ & 10.98 & 10.18 & 10.48 \\
\hline Equipment & 42.95 & 42.95 & 42.95 \\
\hline
\end{tabular}

Table 8: Energy Pattern of the South Room throughout the Process of Diagrid Screen Modification 

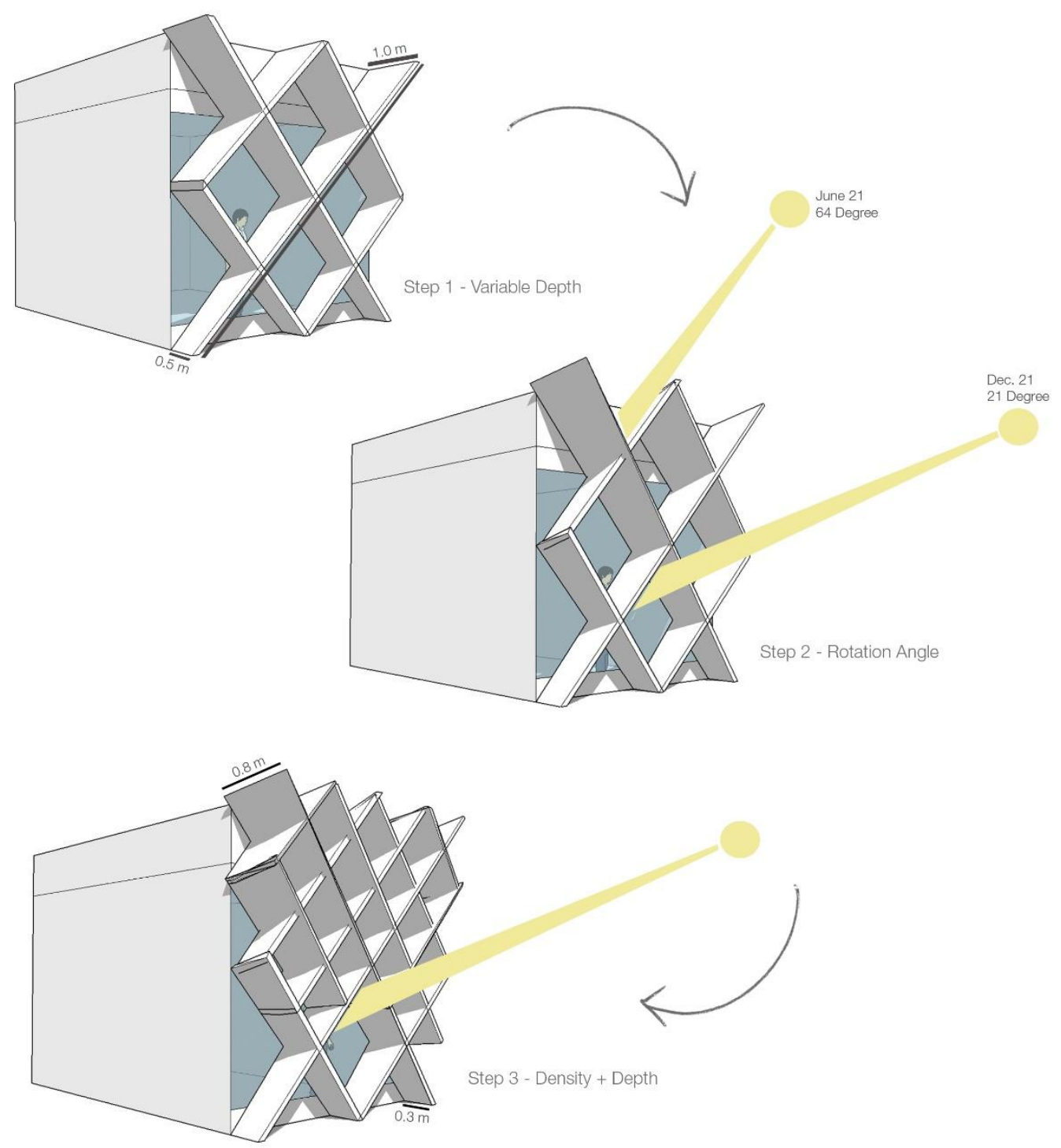

Figure 53: Design Process steps of Diagrid Screen

J une 21

Altitude: 64 Degree
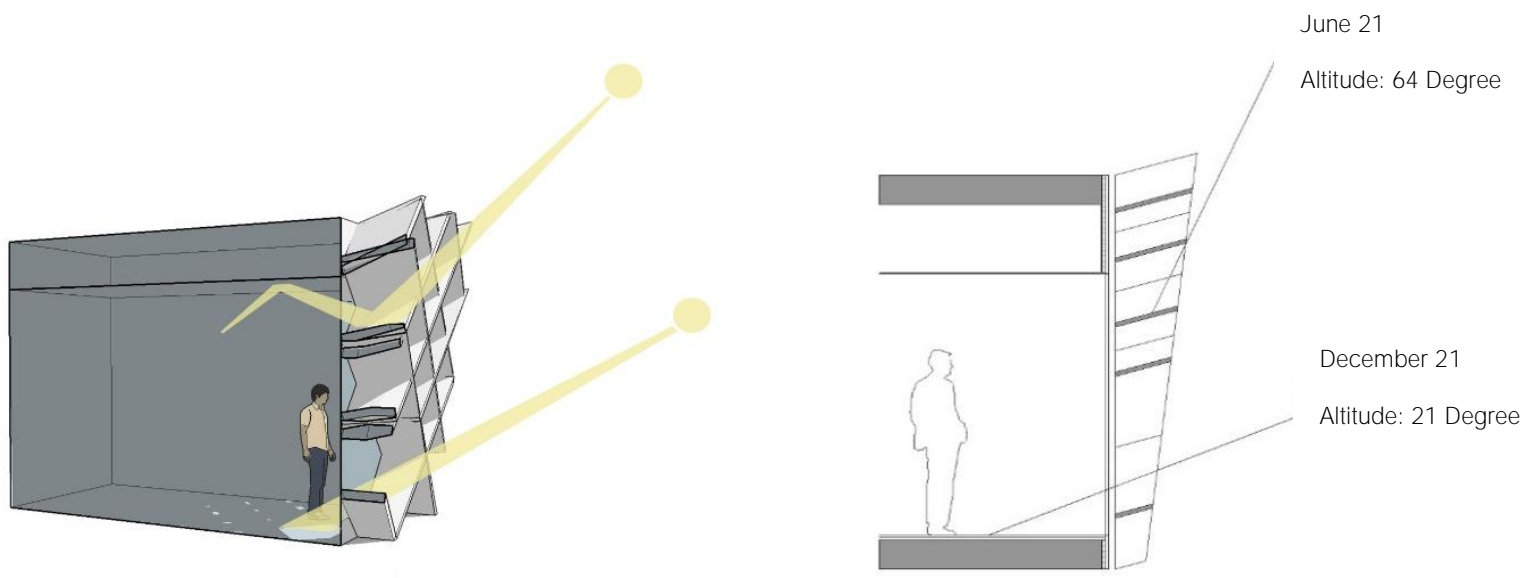

Figure 54: Rotation Angle of Diagrid Screen Based on Solar Incidents 
The impact of modified diagrid screen on daylight quality of the room were analysis through Daysim and compared to some other shading strategies. As Figures 55-57 show, the south facing room with modified shading screen has high Daylight Autonomy (above 68\%) at all three sensors and based on UDI graph the modified screen is among the best options in terms of providing the adequate level of daylight in the room. UDI at sensors 1,2 and 3 are $64 \%, 77 \%$ and $83 \%$, respectively.

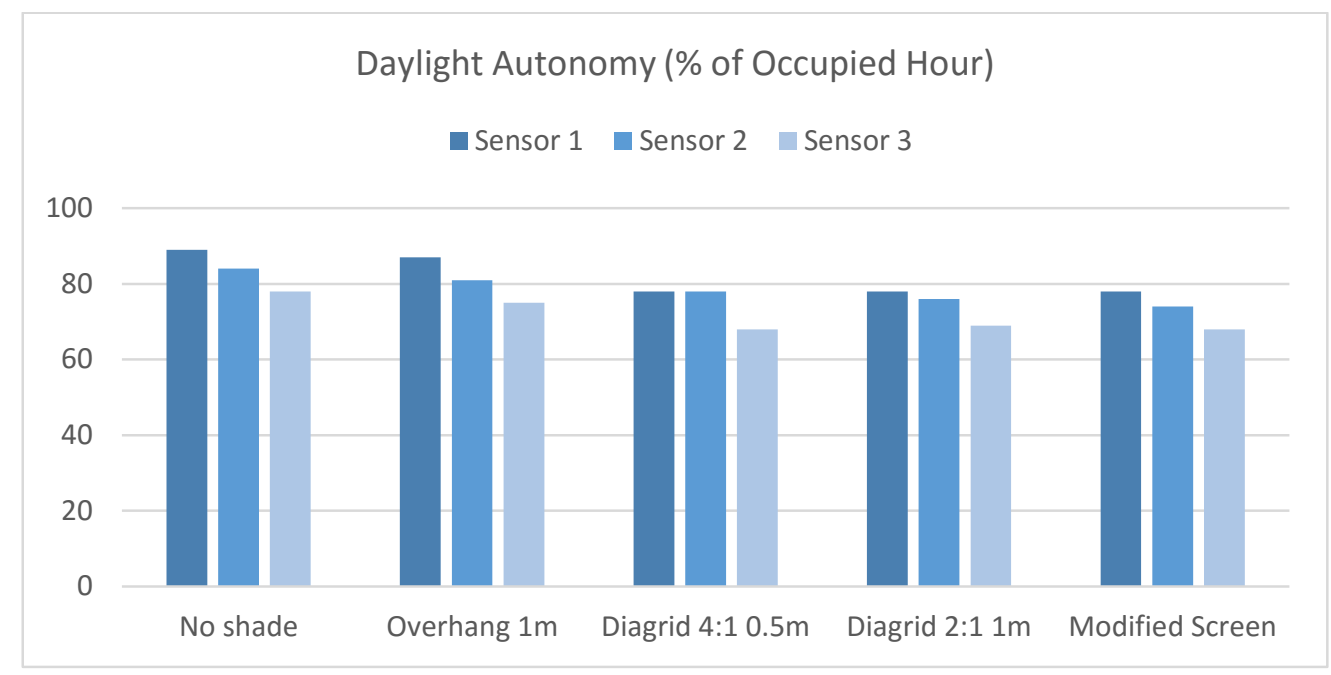

Figure 55: Comparison of DA in the Room with Modified Screen

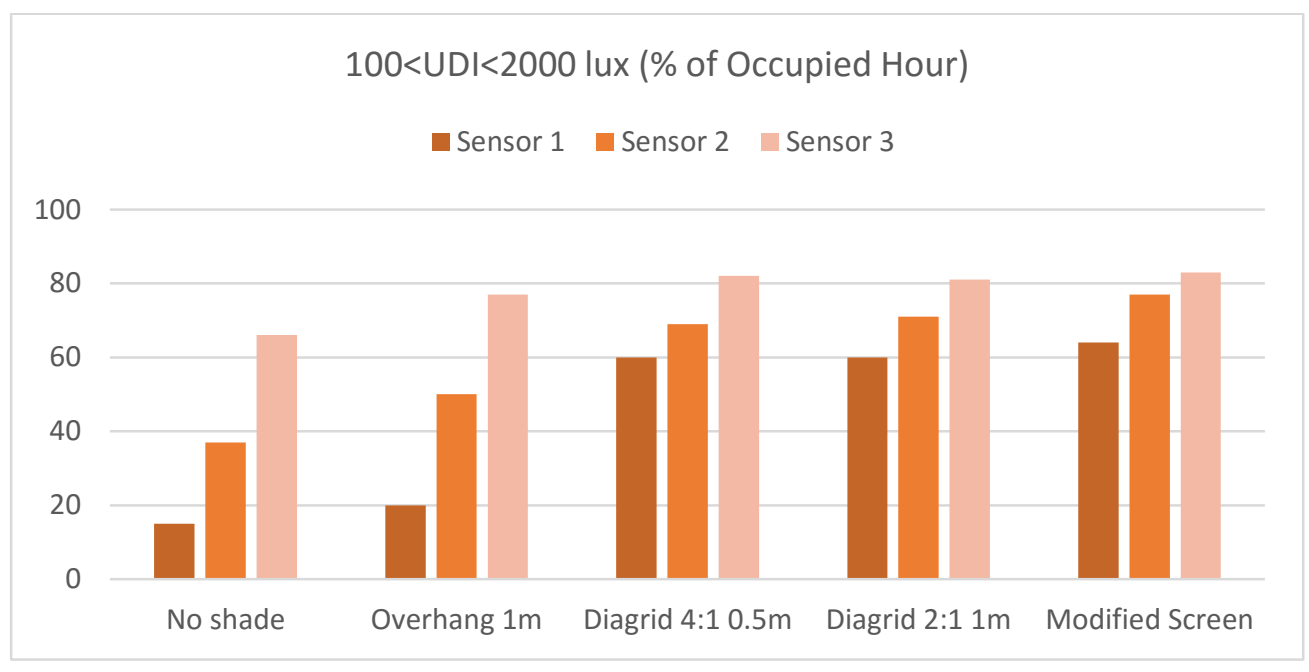

Figure 56: Comparison of UDI in the Room with Modified Screen

The modified screen caused significant reduction in DAmax level in comparison to no shade or even conventional shading strategies. DAmax at sensor 1 of the room with no shade is $61 \%$ and in the room with modified screen is $8 \%$. So possibility of having daylight level 10 times higher than 400 lux, close to window, which can also lead to glare and visual discomfort, is reduced by $87 \%$. 
Moreover, having more depth at the top and lower at the bottom reduced DAmax and daylight glare possibility at sensors 2 and 3 compare to diagrid 2:1 with 1 meter depth.

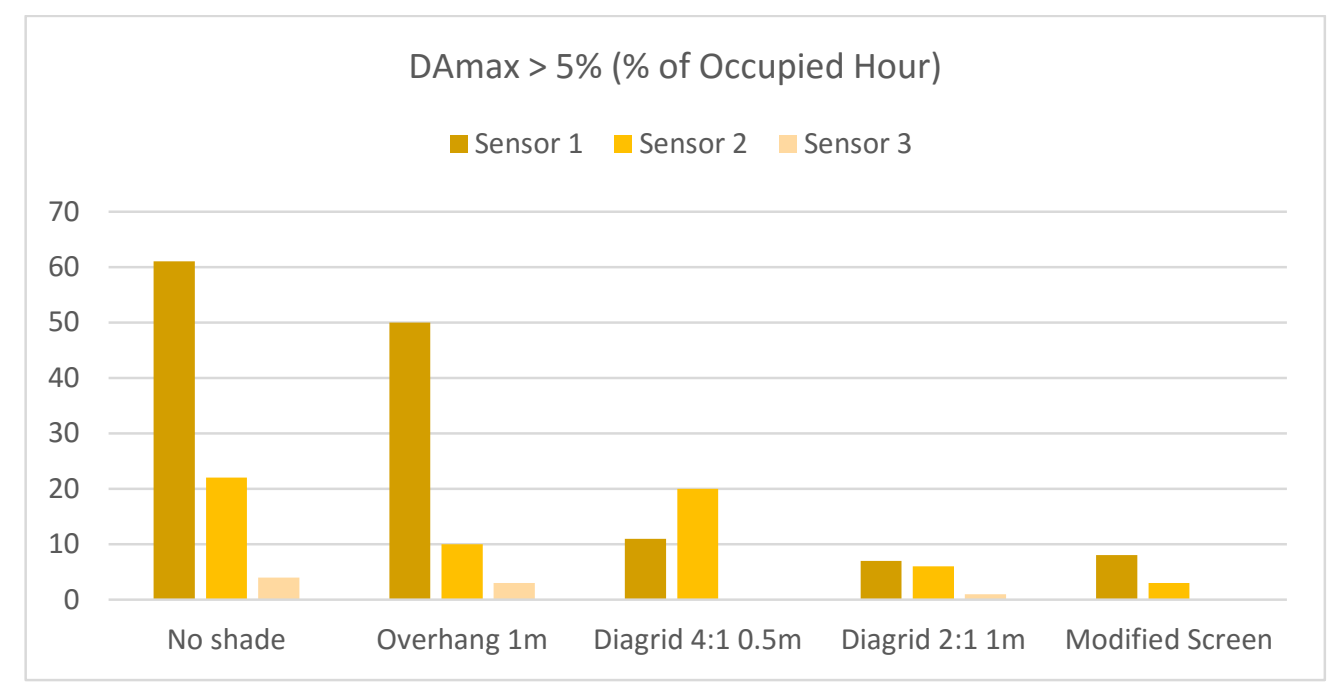

Figure 57: Comparison of DAmax in the Room with Modified Screen

In summary the modified diagrid screen compared to no shade has $7.8 \%$ higher overall energy use. The space heating increased by $27 \%$ and space cooling decreased by $47.5 \%$. On the other hand the daylighting analysis revealed that UDI of the room with modified diagrid screen in comparison to no shade increased from $15 \%$ to $64 \%$ and DAmax decreased from $61 \%$ to $8 \%$ at sensor 1 close to window. 


\section{Radiance Image Based Renderings}

The previous sections provided us with useful information regarding the quantity of daylight at three sensors on horizontal work plane grid along the rooms. However as it mentioned earlier in the literature review section, the amount of light on work plane cannot completely demonstrate the person's visual experience of space, so glare analysis should be based on illuminance distribution in the field of view of observer (Reinhart $\&$ Wienold, 2011).

To better demonstrate the visual experience of occupants, image based renderings of the rooms with no shade and with various shading strategies as 1 meter overhang, 2:1/1m diagrid screen and modified diagrid screen have been provided and presented in this section. The renderings are representation of the room daylight quality on $21^{\text {st }}$ of March, May, J uly, August and December at 3 pm with clear sunny sky. Ecotect software has been used to export data such as room's physical properties and materials to Radiance.

One of the benefits of Radiance rendering is that illuminance level of any point of the image can be retrieved through clicking on that certain point. As Figures 59 - 67 show, lighting level on the work stations and monitors in the rooms with no shade and 1 meter overhang, is significantly higher than desired level. On the other hand, with diagrid screens lighting level on the working stations is maintained in the ranged of 400 to 500 lux in most of the cases.

As Radiance renderings show, the room with no shade has the highest glare possibility. 1 meter overhang can block the direct solar radiation in some extend and minimize glare on work station area, but it cannot completely prevent glare in the room. Basically the overhang is more effective when sun is higher in sky and in winter since the sun is lower the overhang barely block any solar radiation. The regular 2:1 diagrid screen has blocked solar radiation in all the developed rendering except December.

Similar to regular diagrid, the modified screen can significantly reduce daylight glare possibility. The main benefit of the modified screen over regular diagrid screen is that modified screen while preventing direct solar radiation and glare on working stations, allow for more diffuse light into the space which reduces the need for artificial lighting in deeper sections of the room.

As renderings show, illuminance level of the room with diagrid screens is maintained in the useful range of 400 to below 2000 lux in most of the presented cases. However with overhang even if it prevents glare on work station, still the illuminance level of the room close to window is too high. 
To completely prevent glare in winter, the screen should completely cover the glass or internal shading options should be incorporated with external shading devices, however this will reduce the potential for passive solar heat gain in winter and cause energy use to rise. In all other presented cases internal blind is not necessary and external diagrid screen can completely block the glare and provides adequate level of daylight for occupants without blocking the view.
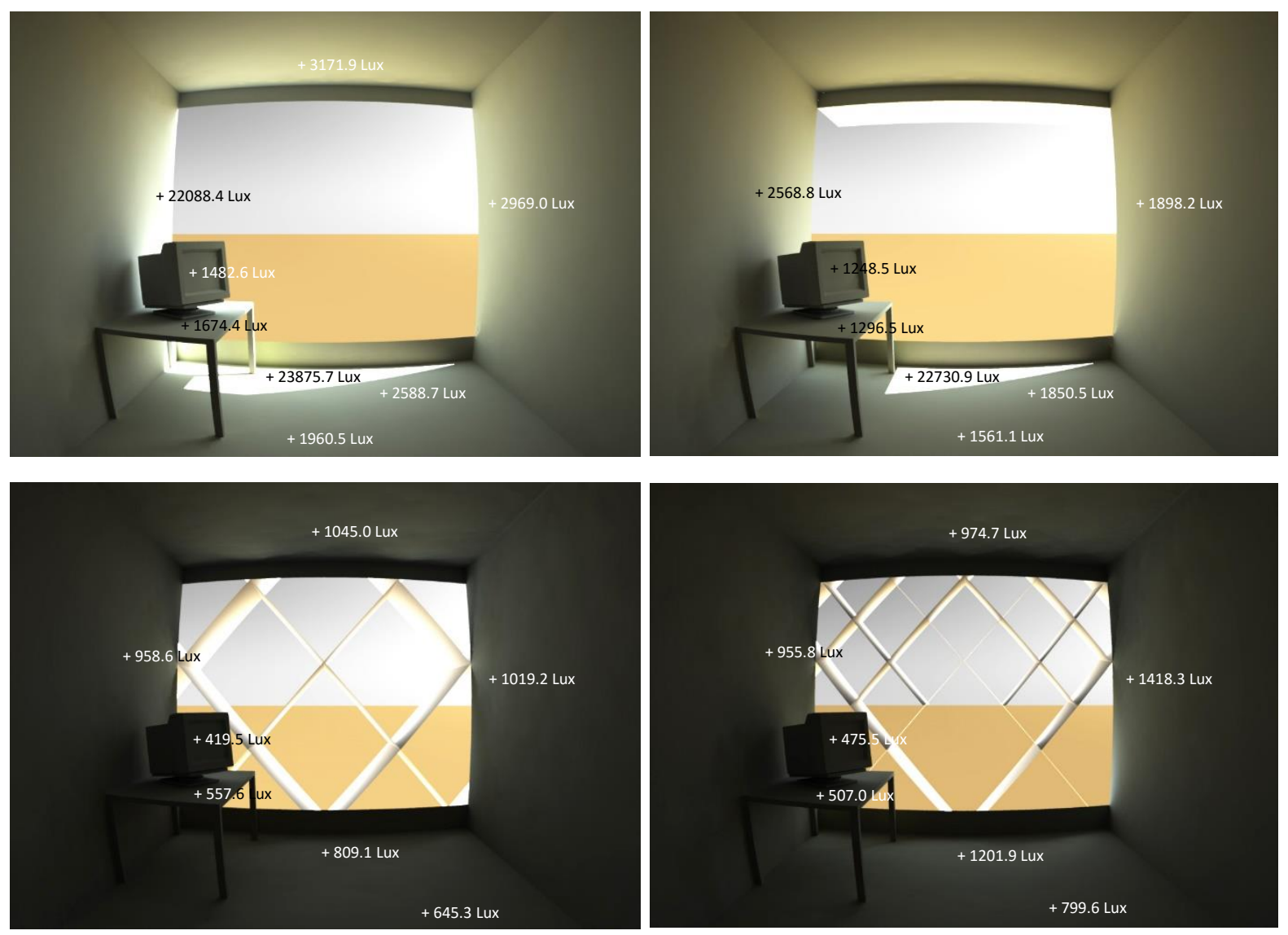

Figure 58: Radiance Renderings of South Room with Various Shading Strategies - May 21 - 3 pm
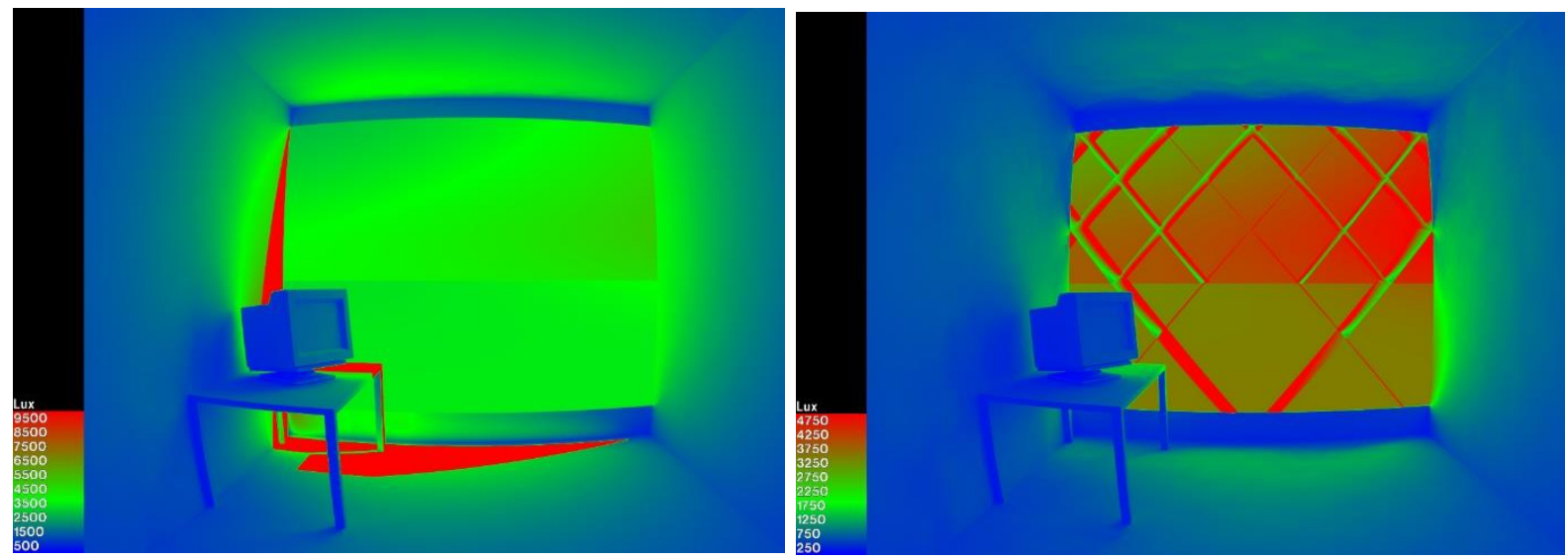

Figure 59: Illuminance Level of the South Room with No Shade \& Modified Diagrid Screen in False Color - May 21 - 3 pm 

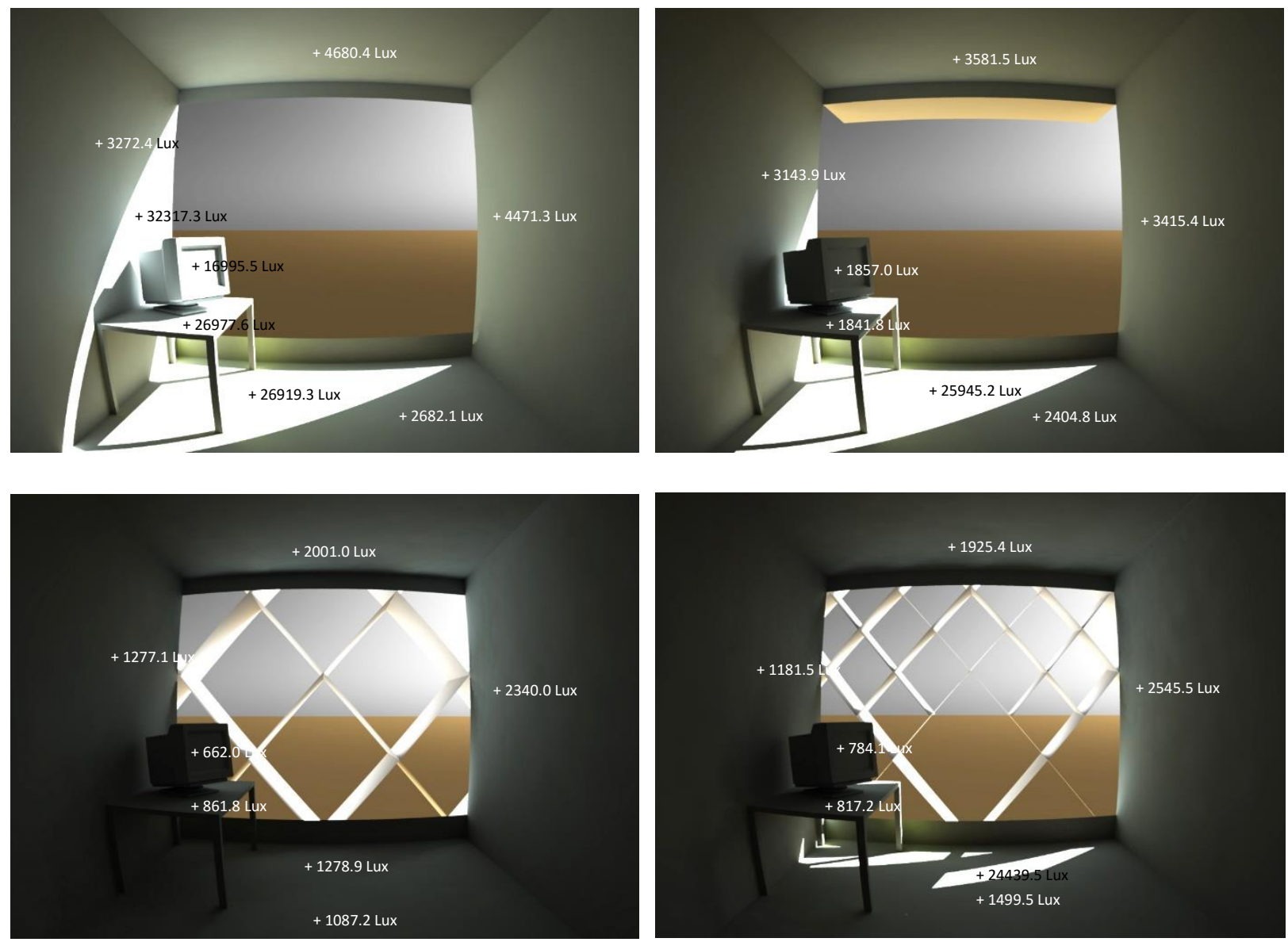

Figure 60: Radiance Renderings of South Room with Various Shading Strategies - March 21 - 3 pm
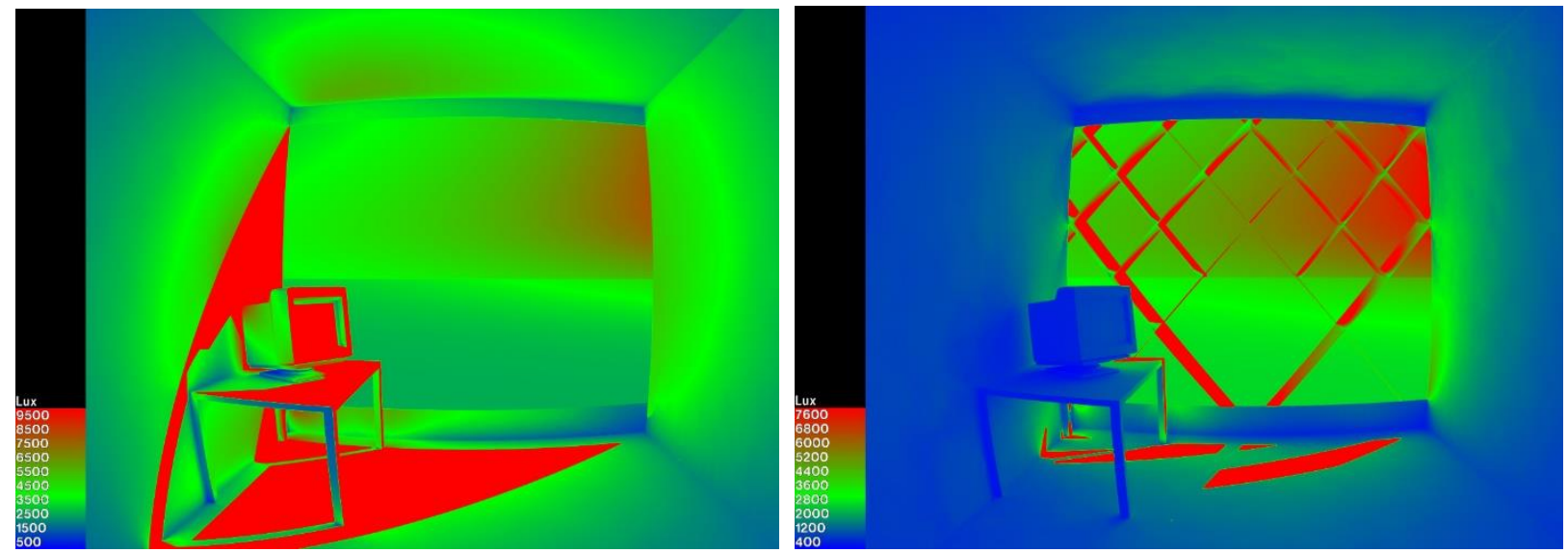

Figure 61: Illuminance Level of the South Room with No Shade \& Modified Diagrid Screen in False Color - March 21 - 3 pm

False Colour creates a thermal imaging overlay on the Radiance Image. Areas of the image are coloured according to the corresponding scale value. 

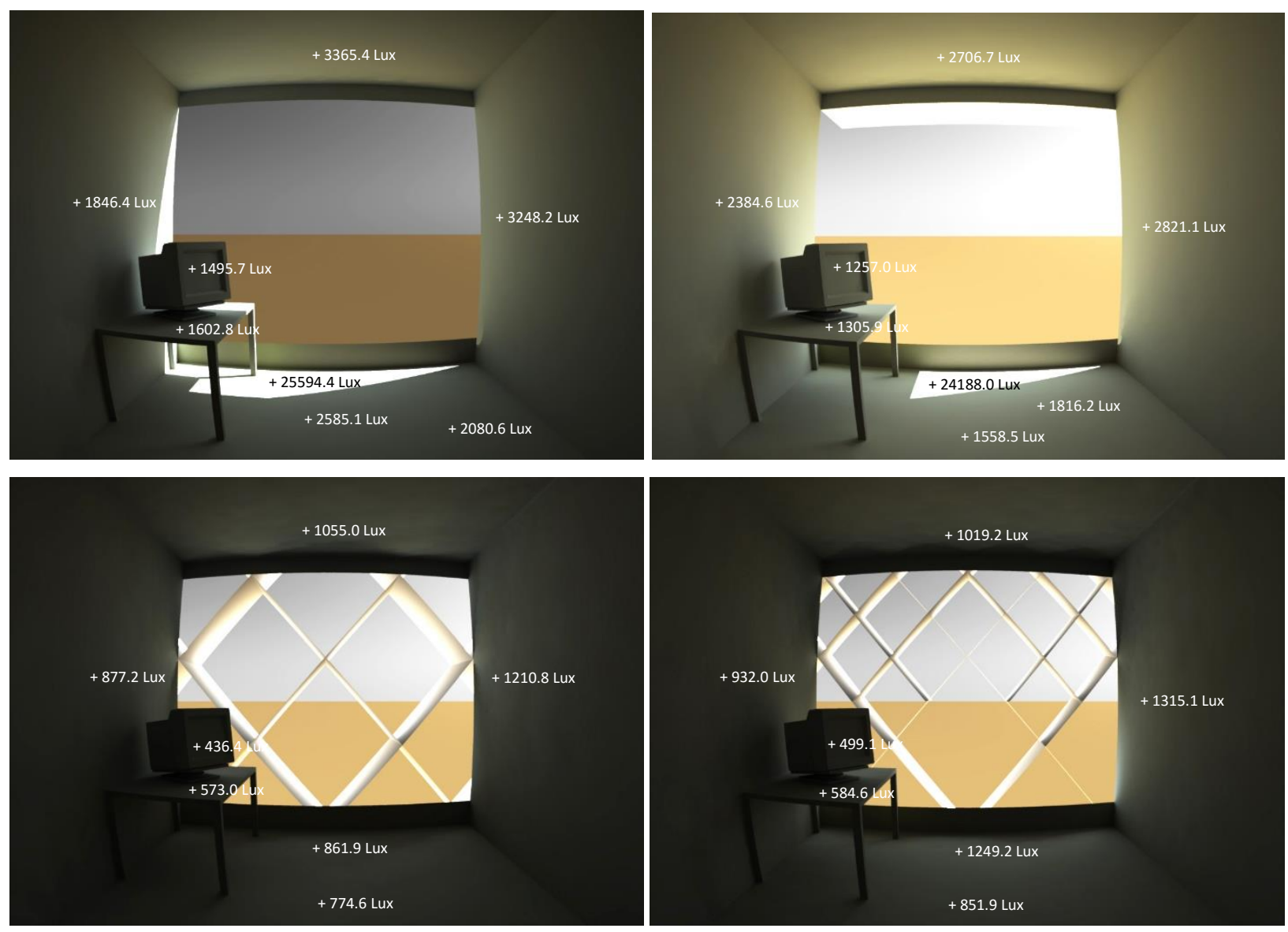

Figure 62: Radiance Renderings of South Room with Various Shading Strategies - July 21 - 3 pm

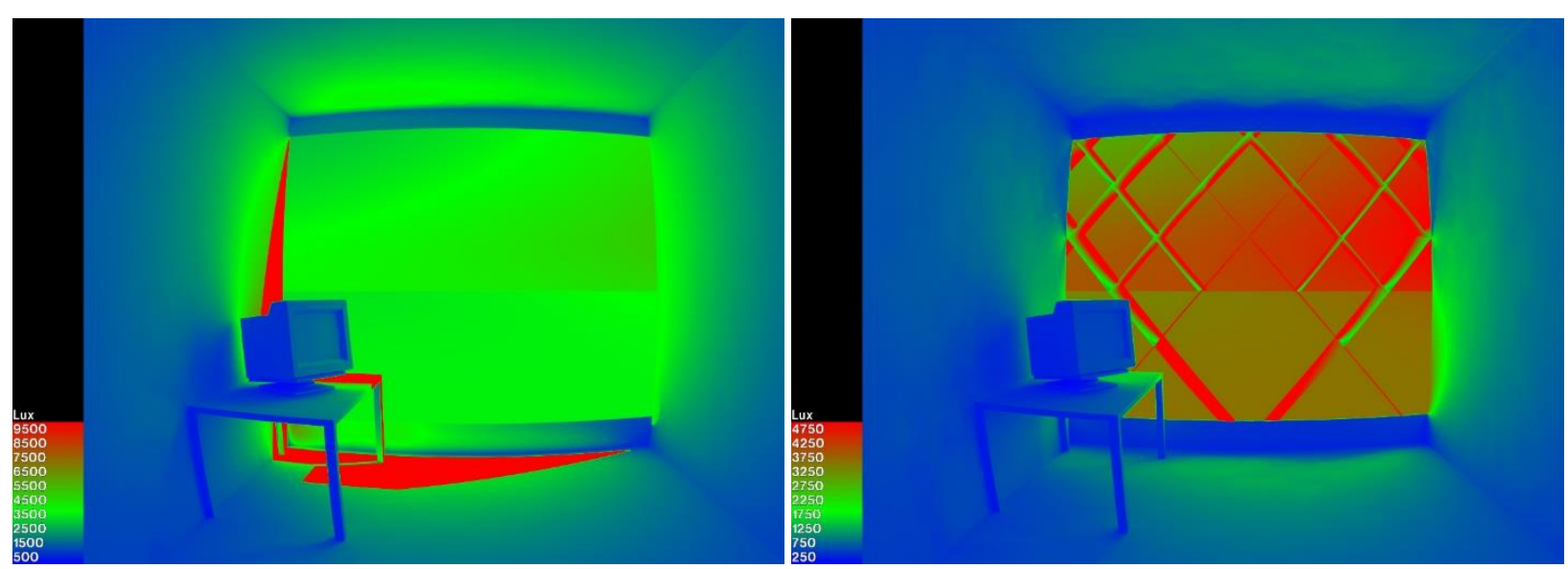

Figure 63: Illuminance Level of the South Room with No Shade \& Modified Diagrid Screen in False Color - July 21 - 3 pm 

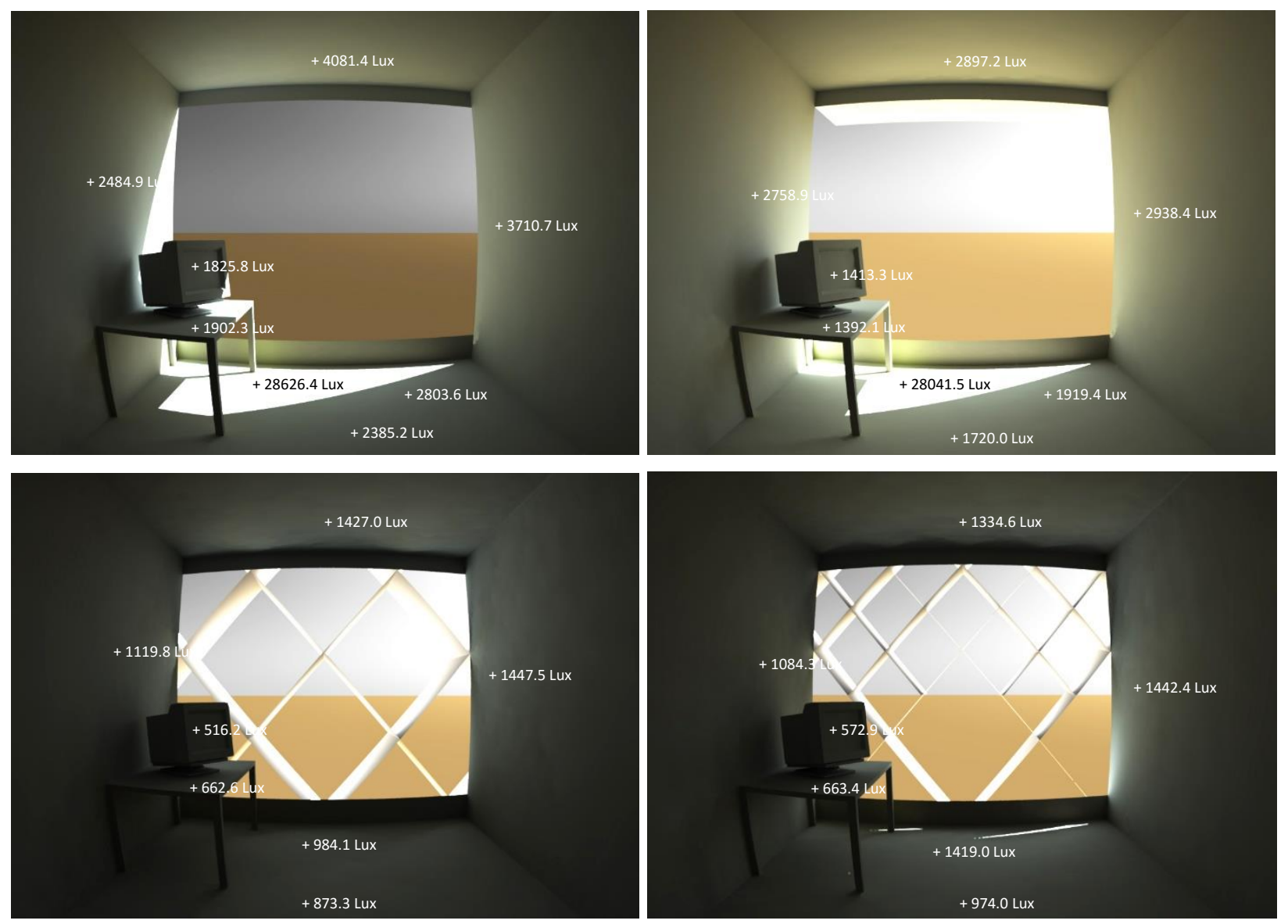

Figure 64: Radiance Renderings of South Room with Various Shading strategies - August 21 - 3 pm
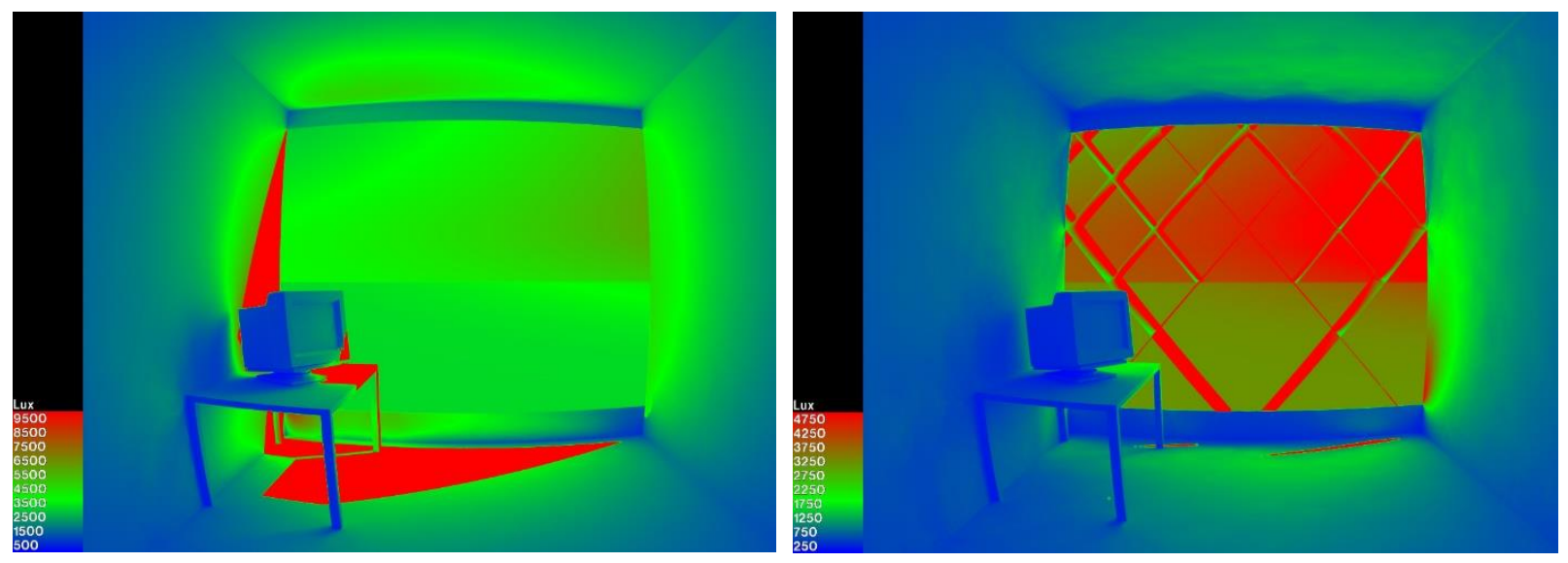

Figure 65: Illuminance Level of the South Room with No Shade \& Modified Diagrid Screen in False Color - August 21 - 3 pm 

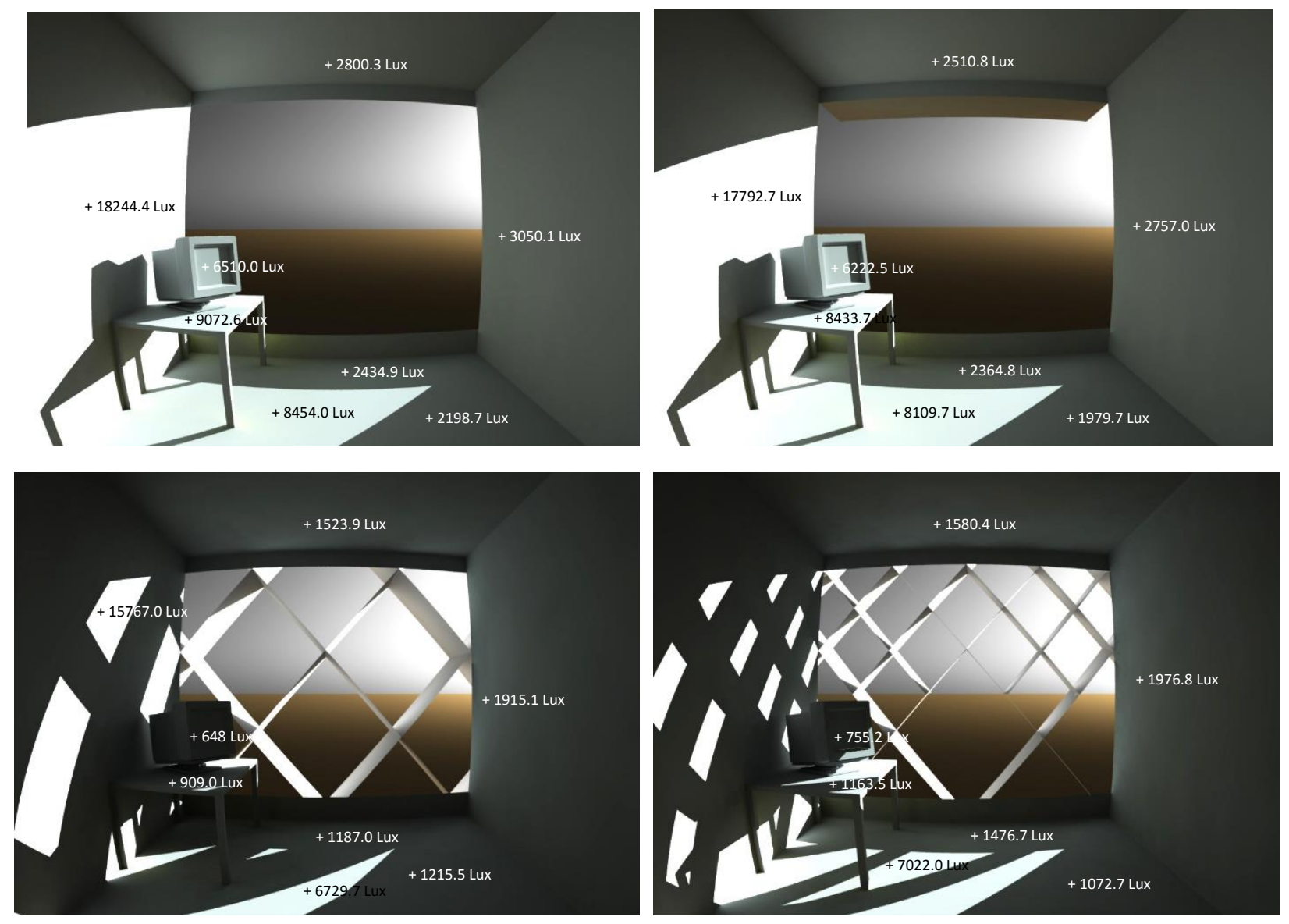

Figure 66: Radiance Renderings of South Room with Various Shading strategies - Dec21 - 3pm
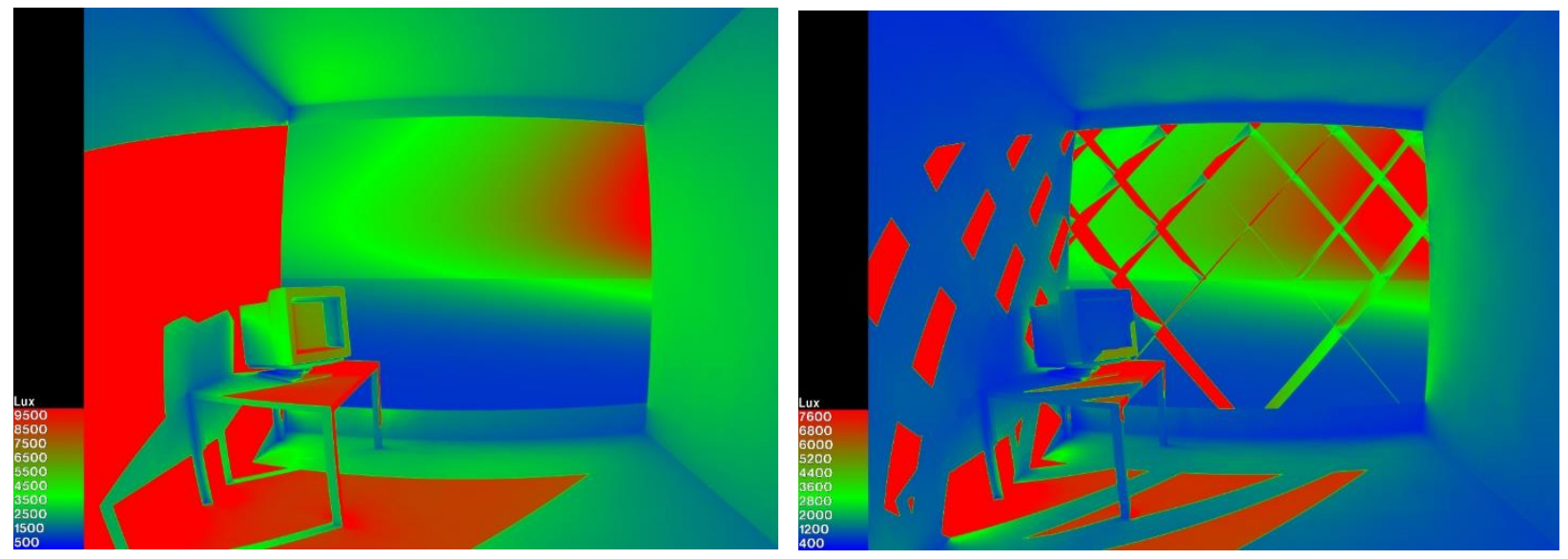

Figure 67: Illuminance Level of the South Room with No Shade \& Modified Diagrid Screen in False Color - Dec21 - 3pm 


\section{Conclusion and Recommendations for Future Work}

A study has been carried out to develop a better understanding of key design parameters affecting shading design performance and propose an appropriate design that balances energy use and lighting conditions in a fully glazed office buildings in Toronto. For the climate like Toronto, it is very important to allow for passive solar heat gain in winter and at the same time protect interior spaces from receiving direct solar radiation in summer. In winter solar radiation is desired to minimize heating load. Thus, a fixed shading structure should be designed to be able to provide adequate shade in summer while allowing solar exposure on windows in winter.

The result of two parallel analysis of energy and daylight confirms that in cold climate regions, in order to minimize heating load which is a dominant part of total energy, unprotected opening is more beneficial since it allows for passive solar heat gain. However looking at lighting analysis, glazed façade without adequate solar protections leads to glare and occupant discomfort.

The study revealed that conventional shading strategies such as horizontal and vertical fins are not the best options to increase energy efficiency and even to minimize glare in building. Beside lighting quality and glare reduction will not improve considerably.

Based on energy simulations results, diagrid screens have better impact on cooling energy reduction and adequate distribution of daylight entering the spaces. In this project, diagrid screens reduced cooling load by half and created the best daylight quality in comparison to other options. The 1 meter overhang reduced cooling load by $32 \%$ and $2: 1 / 1 \mathrm{~m}$ diagrid screen reduced it by $55 \%$ in comparison to no shade scenario. On the other hand heating load increased by $13 \%$ with the overhang and $36 \%$ with the diagrid screen. This confirms that reducing heating and cooling load simultaneously through fixed shading strategies can be challenging, since fixed shadings have divers impacts on heating and cooling loads.

The lighting analysis revealed that space with no shade has a worst daylight quality and highest glare possibility, and conventional shading strategies cannot improve lighting quality considerably. As simulations showed with 1 meter overhang on the south façade, daylight level can still exceed 2000 lux in $50 \%$ of the time during the working hours.

In terms of energy performance of east and west facing rooms, the east room showed higher energy intensity than west room. Monthly solar incidents studies of east and west rooms through DesignBuilder confirmed that east façade receives higher solar incident in summer, in months of 
May, J une and J uly, which leads to higher cooling load compare to west facing room. Also daylighting analysis confirmed that possibility of having glare in east room is higher than west facing room. One important finding was that even though east and west rooms had slightly different energy uses in terms of heating and cooling loads, but impacts of various shading strategies on energy rises or drops were equal. More studies is require in future to further investigate the energy and daylight variations in east and west facing rooms.

In the last section of the study, the diagrid screen have been modified to decrease its negative impacts on total energy grow and at the same time enhance daylight quality of south facing room. The aim was to create a balance between space heating, cooling and lighting energy uses, to reduce the increase on total energy intensity as far as possible. As a result, modified diagrid screen reduced the cooling load by $47.5 \%$ compare to no shade and increase total energy only by $7.8 \%$ compare to no shade and by $6 \%$ compare to 1 meter overhang.

On the other hand the modified screen had the best effect on daylight quality and increasing the Useful Daylight Index (UDI) at all three sensors along the rooms. The UDI of the room with modified screen at sensor 1 , close to window, was $64 \%$ and at sensors 2 and 3 were $77 \%$ and $83 \%$, respectively. The UDI of the room with no shade at sensor 1 , was $15 \%$ and 1 meter overhang could only increase it to $20 \%$.

Also the project confirmed that it is always beneficial to look at more than one measure or metric in daylighting analysis. The study showed that only considering DA or UDI as a metric cannot provide us with sufficient data regarding the daylight quality of spaces.

The conclusions drawn from this study can provide a set of useful information for a design team on the impact of shading strategies and architectural design choices of shading devices on energy demands and daylight quality of glazed office buildings.

Following are some of the key design lessons identified in this research;

- Architectural design choices of façade and shading devices should be taken into consideration from early design stages in order to optimise energy and daylight performance.

- Shading devices can be both a complex geometry that satisfies the aesthetic desires of building façade, while addressing building performance and occupant comfort. 
- Considering the parameters such as depth of the screen, density of the pattern, rotation angle of the screen assembly and reflectivity of the shading materials, can be useful in the process of performance based design of shading screen.

- In the process of designing the shading screens on glazed buildings, both daylight quality and energy efficiency should be taken into consideration simultaneously.

- In the process of shading screen design and production, issues of fixing the screen to the façade and thermal bridges associated with it should be taken into consideration.

Further research is required to study the impact of shading screens with different patterns. Also the window to wall ratio, building geometry and glass property can be treated as a variable and explore if building with different glass property should be treated differently. Moreover additional research and design would be required to modify the screen on east and west facing rooms and effectively deploy the screen on building scale.

Also instead of modifying the screen manually, parametric study software such as Grasshopper can be applied to further optimise the shading screen, to achieve both daylighting and energy performance benefits.

In addition, kinetic shading devices can be studied and compared to fixed shading screens to understand the performance benefits of adaptive shadings over fixed shadings, including the issues of cost and maintenance. 


\section{Appendices}

Monthly Energy Simulations of the South, East and West Facing Rooms - No Shade

\begin{tabular}{|c|c|c|c|c|c|}
\hline South & $\begin{array}{c}\text { Heating } \\
\mathrm{kWh} / \mathrm{m}^{2} / \mathrm{yr}\end{array}$ & $\begin{array}{c}\text { Cooling } \\
\mathrm{kWh} / \mathrm{m}^{2} / \mathrm{yr}\end{array}$ & $\begin{array}{c}\text { Lighting } \\
\mathrm{kWh} / \mathrm{m}^{2} / \mathrm{yr}\end{array}$ & $\begin{array}{c}\text { Equipment } \\
\mathrm{kWh} / \mathrm{m}^{2} / \mathrm{yr}\end{array}$ & $\begin{array}{c}\text { Total } \\
\mathrm{kWh} / \mathrm{m}^{2} / \mathrm{yr}\end{array}$ \\
\hline J anuary & 15.76 & 0.00 & 1.36 & 3.64 & 20.76 \\
\hline February & 12.66 & 0.00 & 0.89 & 3.30 & 16.86 \\
\hline March & 9.14 & 0.00 & 0.85 & 3.78 & 13.77 \\
\hline April & 3.94 & 0.27 & 0.48 & 3.33 & 8.02 \\
\hline May & 1.55 & 0.67 & 0.44 & 3.78 & 6.44 \\
\hline J une & 0.36 & 4.52 & 0.36 & 3.62 & 8.86 \\
\hline July & 0.30 & 9.22 & 0.36 & 3.49 & 13.37 \\
\hline August & 0.33 & 7.89 & 0.38 & 3.78 & 12.38 \\
\hline September & 0.41 & 2.94 & 0.48 & 3.48 & 7.30 \\
\hline October & 1.82 & 0.50 & 0.92 & 3.64 & 6.87 \\
\hline November & 8.05 & 0.00 & 1.41 & 3.62 & 13.08 \\
\hline December & 13.02 & 0.00 & 1.53 & 3.49 & 18.04 \\
\hline Yearly & 67.24 & 25.99 & 9.45 & 42.95 & 145.64 \\
\hline
\end{tabular}

\begin{tabular}{|c|c|c|c|c|c|}
\hline East & $\begin{array}{c}\text { Heating } \\
\mathrm{kWh} / \mathrm{m}^{2} / \mathrm{yr}\end{array}$ & $\begin{array}{c}\text { Cooling } \\
\mathrm{kWh} / \mathrm{m}^{2} / \mathrm{yr}\end{array}$ & $\begin{array}{c}\text { Lighting } \\
\mathrm{kWh} / \mathrm{m}^{2} / \mathrm{yr}\end{array}$ & $\begin{array}{c}\text { Equipment } \\
\mathrm{kWh} / \mathrm{m}^{2} / \mathrm{yr}\end{array}$ & $\begin{array}{c}\text { Total } \\
\mathrm{kWh} / \mathrm{m}^{2} / \mathrm{yr}\end{array}$ \\
\hline J anuary & 24.03 & 0.00 & 1.25 & 3.64 & 28.92 \\
\hline February & 19.42 & 0.00 & 0.83 & 3.30 & 23.56 \\
\hline March & 11.12 & 0.00 & 0.77 & 3.78 & 15.68 \\
\hline April & 4.18 & 0.23 & 0.40 & 3.33 & 8.14 \\
\hline May & 0.83 & 1.01 & 0.40 & 3.78 & 6.02 \\
\hline J une & 0.32 & 6.10 & 0.33 & 3.62 & 10.36 \\
\hline July & 0.30 & 13.24 & 0.31 & 3.49 & 17.35 \\
\hline August & 0.33 & 8.52 & 0.35 & 3.78 & 12.99 \\
\hline September & 0.55 & 2.17 & 0.40 & 3.48 & 6.60 \\
\hline October & 4.63 & 0.16 & 0.18 & 3.64 & 9.24 \\
\hline November & 11.67 & 0.00 & 1.29 & 3.62 & 16.58 \\
\hline December & 19.29 & 0.00 & 1.44 & 3.49 & 24.22 \\
\hline Yearly & 96.88 & 31.42 & 8.60 & 42.95 & 179.85 \\
\hline
\end{tabular}




\begin{tabular}{|c|c|c|c|c|c|}
\hline West & $\begin{array}{c}\text { Heating } \\
\mathrm{kWh} / \mathrm{m}^{2} / \mathrm{yr}\end{array}$ & $\begin{array}{c}\text { Cooling } \\
\mathrm{kWh} / \mathrm{m}^{2} / \mathrm{yr}\end{array}$ & $\begin{array}{c}\text { Lighting } \\
\mathrm{kWh} / \mathrm{m}^{2} / \mathrm{yr}\end{array}$ & $\begin{array}{c}\text { Equipment } \\
\mathrm{kWh} / \mathrm{m}^{2} / \mathrm{yr}\end{array}$ & $\begin{array}{c}\text { Total } \\
\mathrm{kWh} / \mathrm{m}^{2} / \mathrm{yr}\end{array}$ \\
\hline J anuary & 23.88 & 0.00 & 1.42 & 3.64 & 28.93 \\
\hline February & 19.12 & 0.00 & 0.92 & 3.30 & 23.34 \\
\hline March & 13.20 & 0.00 & 0.84 & 3.78 & 17.82 \\
\hline April & 4.94 & 0.26 & 0.48 & 3.33 & 9.02 \\
\hline May & 1.37 & 0.69 & 0.44 & 3.78 & 6.28 \\
\hline J une & 0.35 & 5.34 & 0.36 & 3.62 & 9.67 \\
\hline J uly & 0.30 & 10.60 & 0.36 & 3.49 & 14.75 \\
\hline August & 0.33 & 7.58 & 0.39 & 3.78 & 12.07 \\
\hline September & 0.58 & 2.13 & 0.47 & 3.48 & 6.66 \\
\hline October & 4.39 & 0.09 & 0.95 & 3.64 & 9.06 \\
\hline November & 11.34 & 0.00 & 1.46 & 3.62 & 16.42 \\
\hline December & 19.34 & 0.00 & 1.59 & 3.49 & 24.43 \\
\hline Yearly & 99.02 & 26.57 & 9.69 & 42.95 & 178.23 \\
\hline
\end{tabular}

Monthly Energy Simulations of the South Facing Room with 4:1/0.5m Diagrid Screen

\begin{tabular}{|c|c|c|c|c|c|}
\hline South & $\begin{array}{c}\text { Heating } \\
\mathrm{kWh} / \mathrm{m}^{2} / \mathrm{yr}\end{array}$ & $\begin{array}{c}\text { Cooling } \\
\mathrm{kWh} / \mathrm{m}^{2} / \mathrm{yr}\end{array}$ & $\begin{array}{c}\text { Lighting } \\
\mathrm{kWh} / \mathrm{m}^{2} / \mathrm{yr}\end{array}$ & $\begin{array}{c}\text { Equipment } \\
\mathrm{kWh} / \mathrm{m}^{2} / \mathrm{yr}\end{array}$ & $\begin{array}{c}\text { Total } \\
\mathrm{kWh} / \mathrm{m}^{2} / \mathrm{yr}\end{array}$ \\
\hline J anuary & 21.11 & 0.00 & 1.61 & 3.64 & 26.35 \\
\hline February & 19.60 & 0.00 & 1.10 & 3.30 & 24.01 \\
\hline March & 16.89 & 0.00 & 1.10 & 3.78 & 21.77 \\
\hline April & 9.62 & 0.00 & 0.74 & 3.33 & 13.69 \\
\hline May & 3.89 & 0.18 & 0.65 & 3.78 & 8.50 \\
\hline J une & 0.68 & 2.12 & 0.58 & 3.62 & 7.00 \\
\hline J uly & 0.33 & 4.82 & 0.61 & 3.49 & 9.25 \\
\hline August & 0.39 & 3.42 & 0.61 & 3.78 & 8.21 \\
\hline September & 1.41 & 0.77 & 0.73 & 3.48 & 6.38 \\
\hline October & 5.47 & 0.05 & 1.20 & 3.64 & 10.36 \\
\hline November & 10.52 & 0.00 & 1.67 & 3.62 & 15.81 \\
\hline December & 16.43 & 0.00 & 1.75 & 3.49 & 21.67 \\
\hline Yearly & 106.18 & 11.29 & 12.36 & 42.95 & 172.78 \\
\hline
\end{tabular}


Design Builder Energy Simulations Results for the Rooms with clear glass - No Shade:

South: Double pane clear glass $6 \mathrm{~mm} / 13 \mathrm{~mm}$ air with R-4 Curtain Wall System:

70\% WWR $=174.64 \mathrm{kWh} / \mathrm{m}^{2} / \mathrm{yr}$ (Heating: 88.53 and Cooling: 34.01)

East: Double pane clear glass $6 \mathrm{~mm} / 13 \mathrm{~mm}$ air:

70\% WWR $=220.58 \mathrm{kWh} / \mathrm{m}^{2} / \mathrm{yr}$ (Heating: 126.80 and Cooling: 42.46)

West: Double pane clear glass $6 \mathrm{~mm} / 13 \mathrm{~mm}$ air:

$70 \%$ WWR $=217.66 \mathrm{kWh} / \mathrm{m}^{2} / \mathrm{yr}$ (Heating: 131.00 and Cooling: 34.37)

Solar Incidents and Heat Gains Analysis through DesignBuilder:

\begin{tabular}{|c|c|c|c|c|c|c|c|c|c|c|c|c|}
\hline $\begin{array}{c}\text { Unit: } \\
\text { kWh }\end{array}$ & Jan & Feb & March & April & May & J une & J uly & August & Sep & Oct & Nov & Dec \\
\hline South & 1170.37 & 1225.44 & 1308.70 & 1266.01 & 1221.16 & 1152.68 & 1216.04 & 1339.07 & 1481.67 & 1317.01 & 745.49 & 863.18 \\
\hline East & 486.94 & 599.77 & 978.91 & 1130.18 & 1581.67 & 1508.19 & 1570.68 & 1391.52 & 1154.18 & 731.28 & 330.46 & 330.78 \\
\hline West & 513.40 & 663.39 & 835.67 & 1070.05 & 1243.11 & 1397.39 & 1418.27 & 1299.03 & 1016.44 & 740.09 & 359.18 & 328.76 \\
\hline
\end{tabular}

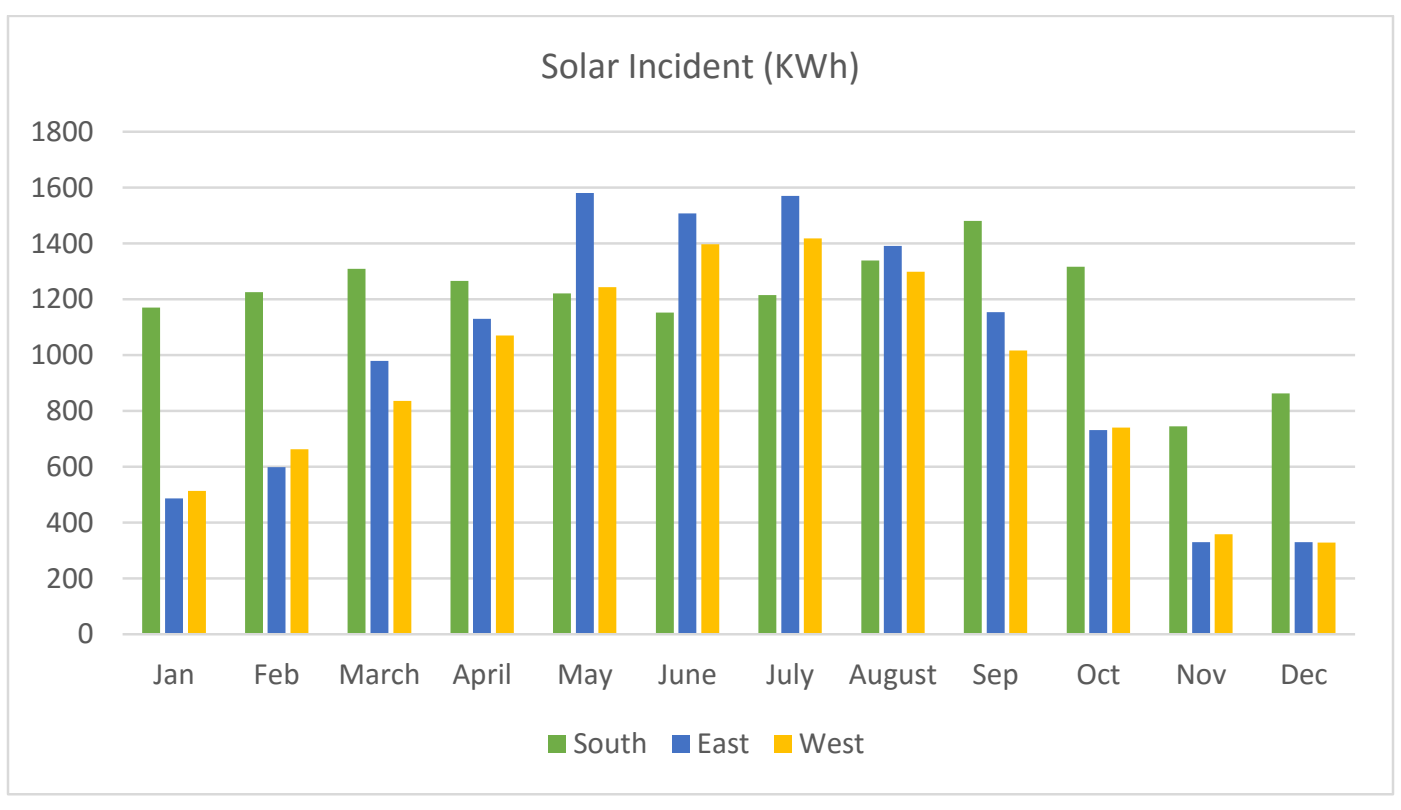




\section{South Facing Room}

\section{Cooling Design}

\section{Temperature and Heat Gains}

\begin{tabular}{|c|c|c|c|c|c|c|c|c|c|c|c|}
\hline Air Temperature (c) & 26.70 & 26.49 & 24.00 & 24.00 & 24.00 & 24.00 & 24.00 & 24.00 & 24.00 & 27.47 & 27.19 \\
\hline Radiant Temperature ('C) & 27.13 & 26.95 & 26.37 & 26.43 & 27.20 & 28.23 & 28.69 & 28.20 & 27.49 & 27.53 & 27.44 \\
\hline Operative Temperature ( $\mathrm{C}$ ) & 26.91 & 26.72 & 25.19 & 25.22 & 25.60 & 26.12 & 26.35 & 26.10 & 25.75 & 27.50 & 27.31 \\
\hline Outside Dry-Bulb Temperature ("C) & 23.36 & 22.87 & 22.87 & 24.86 & 27.85 & 29.92 & 31.00 & 30.50 & 29.01 & 26.85 & 25.36 \\
\hline Glazing (kW) & -0.07 & .0 .08 & -0.03 & 0.07 & 0.33 & 0.48 & 0.43 & 0.18 & 0.06 & .0 .04 & -0.06 \\
\hline Walls $(\mathrm{kW})$ & -0.02 & .0 .02 & -0.01 & .0 .00 & 0.03 & 0.07 & 0.09 & 0.07 & 0.04 & 0.00 & .0 .01 \\
\hline Ceilings (int) $(\mathrm{kW})$ & 0.04 & 0.05 & 0.11 & 0.03 & -0.09 & -0.17 & -0.13 & -0.00 & 0.09 & 0.03 & 0.03 \\
\hline Floors (int) (kW) & 0.04 & 0.05 & 0.14 & 0.05 & -0.19 & -0.35 & -0.15 & 0.15 & 0.18 & 0.03 & 0.03 \\
\hline 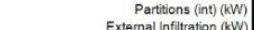 & 0.04 & 0.04 & 0.13 & -0.02 & -0.16 & -0.18 & -0.06 & 0.11 & 0.13 & -0.02 & 0.01 \\
\hline $\begin{array}{l}\text { Extermal Infittation }(\mathrm{kW}) \\
\text { External }\end{array}$ & $\begin{array}{r}-0.05 \\
0.00\end{array}$ & -0.06 & -0.02 & 0.01 & 0.06 & 0.09 & 0.11 & 0.10 & 0.08 & -0.01 & -0.03 \\
\hline $\begin{array}{r}\text { External Vent. }(\mathrm{kW}) \\
\text { General Lighting }(\mathrm{kW})\end{array}$ & 0.00 & 0.00 & 0.00 & -0.01 & -0.05 & -0.06 & -0.09 & -0.08 & -0.02 & 0.00 & 0.00 \\
\hline $\begin{array}{r}\text { General Lighting }(\mathrm{kW}) \\
\text { Computer + Equip (kW) }\end{array}$ & 001 & 0.01 & $\begin{array}{l}0.00 \\
0.01\end{array}$ & 0.02 & 0.02 & 0.02 & 0.02 & 0.02 & 0.02 & 0.00 & 0.00 \\
\hline Occupancy (kW) & 0.00 & 0.00 & 0.00 & 0.03 & 0.07 & $\begin{array}{l}0.21 \\
0.05\end{array}$ & $\begin{array}{l}0.21 \\
0.07\end{array}$ & $\begin{array}{l}0.21 \\
0.07\end{array}$ & $\begin{array}{l}0.21 \\
0.02\end{array}$ & 0.01 & 0.01 \\
\hline Solar Gains Exterior Windows $(\mathrm{kW})$ ) & 0.00 & 0.00 & 0.10 & 0.25 & 0.63 & 1.00 & 0.82 & 0.35 & 0.17 & 0.00 & 0.00 \\
\hline Zone Sensible Cooling (kW) & 0.00 & 0.00 & -0.42 & -0.64 & -0.90 & -1.21 & -1.39 & -1.24 & -0.98 & 0.00 & 0.00 \\
\hline Sensible Cooling (kW) & 0.00 & 0.00 & .0 .42 & .0 .65 & .0 .95 & -1.27 & -1.48 & -1.33 & -1.00 & 0.00 & 0.00 \\
\hline Total Cooling (kW) & 0.00 & 0.00 & -0.58 & -0.92 & -1.34 & -1.63 & -1.87 & -1.71 & -1.23 & 0.00 & 0.00 \\
\hline Relative Humidity (\%) & 66.11 & 67.03 & 56.19 & 54.84 & 53.60 & 51.82 & 51.35 & 51.70 & 52.10 & 53.83 & 62.46 \\
\hline Mech Vent + Nat Vent + Infiltration (ac/h) & 0.71 & 0.71 & 0.70 & 0.97 & 1.24 & 1.10 & 1.23 & 1.23 & 0.83 & 0.70 & 0.70 \\
\hline
\end{tabular}

\section{Heating Design}

\section{Temperature and Heat Loss}

\begin{tabular}{r|r|} 
Air Temperature $\left({ }^{\circ} \mathrm{C}\right)$ & 22.00 \\
Radiant Temperature $\left({ }^{\circ} \mathrm{C}\right)$ & 19.32 \\
Operative Temperature $\left({ }^{\circ} \mathrm{C}\right)$ & 20.66 \\
Outside Dry-Bulb Temperature $\left({ }^{\circ} \mathrm{C}\right)$ & -16.40 \\
Glazing $(\mathrm{kW})$ & -0.44 \\
Walls $(\mathrm{kW})$ & -0.11 \\
External Infiltration $(\mathrm{kW})$ & -0.72 \\
External Vent. $(\mathrm{kW})$ & -0.47 \\
Zone Sensible Heating $(\mathrm{kW})$ & 1.74 \\
\hline
\end{tabular}

\section{Internal Gains + Solar}

0.00

EnergyPlus Output
Internal Gains + solar - Site, Building 1 15 Jul, Sub-hourly

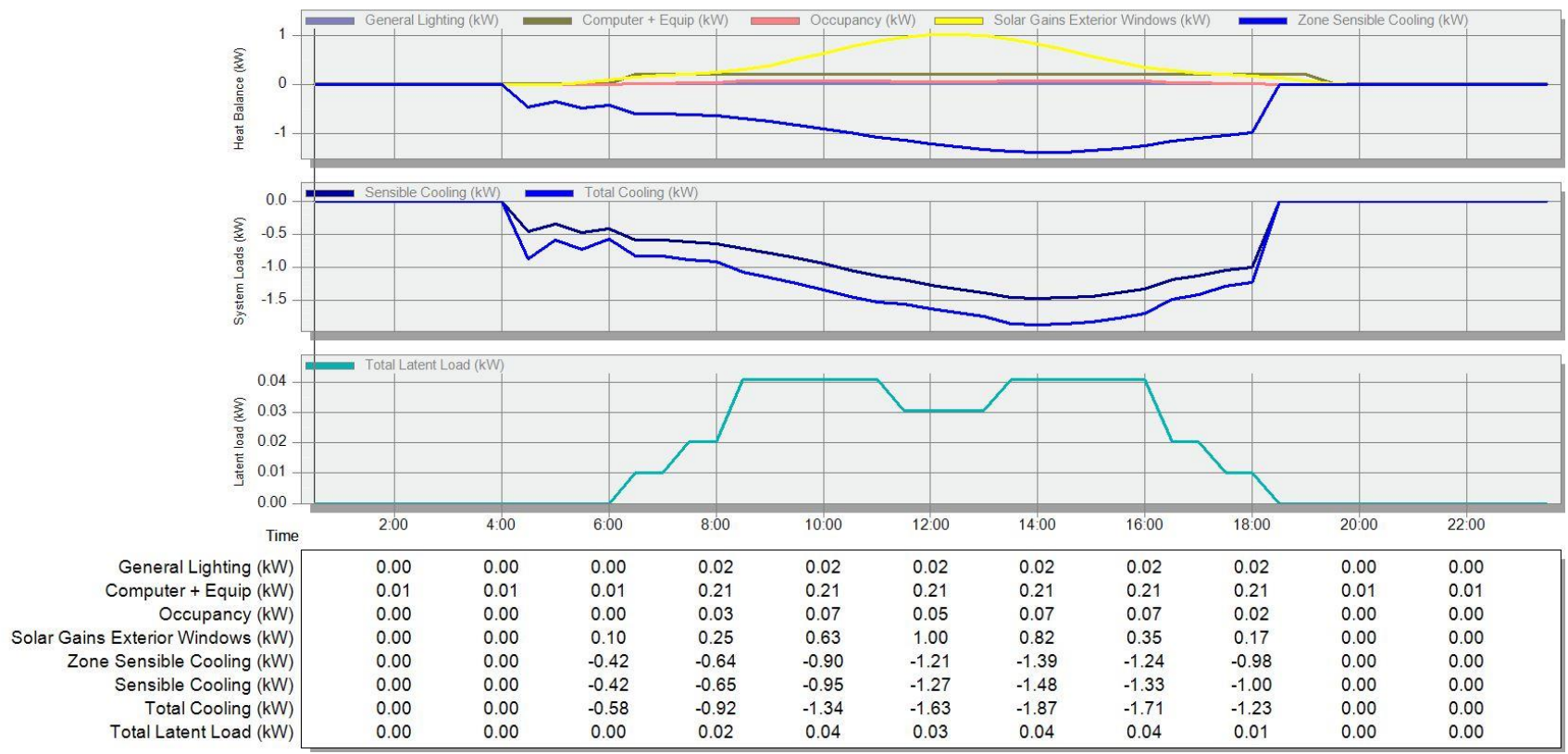




\section{East Facing Room}

\section{Cooling Design}

\section{Temperature and Heat Gains}

\begin{tabular}{|c|c|c|c|c|c|c|c|c|c|c|c|}
\hline Air Temperature ("C) & 27.02 & 26.80 & 24.00 & 24.00 & 24.00 & 24.00 & 24.00 & 24.00 & 24.00 & 27.77 & 27.51 \\
\hline Radiant Temperature $\left({ }^{\circ} \mathrm{C}\right)$ & 27.49 & 27.31 & 27.88 & 30.25 & 31.00 & 29.84 & 29.01 & 28.43 & 27.80 & 27.88 & 27.81 \\
\hline Operative Temperature ( $\mathrm{C} C$ ) & 2725 & 27.06 & 25.94 & 27.12 & 27.50 & 26.92 & 26.50 & 26.22 & 25.90 & 27.83 & 27.66 \\
\hline Outside Dry-Bulb Temperature $\left({ }^{\circ} \mathrm{C}\right)$ & 23.36 & 22.87 & 22.87 & 24.86 & 27.85 & 29.92 & 31.00 & 30.50 & 29.01 & 26.85 & 25.36 \\
\hline Glazing $(\mathrm{kW})$ & -0.08 & -0.08 & 0.38 & 0.71 & 0.58 & 0.17 & 0.15 & 0.12 & 0.06 & -0.05 & -0.06 \\
\hline Walls $(\mathrm{kW})$ & -0.02 & -0.02 & .0 .02 & 0.08 & 0.12 & 0.09 & 0.04 & 0.03 & 0.03 & 0.00 & -0.01 \\
\hline Ceilings (int) (kW) & 0.05 & 0.05 & -0.10 & -0.35 & -0.23 & 0.04 & 0.10 & 0.12 & 0.15 & 0.06 & 0.05 \\
\hline Floors (int) (kW)] & 0.05 & 0.05 & -0.54 & -0.86 & -0.18 & 0.49 & 0.35 & 0.25 & 0.22 & 0.03 & 0.03 \\
\hline Partitions (int) $(\mathrm{kW})$ & 0.04 & 0.04 & .0 .24 & -0.39 & .0 .06 & 0.23 & 0.14 & 0.11 & 0.13 & -0.04 & 0.01 \\
\hline External Infiltration $(\mathrm{kW})$ & -0.06 & -0.06 & -0.02 & 0.01 & 0.06 & 0.09 & 0.11 & 0.10 & 0.08 & -0.01 & -0.03 \\
\hline External Vent $(\mathrm{kW})$ ] & 0.00 & 0.00 & 0.00 & -0.01 & -0.05 & -0.06 & -0.09 & -0.08 & -0.02 & 0.00 & 0.00 \\
\hline General Lighting $(\mathrm{kW})$ ] & 0.00 & 0.00 & 0.00 & 0.02 & 0.02 & 0.02 & 0.02 & 0.02 & 0.02 & 0.00 & 0.00 \\
\hline Computer + Equip (kW) & 0.01 & 0.01 & 0.01 & 0.21 & 0.21 & 0.21 & 0.21 & 0.21 & 0.21 & 0.01 & 0.01 \\
\hline Occupancy $(\mathrm{kW})$ & 0.00 & 0.00 & 0.00 & 0.03 & 0.07 & 0.05 & 0.07 & 0.07 & 0.02 & 0.00 & 0.00 \\
\hline Solar Gains Exterior Windows $(\mathrm{kW})$ ] & 0.00 & 0.00 & 1.30 & 2.28 & 1.55 & 0.38 & 0.33 & 0.28 & 0.17 & 0.00 & 0.00 \\
\hline Zone Sensible Cooling $(\mathrm{kW})$ & 0.00 & 0.00 & -0.78 & -1.74 & -2.10 & -1.75 & -1.49 & -1.30 & -1.06 & 0.00 & 0.00 \\
\hline Sensible Cooling $(\mathrm{kW})$ & 0.00 & 0.00 & -0.78 & -1.74 & -2.15 & -1.81 & -1.58 & -1.39 & -1.08 & 0.00 & 0.00 \\
\hline Total Cooling $(\mathrm{kW})$ & 0.00 & 0.00 & -1.02 & -2.08 & -2.57 & -2.15 & -1.97 & -1.77 & -1.31 & 0.00 & 0.00 \\
\hline $\begin{aligned} \text { Relative Humidity }(\%) \\
\text { Mech Vent + Nat Vent + fiftration }\end{aligned}$ & 64.88 & $\begin{array}{l}65.80 \\
071\end{array}$ & $\begin{array}{l}53.54 \\
070\end{array}$ & 50.41 & $\begin{array}{c}50.00 \\
124\end{array}$ & 50.34 & 51.02 & 51.53 & 51.78 & 52.81 & 61.29 \\
\hline Mech Vent + Nat Vent + Infilitration (ac/h) & 0.71 & 0.71 & 0.70 & 0.97 & 1.24 & 1.10 & 1.23 & 1.23 & 0.83 & 0.70 & 0.71 \\
\hline
\end{tabular}

\section{Heating Design}

\section{Temperature and Heat Loss}

\begin{tabular}{r|r|} 
Air Temperature $\left({ }^{\circ} \mathrm{C}\right)$ & 22.00 \\
Radiant Temperature $\left.{ }^{\circ} \mathrm{C}\right)$ & 19.34 \\
Operative Temperature $\left({ }^{\circ} \mathrm{C}\right)$ & 20.67 \\
Outside Dry-Bulb Temperature $\left({ }^{\circ} \mathrm{C}\right)$ & -16.40 \\
Glazing $(\mathrm{kW})$ & -0.44 \\
Walls $(\mathrm{kW})$ & -0.11 \\
External Infiltration $(\mathrm{kW})$ & -0.72 \\
External Vent. & $\mathrm{kW})$ \\
Zone Sensible Heating $(\mathrm{kW})$ & -0.47 \\
\hline
\end{tabular}

\section{Internal Gains + Solar}

EnergyPlus Output
Internal Gains + solar - Site, Building 1 15 Jul, Sub-hourly

Student

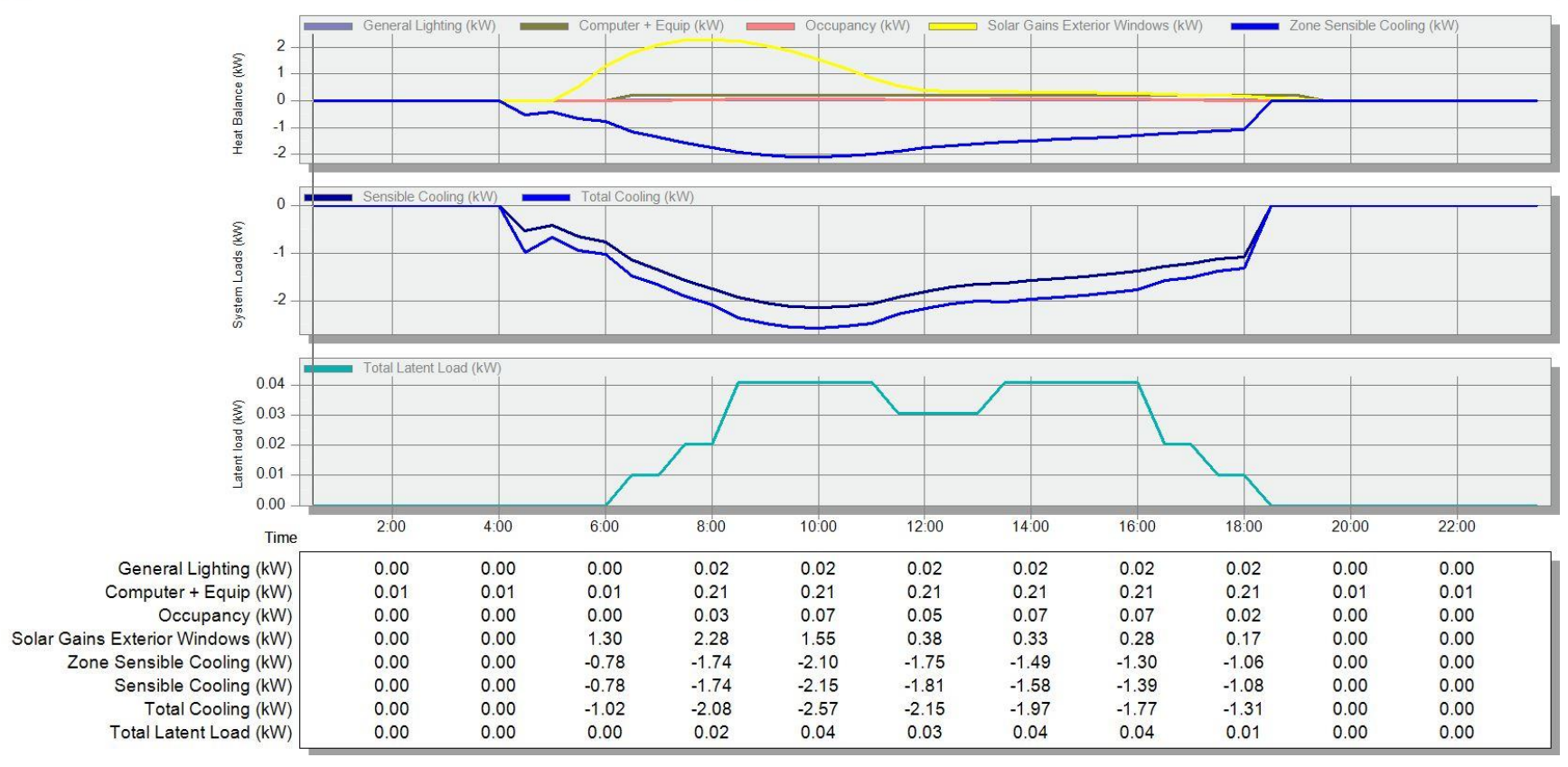




\section{West Facing Room}

\section{Cooling Design}

\section{Temperature and Heat Gains}

\begin{tabular}{|c|c|c|c|c|c|c|c|c|c|c|c|}
\hline Air Temperature $\left({ }^{\circ} \mathrm{C}\right)$ & 29.91 & 29.59 & 24.00 & 24.00 & 24.00 & 24.00 & 24.00 & 24.00 & 24.00 & 30.84 & 30.65 \\
\hline Radiant Temperature $\left({ }^{\circ} \mathrm{C}\right)$ & 30.64 & 30.35 & 28.73 & 28.15 & 27.92 & 27.78 & 28.58 & 30.46 & 31.47 & 31.43 & 31.19 \\
\hline Operative Temperature $\left({ }^{\circ} \mathrm{C}\right)$ & 30.27 & 29.97 & 26.37 & 26.07 & 25.96 & 25.89 & 26.29 & 27.23 & 27.73 & 31.13 & 30.92 \\
\hline Outside Dry-Bulb Temperature $\left({ }^{\circ} \mathrm{C}\right)$ & 23.36 & 22.87 & 22.87 & 24.86 & 27.85 & 29.92 & 31.00 & 30.50 & 29.01 & 26.85 & 25.36 \\
\hline Glazing (kW) & -0.11 & -0.11 & -0.05 & 0.05 & 0.12 & 0.14 & 0.50 & 0.76 & 0.63 & -0.08 & -0.10 \\
\hline Walls (kW) & -0.02 & -0.03 & -0.01 & -0.00 & 0.02 & 0.03 & 0.05 & 0.10 & 0.12 & 0.05 & -0.01 \\
\hline Ceilings (int) (kW) & 0.03 & 0.05 & 0.28 & 0.19 & 0.13 & 0.09 & -0.07 & -0.29 & -0.24 & -0.11 & -0.04 \\
\hline Floors (int) (kW) & 0.12 & 0.11 & 0.40 & 0.24 & 0.15 & 0.10 & -0.35 & -0.84 & -0.45 & 0.24 & 0.17 \\
\hline Partitions (int) (kW) & 0.07 & 0.07 & 0.39 & 0.10 & 0.03 & 0.02 & -0.20 & $\begin{array}{l}-0.04 \\
-0.35\end{array}$ & $\begin{array}{l}-0.45 \\
-0.12\end{array}$ & $\begin{array}{r}-0.04 \\
\end{array}$ & 0.03 \\
\hline External Infiltration (kW) & -0.11 & -0.11 & -0.02 & 0.01 & 0.06 & 0.09 & 0.11 & 0.10 & 0.08 & -0.06 & -0.09 \\
\hline External Vent. (kW) & 0.00 & 0.00 & 0.00 & -0.01 & -0.05 & -0.06 & -0.09 & -0.08 & -0.02 & 0.00 & 0.00 \\
\hline General Lighting $(\mathrm{kW})$ & 0.00 & 0.00 & 0.00 & 0.02 & 0.02 & 0.02 & 0.02 & 0.02 & 0.02 & 0.00 & 0.00 \\
\hline Computer + Equip (kW) & 0.01 & 0.01 & 0.01 & 0.21 & 0.21 & 0.21 & 0.21 & 0.21 & 0.21 & 0.01 & 0.01 \\
\hline Occupancy (kW) & 0.00 & 0.00 & 0.00 & 0.03 & 0.07 & 0.05 & 0.07 & 0.07 & 0.02 & 0.00 & 0.00 \\
\hline Solar Gains Exterior Windows ( $\mathrm{kW}$ ) & 0.00 & 0.00 & 0.10 & 0.25 & 0.32 & 0.34 & 1.01 & 2.15 & 1.99 & 0.00 & 0.00 \\
\hline Zone Sensible Cooling ( $\mathrm{kW}$ ) & 0.00 & 0.00 & -1.07 & -1.10 & -1.10 & -1.08 & -1.32 & -1.91 & -2.24 & 0.00 & 0.00 \\
\hline Sensible Cooling (KW) & 0.00 & 0.00 & -1.07 & -1.10 & -1.15 & -1.14 & -1.41 & -2.00 & -2.25 & 0.00 & 0.00 \\
\hline Total Cooling (kW) & 0.00 & 0.00 & -1.19 & -1.39 & -1.54 & -1.48 & -1.83 & -2.43 & -2.52 & 0.00 & 0.00 \\
\hline Relative Humidity (\%) & 54.82 & 55.94 & 51.34 & 51.91 & 52.35 & 52.20 & 51.66 & 50.32 & 49.51 & 42.48 & 50.38 \\
\hline Mech Vent + Nat Vent + Infiltration (ac/h) & 0.72 & 0.72 & 0.70 & 0.97 & 1.24 & 1.10 & 1.23 & 1.23 & 0.83 & 0.71 & 0.71 \\
\hline
\end{tabular}

\section{Heating Design}

\section{Temperature and Heat Loss}

\begin{tabular}{r|r} 
Air Temperature $\left({ }^{\circ} \mathrm{C}\right)$ & 22.00 \\
Radiant Temperature $\left({ }^{\circ} \mathrm{C}\right)$ & 19.34 \\
Operative Temperature $\left({ }^{\circ} \mathrm{C}\right)$ & 20.67 \\
Outside Dry-Bulb Temperature $\left({ }^{\circ} \mathrm{C}\right)$ & -16.40 \\
Glazing $(\mathrm{kW})$ & -0.44 \\
Walls $(\mathrm{kW})$ & -0.11 \\
External Infiltration $(\mathrm{kW})$ & -0.72 \\
External Vent. $(\mathrm{kW})$ & -0.47 \\
Zone Sensible Heating $(\mathrm{kW})$ & 1.74 \\
\hline
\end{tabular}

\section{Internal Gains + Solar}

0.00

EnergyPlus Output
Internal Gains + solar - Site, Building 1 15 Jul, Sub-hourly

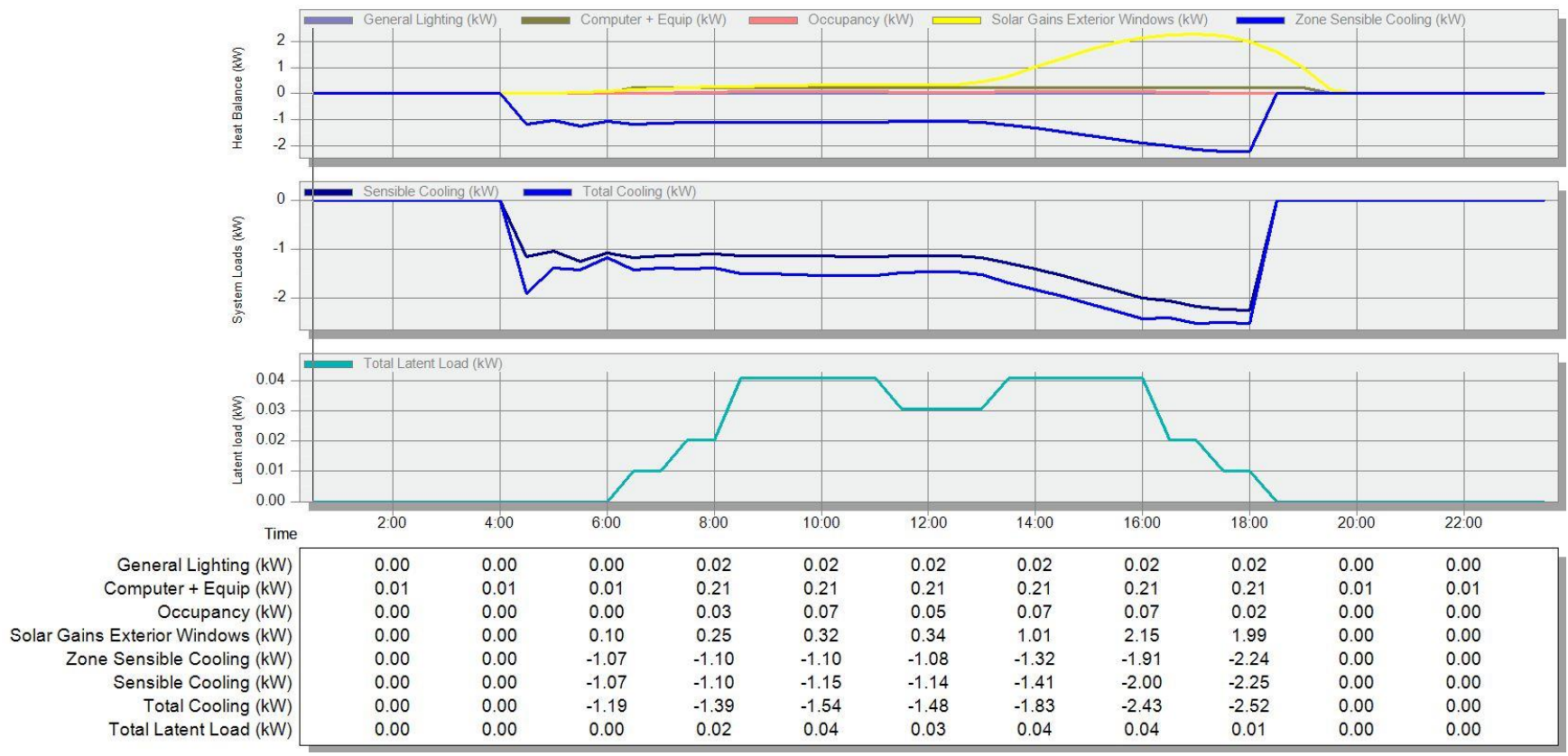




\section{References}

ASHRAE, (2004). Advanced Energy Design Guide for Small Office Buildings: Achieving 30\% Energy Savings Over ANSI/ASHRAE/IESNA Standard 90.1-1999.

Boake, T.M., (2014). Hot Climate Double Facades: Avoiding Solar Gain. Façade Tectonics, 14

Berardi, U., \& Wang, T., (2014). Daylighting in an atrium-type high performance house. Building and Environment, 76, 92-104.

Canadian Consulting Engineer, (2015). Open-Plan Offices, Retrieved from:

http://www.canadianconsultingengineer.com/features/openplanoffices/

Canada Mortgage and Housing Corporation, (2014). Impact of Architectural Form on the Potential Energy Performance of Multi-Unit Residential Buildings, Technical Series 14-103

Carpenter, S., (2011). Should Net Zero be Today's Goal? SAB Magazine, 31, 79-81

Cellai, G., Carletti, C., Sciurpi, F., \& Secchi, S., (2014). Transparent Building Envelope:

Windows and Shading Devices Typologies for Energy Efficiency Refurbishments, Building Refurbishment for Energy Performance, Green Energy and Technology, DOI: 10.1007/978-3319-03074-6_2

Etman, O., Tolba, O., \& Ezzeldin, Sh., (2013). Double-Skin Façades in Egypt between Parametric and Climatic Approaches, Arab Academy for Science, Technology and Maritime Transport, Egypt, Performative and Interactive Architecture, Computation and Performance eCAADe 31, 1

EI Sheikh, M., (2011). Intelligent B uilding Skin: Parametric-Based Algorithm for Kinetic Facades Design and Daylighting Performance Integration, a Master of Building Science Thesis Presented to the Faculty of USC School of Architecture, University of Southern California Galasiu A., \& Reinhart C.F., (2007). Current daylighting design practice: a survey. Building Research and Information, 36(2)

Gratia, E. \& De Herde, A., (2003). Design of low energy office buildings. Energy and Buildings, $35,473-491$ 
Greater Toronto CivicAction Alliance, (2010). Commercial Building Energy Initiative: Tenant Business Case, Greening Greater Toronto

Houska, C., (2013). The Use of Stainless Steel in second-Skin Façades, CTBUH J ournal, Tall Buildings: Design, Construction and Operation, 3

IESNA, (2000). IESNA lighting handbook. New York, NY: Illuminating Engineering Society of North America, 9th edition, 482

Lang, W., \& Bader, S., (2011). High-performance façades for commercial buildings, Professional Report, University of Texas, Austin, School of Architecture

Manzan, M., (2014). Genetic optimization of external fixed shading devices, Energy and Buildings, 72, 431- 440

Moon, K.S., Connor, J ., \& Fernandez, J .E., (2007). Diagrid structural systems for tall buildings: characteristics and methodology for preliminary design, the structural design of tall and special buildings structure, Design Tall Spec. Building, 16, 205-230

National Resources Canada, (2008). Commercial \& Institutional Consumption of Energy Survey Fact Sheet. Retrieved from:

http://oee.nrcan.gc.ca/Publications/statistics/cices08/pdf/cices08.pdf

Nabil, A., \& Mardaljevic J ., (2005a). Useful Daylight Illuminance: A New Paradigm to Access Daylight in Buildings. Lighting Research \& Technology, 37(1), 41-59.

Ochoa, C.E., Aries, M.B.S., \& Hensen, J .L.M., (2010). Current perspective on Lighting Simulation for Building Science, IBPSA-NVL 2010 Event, Eindhoven, Nederland, Paper ID: 14

Omidfar, A., (2011). Methodology for designing contemporary performance shading screen The integration of 'form' and the DIVA simulation tool, Building Simulation, Sydney

Patel, P. \& Griffiths, S., (2013). Masdar City Showcases Sustainability. Cambridge J ournals Online, 38(6) 
Pope, S., (2008). Building Envelopes for the 2030 Challenge: an Early Discussion

[Presentation]. Paper presented at BC Building Envelope Council. Retrieved from:

http://www.bcbec.com/SPope.pdf

Reinhart, C.F, Walkenhorst, O., (2011). Validation of dynamic RADIANCE-based daylight simulations for a test office with external blinds, Energy and Buildings, 33(7), 683-697

Reinhart C F, Mardaljevic J, Rogers Z., (2006) Dynamic Daylight Performance Metrics for Sustainable Building Design. LEUKOS: The J ournal of the Illuminating Engineering Society of North America, 3(1), 7-13

Straube, J ., (2008). Can Highly Glazed Façade Be green?, Building Science Corporation, Insight-006

Tong LEE, I., Black, Ch., \& Lomanowski, B., (2010). High Performance Facades for Heating and Cooling in Northern Climates, International High Performance Buildings Conference at Purdue, J uly 12-15

Urban Green Council, (2013). Seduced by the View: A closer look at all glass buildings, New York Chapter of the U.S. Green Building Council

Urban Green Council, (2014). High Cholesterol Buildings, New York Chapter of the U.S. Green Building Council

US Department of Energy, (2011). Building Energy Software Tools Directory. Retrieved from US Department of Energy:

http://apps1.eere.energy.gov/buildings/tools_directory/subjects.cfm/pagename=subjects/page name_menu=materials_components/pagename_submenu=lighting_systems

Verso, V.R.M. Lo, Serra, V., Giovannini, L., \& lennarella, S., (2014). Light versus energy performance of office rooms with curtain walls: a parametric study, 6 th International Conference on Sustainability in Energy and Buildings, SEB-14, Energy Procedia 62, $462-471$

Wilson, A., (2010). Rethinking the All-Glass Building: Is it time to stop designing buildings with highly glazed façades?, Environmental Building News, 19(7) 